\title{
بحث بعقان:
}

اتجامات الشباب الجامعي نمو الهندسة الاجتعاعية

وعلامتها بالموبة الثقافية

$$
\begin{aligned}
& \text { إعداد: } \\
& \text { د/ منان طنطاوي أحمد عبد التواب } \\
& \text { مدرس بقسم مجالات الخدمة الاجتماعية } \\
& \text { كلية الخدمة الاجتماعية - جامعة الفيوم }
\end{aligned}
$$


الملخص: هدفت الباحثة في هذه الدراسة إلى تحديد اتجاهات الثباب الجامعي نحو الهندة الاجتماعية، وتحديد مستوى الهوية الثقافية لديهم، ومن ثم تحديد العلاقة بينهما، من أجل التوصل إلى آليات من منظور الخدمة الاجتماعية للتخفيف من مخاطر الهندسة الاجتماعية لدى الثباب الجامعي، وقد اعتمدت الباحثة على استخدام المنهج الوصفي بالاعتماد على طريقة المسح الاجتماعي بالعينة لعينة عشوائية من طلاب كلية الخدمة الاجتماعية "كنموذج للشباب الجامعي"، وذلك من خلال الاستناد إلى أداتين أساسيتين هما: (مقياس اتجاهات الثباب الجامعي نحو الهندسة الاجتماعية، ومقياس مستوى الهوية الثقافية لدى الثباب الجامعي)، وتم تطبيق البحث على عينة قوامها هوء طالب وطالب من طلاب كلية الخدمة الاجتماعية جامعة الفيوم، وذلك بنسبة • أ وتوصلت الباحثة إلى مجموعة من النتائج من أهمها: أن اتجاهات الثباب الجامعي نحو الهندسة الاجتماعية "القائمة على أساس تقني" كانت متوسطة بمتوسط حسابي عام († (؟,ک) وقوة نسبية بلغت

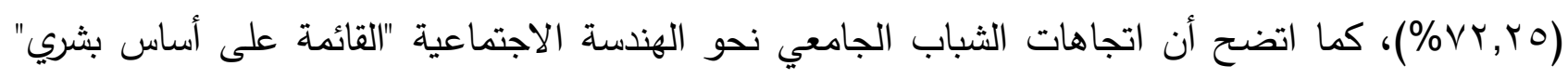

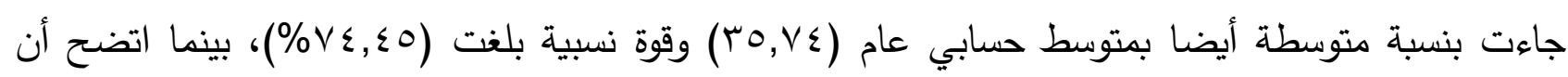
مستوى الهوية الثقافية لهم تمت الموافقة عليه بنسبة متوسطة أيضًا، كما اتضح وجود علاقة عكسية بين المتغيرين وهو ما يؤكد أنه كلما ارتفعت اتجاهات الثباب الجامعي نحو الهندسة الاجتماعية كلما قل مستوى الهوية الثقافية لايهم، وبناءًا عليه تم التوصل إلى العديد من الآليات من منظور الخدمة الاجتماعية للتخفيف من حدة مخاطر الهندسة الاجتماعية على الهوية الثقافية لدى الثباب الجامعي. الكلمات الدالة: الاتجاه، الهندسة الاجتماعية، الهوية الثقافية. 
Abstract: The researcher aimed in this study to determine the attitudes of university youth towards social engineering, and to determine the level of their cultural identity, and then determine the relationship between them, in order to reach mechanisms from a social work perspective to mitigate the risks of social engineering among university youth, and the researcher relied on Using the descriptive approach based on the sampling social survey method for a random sample of students of the College of Social Work as a "model for university youth" by relying on two basic tools: (a scale of university youth's attitudes towards social engineering, and a scale of the level of cultural identity among university youth), and it was applied The research was conducted on a sample of 498 students from the Faculty of Social Work, Fayoum University, with a percentage of $10 \%$. The researcher reached a number of results, the most important of which are: The attitudes of university youth towards social engineering "based on a technical basis" were moderate with a general arithmetic average. (34.68) and a relative strength of (72.25\%), as it became clear that the university youth's attitudes towards social engineering "based on human beings" came at a medium rate as well, with an average sensitivity B year (35.74) and a relative strength of $(74.45 \%)$, while it turned out that the level of cultural identity for them was approved at a medium rate as well, and it became clear that there was an inverse relationship between the two variables, which confirms that the higher the university youth's attitudes towards social engineering, the lower the identity level Accordingly, many mechanisms have been reached from the perspective of social work to mitigate the risks of social engineering on the cultural identity of university youth.

Key words: (Attitude, Social Engineering, Cultural Identity). 
مقدمة:

يشهد العالم في الوقت الراهن العديد من التغيرات والتطورات الهائلة، والتي نتجت عن إبداعات العقل

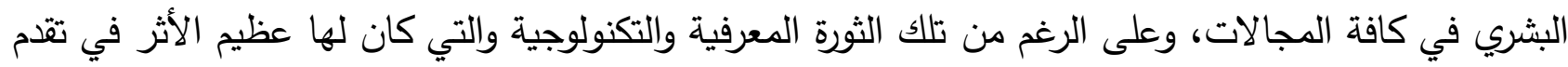
العديد من المجتمعات وزيادة معدلات التمية فيها؛ إلا أنها قد نتج عنها العديد التهايد من الآثار السلبية بأشكالها المختلفة والتي من بينها استغلال البشر بكافة فئاتهم، وبالأخص فئئة الثباب.

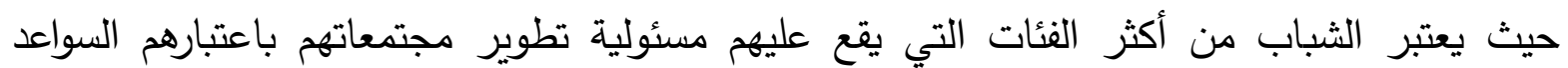
والطاقات الانتاجية والعقول المفكرة. ففي المتمع المصري يمثل الشباب نسبة كبيرة من السكان، فوفقًا للإحصائية الصادرة عن الجهاز

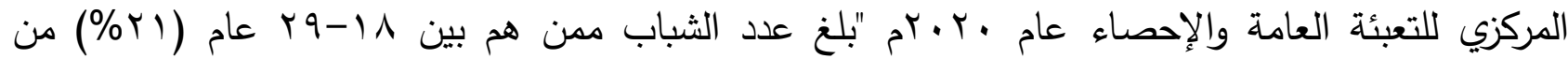

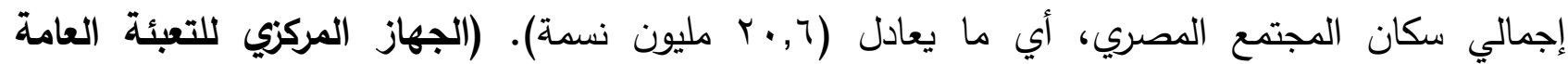

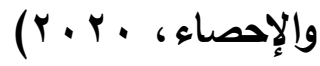
وباعتبارهم الفئة الأكثر تأثيرا في المجتمع نظرا لخصائصهم المختلة، فعادة ما يتم التركيز عليهم

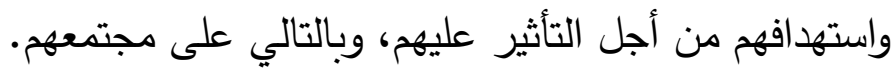
فقد تعاظمت تدخلات الغزو الثقافي للمجتمعات العربية ومن بينها مصر ، وكتئه وكان الثباب من أكثر الفئات

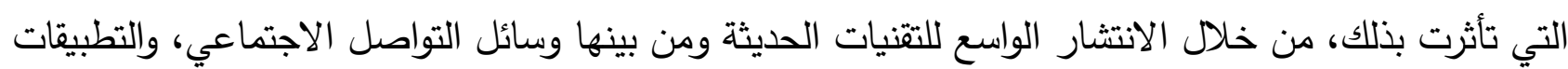

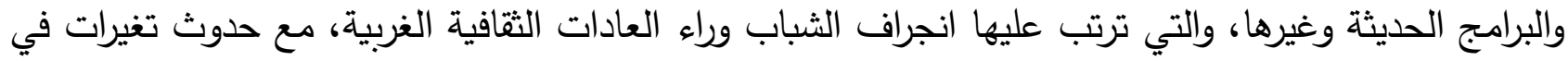
اللغة، والاتحراف عن القيم الأصيلة، والتخلي عن بعض العادات والتقاليد المتعارف عليها، وغيرها من مظاهر تقلص الهوية الثقافية. ومن أكثر الأساليب التي تستخدم للتأثير على الهوية الثقافية للشباب ما يعرف بـ"الهندسة الاجتماعية" والتي تعتبر من أخطر أنواع الهندسة التي تعد بمثابة أداة لاختراق عقول البشر من خلاد الثات أشخاص يمتلكون

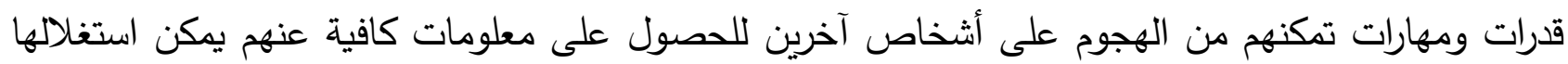
لتحقيق أغراض خبيثة، من خلال استخدام التقنيات الحديثة، أو وجهًا لوجها. وفيما يلي سوف نتناول بالتقصيل أهم مظاهر الهندسة الاجتماعية وكيف تؤثر على الهوية الثقافية 


\section{أولًا: مثكلة الاراسة وأهميتها:}

تتزايد أعداد الثباب الجامعي من عام لآخر وفقًا لزيادة أعداد السكان بالهجتمع المصري، فوفقًا للنشرة

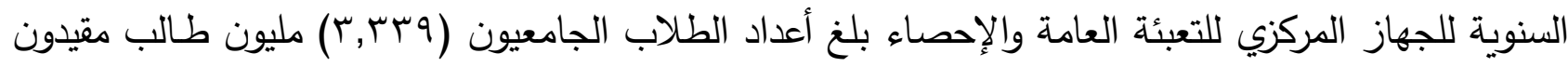

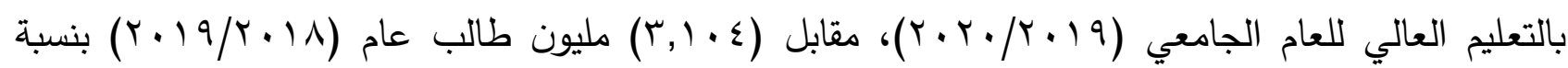

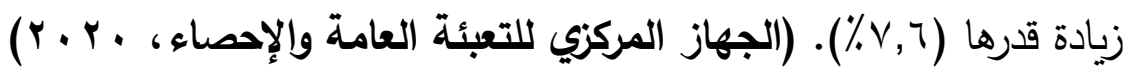

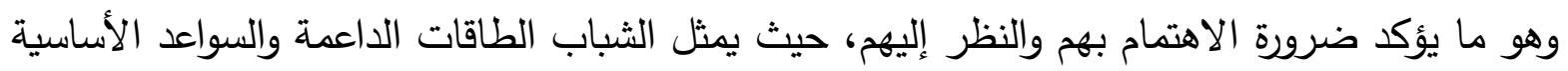

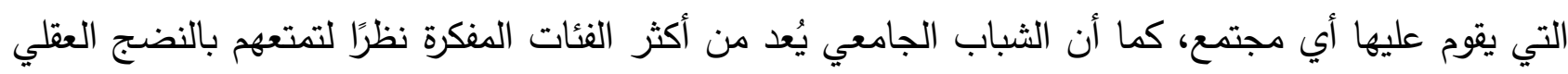
والفكري، والذي تتعكس آثاره على المجتمع ككل، كما يمكن الاعتماد عليهم في دفع عجلة الإنتاج والتتمية.

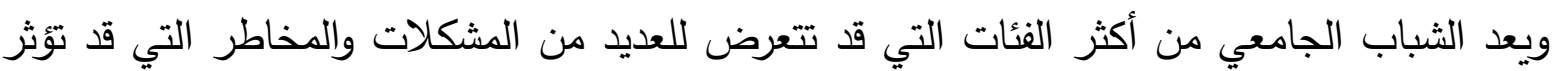
على أنماط تفكيرهم وأسلوب حياتهم وهويتهم الثقافية بثكل أساسي.

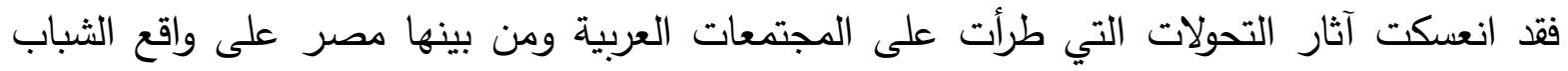

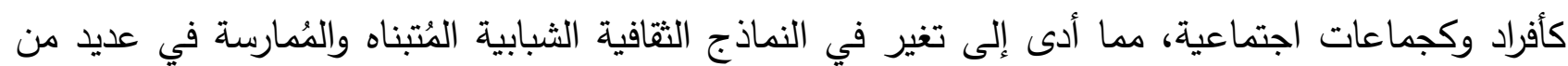

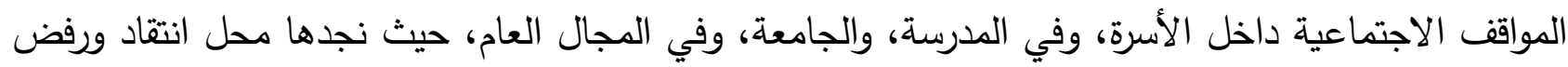

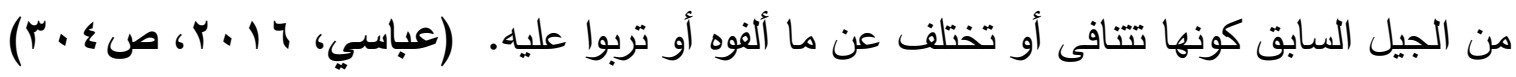

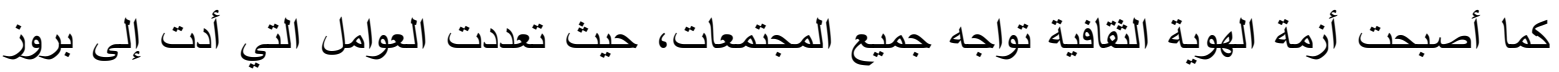
الهويات الثانوية، والتي أصبحت تثكل عبئًا على الهويات الرئيسية أو التقليدية، ومن بين أهئ أهم هذه العوامل:

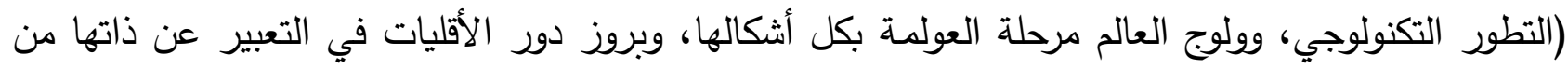

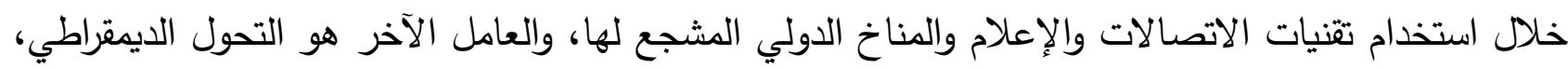

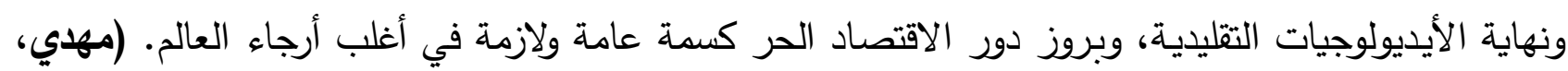

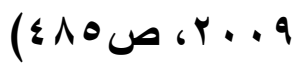

فقد نتج عن تداعيات العولمة العديد من أوجه اختراق الهوية الثقافية بما تتضمنه من عادات وتقاليد

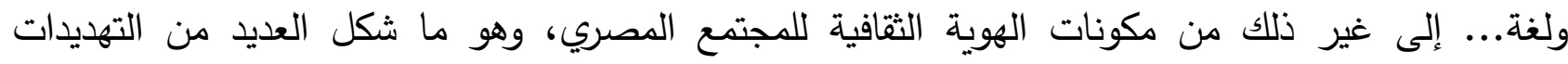

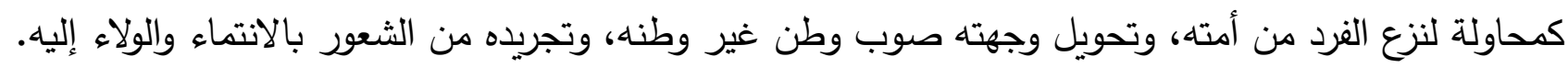

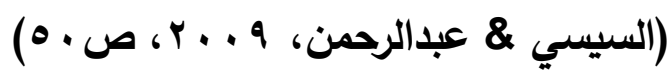

وهو ما أكدت عليه نتائج دراسة (2015) على أن هناك اتجاه متتامي للتلاعب بالثقافات وخاصة الثقافة الإسلامية من خلال التأسيس لطريقة الحياة الغربية التي تسبيت في انعدام الأمن الأخلاقي في المجتمعات المختلفة، ومظاهر عديدة للغزو الثقافي منها: الدظاهر الداخلية. على سبيل المثال؛ يحاول إزالة

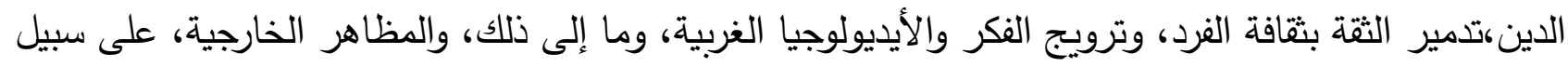
المثال؛ جعل البلدان متخلفة في جميع الجوانب (العلمية والصناعية) والحرمان الاقتصادي والثئون الثقافئية. 


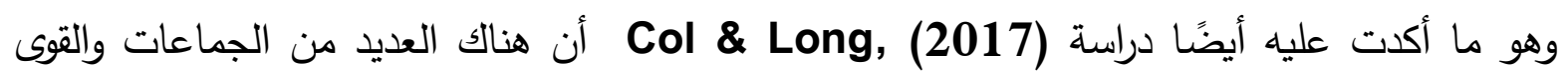
المعادية والانتهازيون السياسيون في الكثير من الدول، يستخدمون كل الوسائل الممكنة، التي تعطي أهمية كبيرة

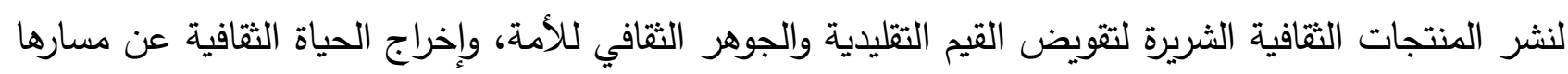

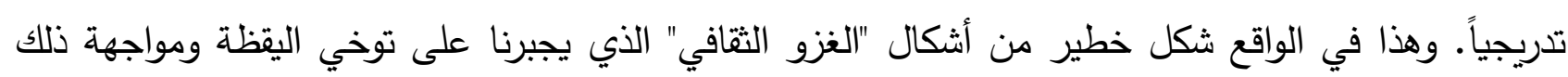
مسبقًا.

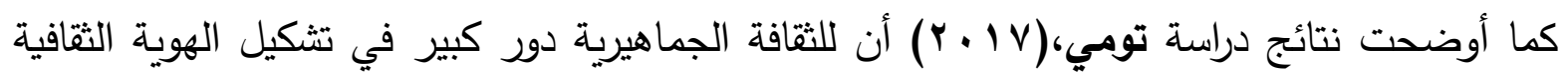

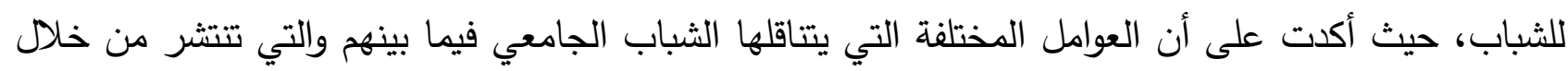

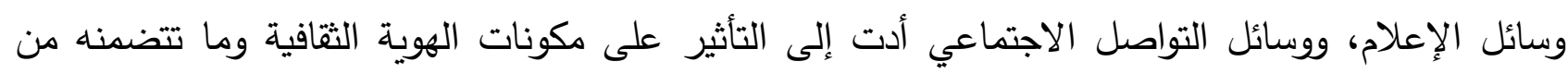

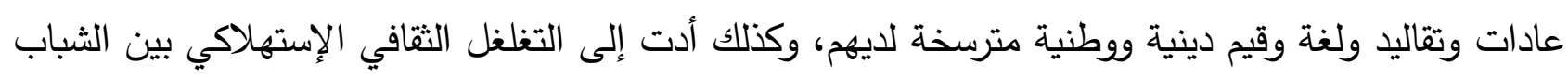
الجامعي.

ففيما يتعلق باللغة كأحد مكونات الهوية الثقافية، فإن أخطر ما نشهده هو وجود ما يشبه 》الانفصام

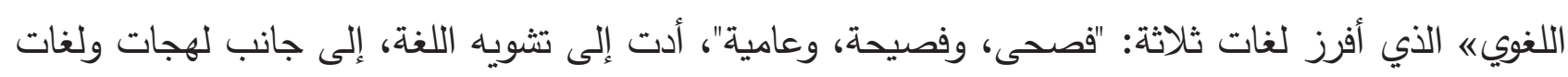

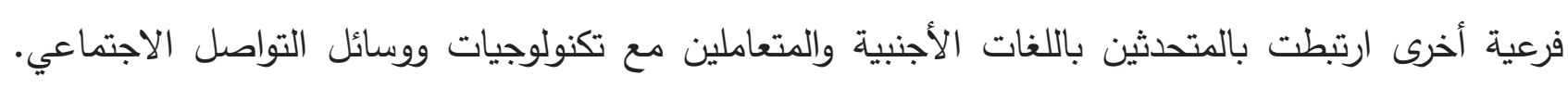

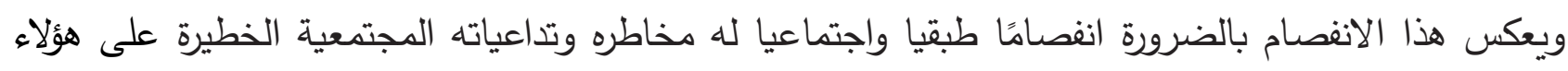

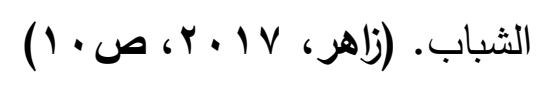

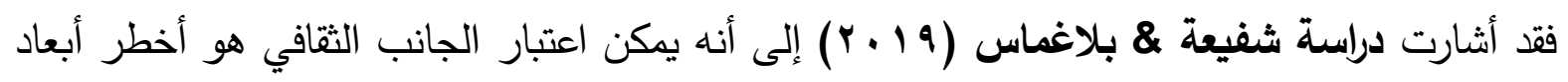

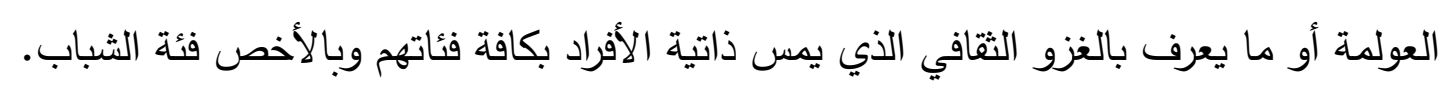

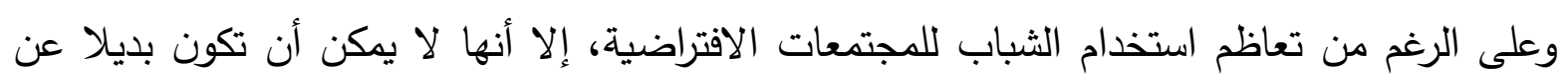

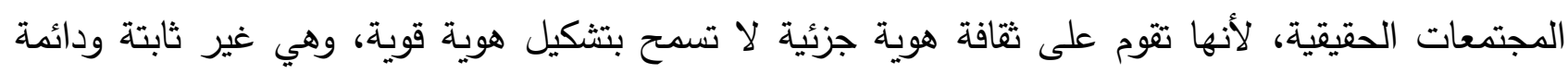

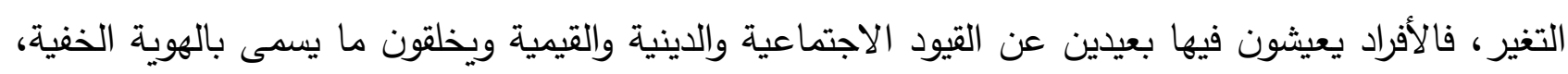

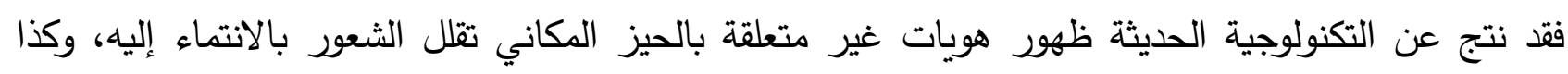

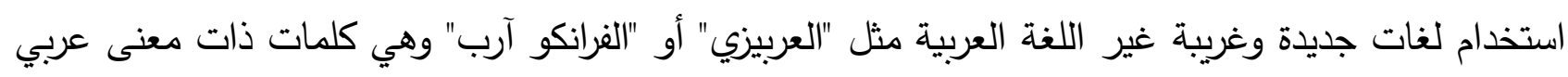

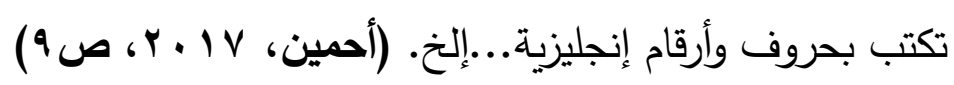

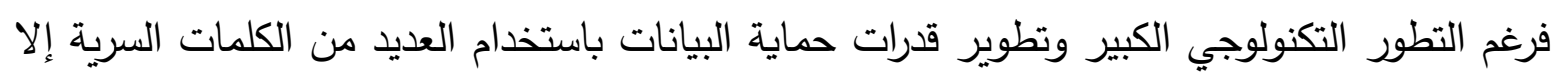

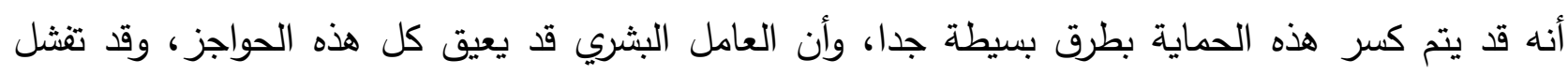

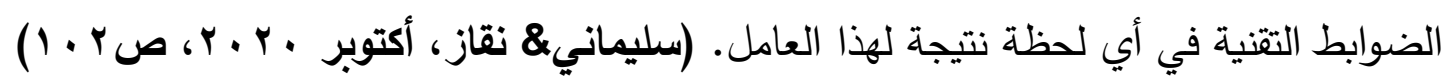

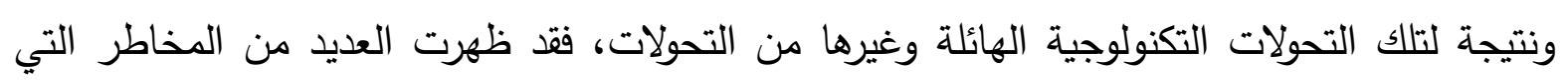
تهدد أفراد المجتمع وبالأخص فئة الثباب. 


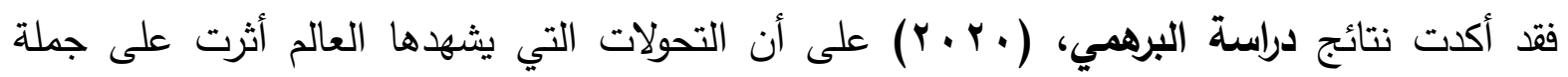

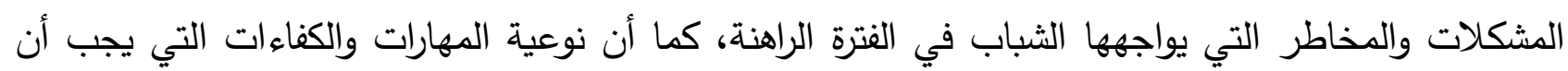
تتوفر للى الثاب قد تؤثر في مواجهتهم لتلك المخاطر والمشكلات. ومن بين تلك المخاطر ما يسمى بـ:"الهندسة الاجتماعية"، فترى الباحثة أن الكثيرون قد ينظرون إلى الى الى

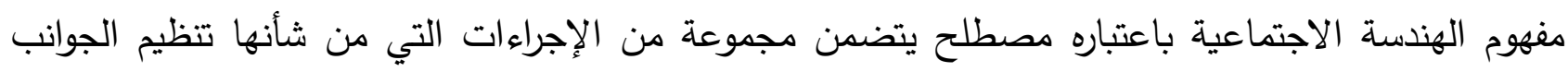

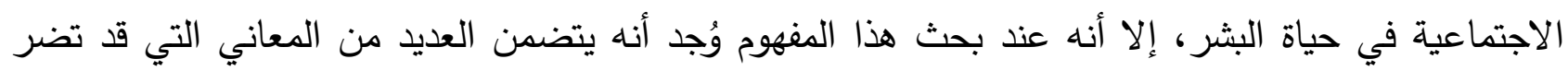
بحياة البشر وتسيطر على عقولهم وتفكيرهم. بل تتعدى ذلك إلى استخدام طرق وتقنيات الخداع والتلاعب والحيل

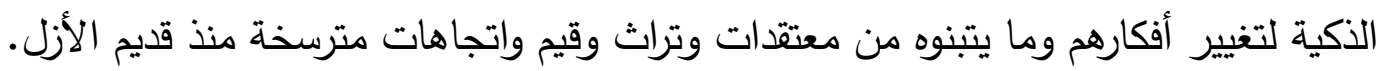

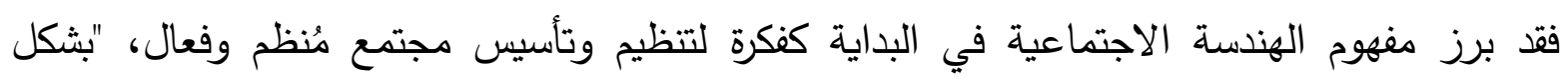
منهجي"، وهو ما يشبه آلة منظمة، يمكنها حمل أجيال نحو معدلات الازدهار والرفاهية والوفرة المتزايدة

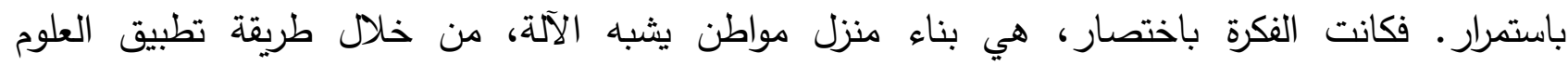
الاجتماعية، أي الهندسة الاجتماعية. فكان يستخدمها السياسيون ويسترشدون بها في عملية صنع القرار بمعرفة

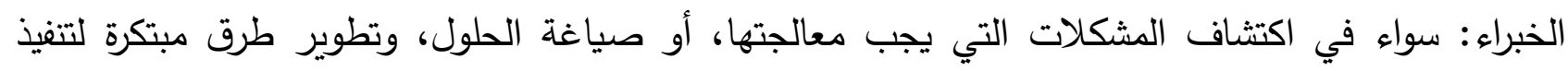
الحلول بشكل فعال. وفي هذا المعنى لم تكن الهندة الاجتماعية مجرد مسألة حرفية حكومية، ولكنها أيضا

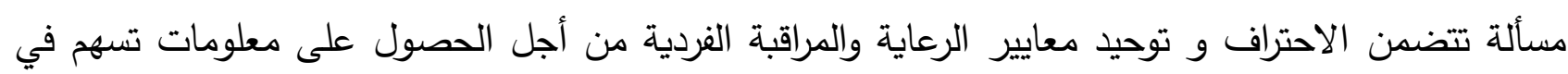

تحقيق أغراض معينة تسهم في تشكيل المجتمع والتحكم في شئونه. (Bengt, et. al,2012, p.p12:13)

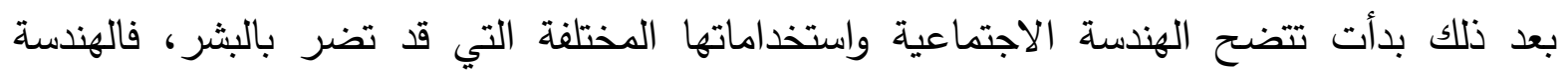
الاجتماعية تعتد على أساليب عديدة للاحتيال: كالكذب على الناس من أجل الحصول على على الماعلى المعلومات، كما

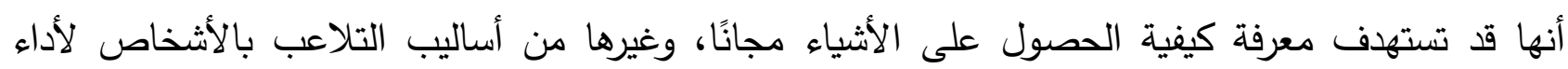

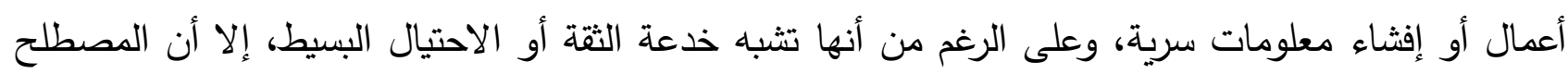

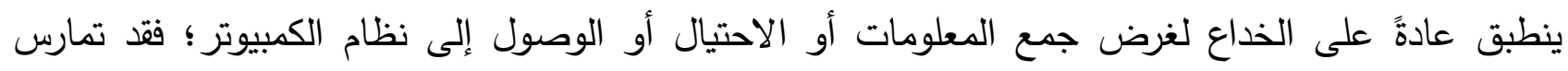

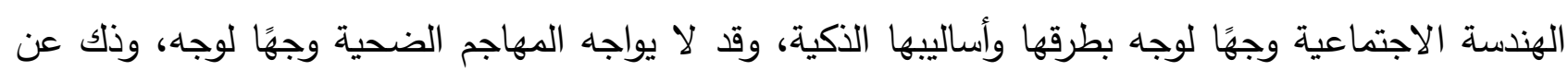

طريق استخدام التثنيات الحديثة". (Hadnagy, 2011, p.p 31:32)

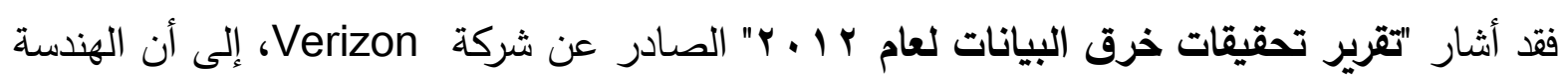
الاجتماعية لا تهدد الشركات والوكالات الحكومية فحسب، بل تهدد أيضًا الأفراد (في الغالب فيما يتعلق بالاحتيال على الهوية). (Uebelacker \& Quiel, 2013, p5) وهناك العديد من أنواع المهندسين الاجتماعيين، ومن بينها: (المخترقون، الجواسيس، لصوص الهوية،

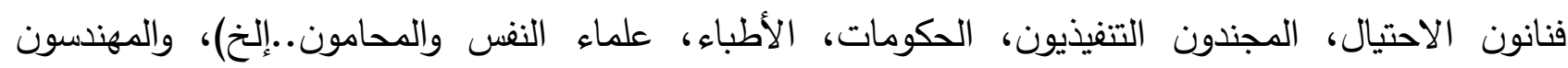

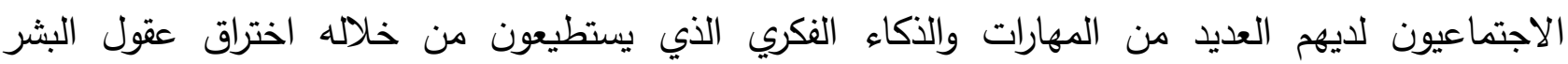


واستهدافهم لتحقيق أغراض خبيثة تضر بهم، فالمهنس الاجتماعي هو شخص موهوب كما أنه يتمتع بالقدرة

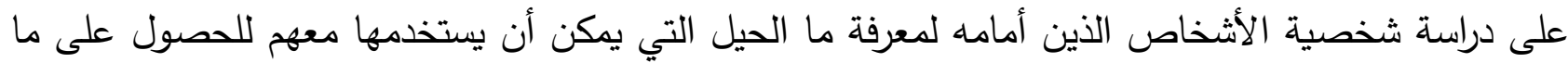

يريده من معلومات. (Hadnagy, 2011, p.p 41:42) فقد أظهرت نتائج دراسة (Holz, et. al, (2011) أن هجمات الهندسة الاجتماعية التي يمارسها

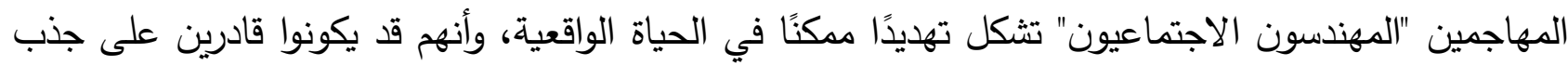

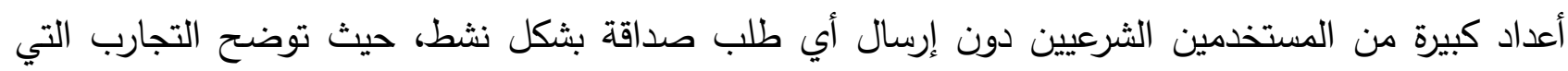

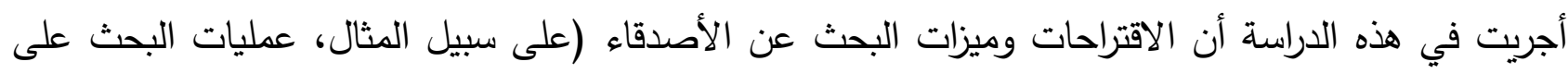

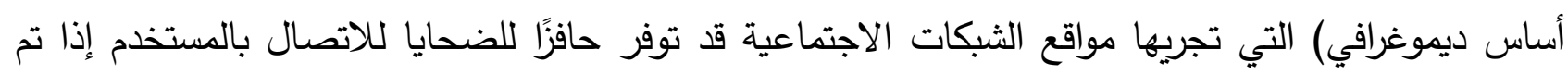

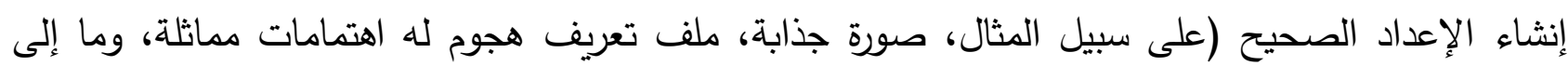

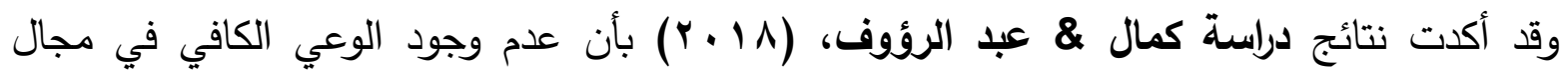
الهندسة الاجتماعية لاى الكثير هو السبب الرئيسي في العديد من المشكلات التي قد تلحق بهم، وبناءً عليه أوصت بضرورة رفع مستوى الوعي بالهندسة الاجتماعية وبأساليبها المختلفة.

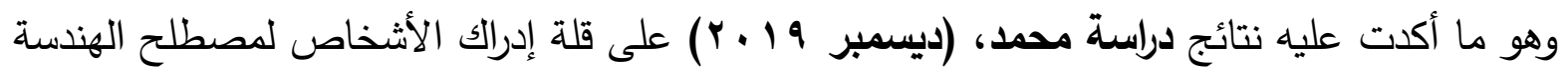

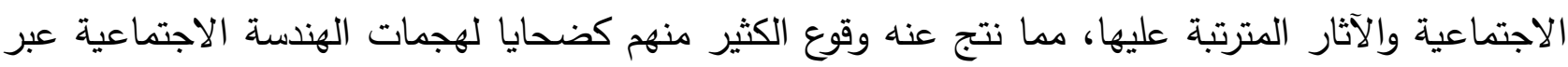

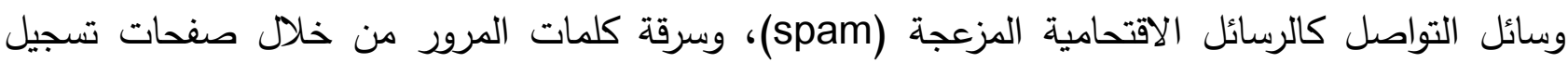
الاخول المزيفة وغيرها. ويبرز دور إجراءات الأمن المعلوماتي في الحد من مخاطر الهندة الاجتماعية، وهو ما أشارت إليه

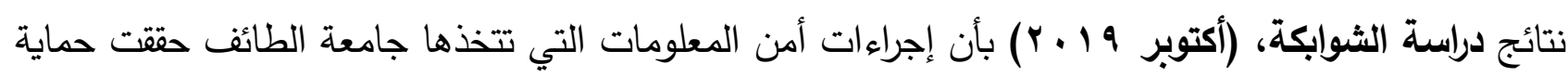

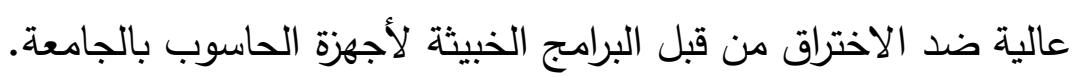

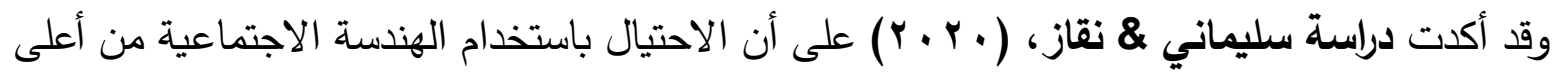
المخاطر حسب تصنيف شركات رائدة في أمن وسلامة المعلومات، كما أكدت أن التدقيق الداخلي ونظم أمن الاحن المعلومات ليس وحده ما يساهم في محاربة الغش وطرق الاحتيال وغيرها من أساليب الهندسة الاجتماعية، وإنما هي مسئولية مشتركة بين الفاعلين من الأثخاص، وتتطلب منهم التعرف على أساليبها المختلفة.

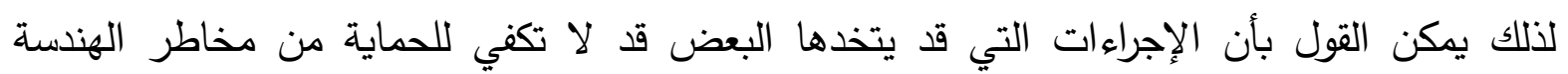

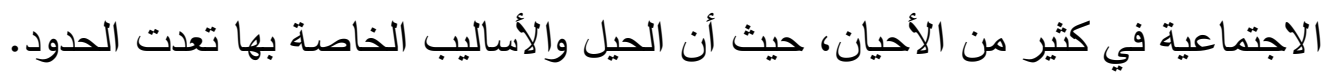

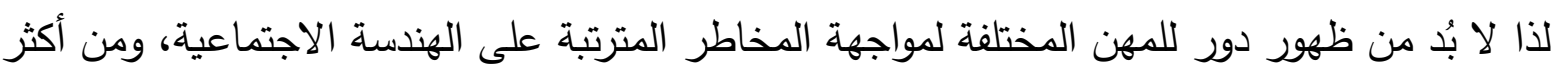

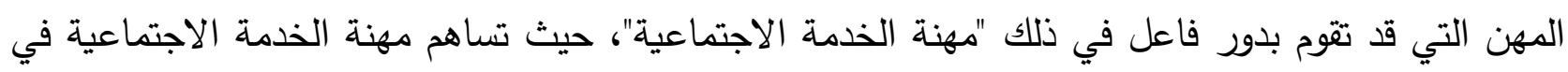
توفير الوسائل والإمكانيات الضرورية وتوجيه طاقات الثباب من خلال تقديم العديد من الخدمات الوقائية 
والعلاجية والإنمائية في شتى القطاعات التي يتواجد فيها عنصر الثباب، كما تسعى لتحقيق أهداف تلك الخدمات من أجل مواجهة مشكلات الشباب كأفراد وجماعات لمواجهة مشكلاتهم والمخاطر التي يتعرضون لها،

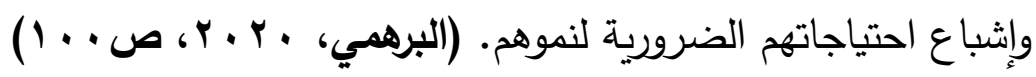
ومن هنا ترى الباحثة أن مهنة الخدمة الاجتماعية يمكن أن يكون لها دور كبير في مواجهة مخاطر الهندسة الاجتماعية على الفئات المختلفة والتي من أكثرها فئة الثباب الجامعي، وذلك من خلال جهود الممارسيين المهنيين العاملين بمؤسسات رعاية الثباب وغيرها من المؤسسات التي تسهم في ذلك. وتأسيسًا على ما سبق تتضح مشكلة الدراسة الحالية في: أن هناك العديد من التغيرات والتطورات التي طرأت على المجتمعات العربية وهن بينها المجتمع المصري، وكان من أبرز تلك التطورات انتثار التكنولوجيا الحديثة التي نتج عنها تطوير المهارات والقدرات الخاصة بالأفراد داخل المجتمع، وكان من أبرز الفئات المتأثرة بذلك فئة الثباب ومن بينهم الثباب الجامعي، حيث ظهرت انعكاسات تلك التطورات في ظهور ما يسمى بالهندسة الاجتماعية والتي تعد بمثابة خطر يهدد الثباب حيث أنها تعتمد على الاحتيال والتلاعب بالبشر من قبل آخرين من أجل تحقيق أغراض خبيثة تستهدف اختراق الهوية وتغيير الأفكار والمعتقدات، بالإضافة إلى تحقيق مكاسب مادية وغيرها من الأغراض، ويستخدم المهندسون الاجتماعيون في تنفيذ هجماتهم العديد من الأساليب سواء كانت أساليب معتمدة على "الجانب البشري" وما يرتبط به من معارف ومهارات وقدرات للاختراق، أو "أساليب تقنية" كالتطبيقات والبرامج الإكترونية ووسائل التواصل الاجتماعي وغيرها، إلا أن معظم الثباب الجامعي ليس لديهح الوعي الكافِ بتلك الأساليب وكيفية الحماية منها، حيث أنها تؤثر عليهح بالسلب في كافة مناحي الحياة الثخصية والاجتماعية، ومن بين تلك المخاطر التأثير على الهوية الثقافية للشباب الجامعي، حيث أنها من خلال أساليبها المختلفة قد تؤدي إلى تقلص الهوية الثقافية لديهه، وبناءًا على ذلك، كان لا بُد من بروز دور للمهن المختلفة ومن بينها مهنة الخدمة الاجتماعية والتي لها دور كبير في مواجهة العديد من التحديات المختلفة والمخاطر التي قد تتعرض لها الفئات المختلفة ومن بينها فئة الشباب الجامعي. ثانيًا: مفاهيم الدراسة: 1 - مفهوم الاتجاه: "Attitude"

يُعرف الاتجاه في قاموس علم الاجتماع بأنه: "موقف (شبه مبلور) يتخذه فاعل ما (فردي أو جماعي) إزاء مادة (شخص أو مجموعة أو وضع ما). فهو يرتبط بما هو ميكتسب وليس بما هو فطري. أي أنه يمثل

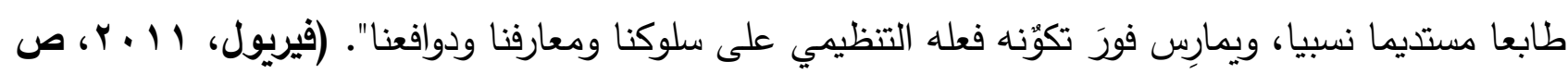
ص ص מ كما يعرف الاتجاه في موسوعة علم الاجتماع بأنه: "توجه نحو شخص، أو موقف، أو نظام، أوعملية

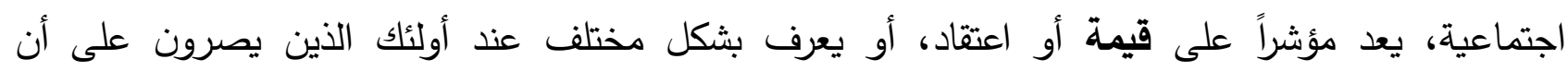


الاتجاهات لا يمكن أن تستتج إلا من السلوك الملاحظ فقط، باعتبارها ميل للسلوك بطريقة ما (متسقة إلى حد

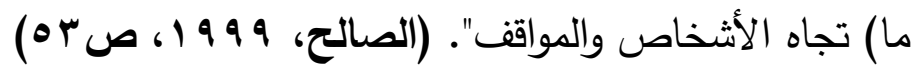
بينما يرى البعض أن الاتجاه عبارة عن "مجموعة من الميول الإرادية الثعورية المعرفية والتي يُستَّل

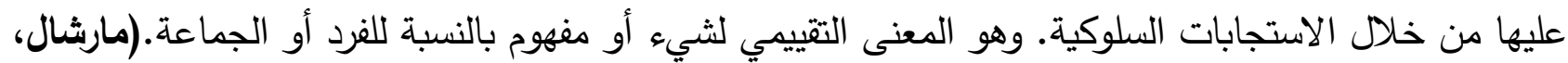
$(V \cdot \omega, r \cdot V$

r- مفهوم الهندسة الاجتماعية: "Social Engineering"

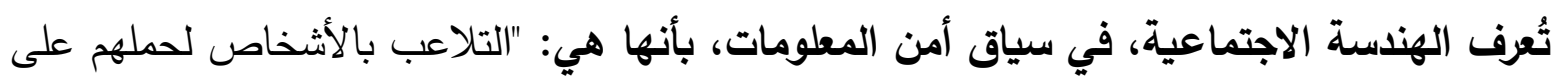

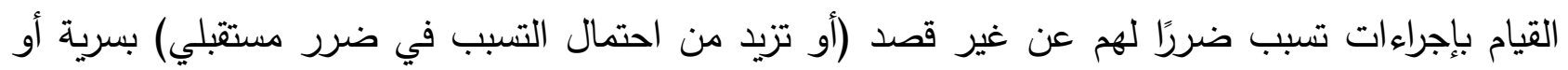

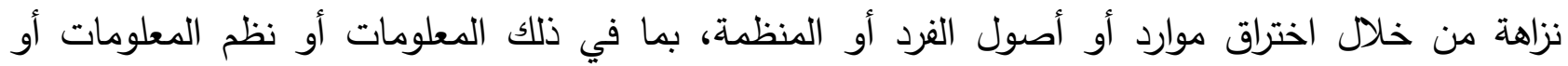
الأنظمة المالية...إلخ". (Greitzer, 2014) ويرى البعض أن الهندسة الاجتماعية عبارة عن: مجموعة من الطرق السرية التي تمكن من يمارسونها

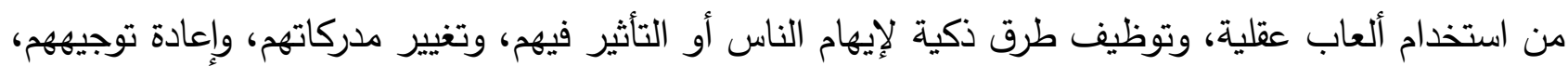

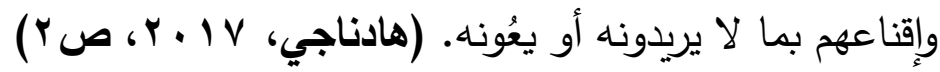

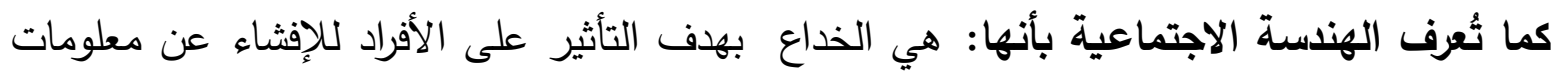

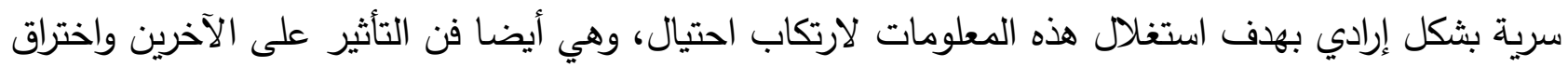

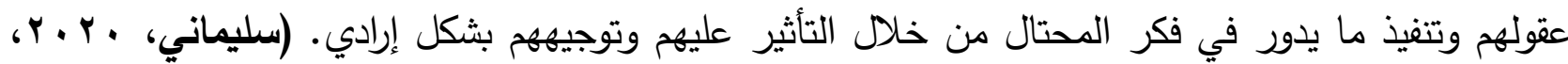

\section{التعريف الإجرائي:}

1- ممارسة أوجه الخداع/الاحتيال من قبل شخص ما تجاه الآخر . ץ- يستتد المهند الاجتماعي مجموعة من المهارات والقدرات الخاصة التي تمكنه من الهجوم على الى

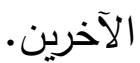

r- يتم استخدام العديد من الأساليب التقنية أو البشرية من قبل المهند الاجتماعي لتنفيذ الهجمات.

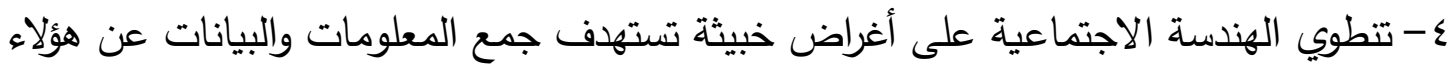

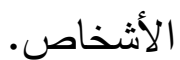

ه- تتمثل تلك الأغراض في (جمع المال- السرقة- تغيير الأفكار التي يتبناها الأشخاص- توجيه الفرد

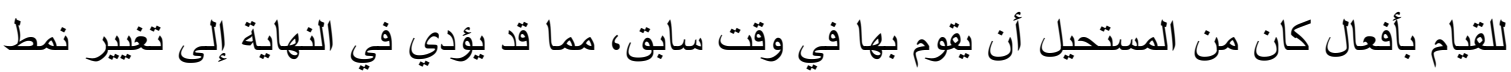

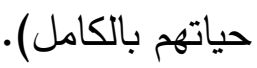




\section{r- ب- مفهوم الهوية الثقافية: "Identity"}

الهوية في اللغة هي: كلمة مشتقة من: من هو؟ فهي عملية تمييز الفرد لنفسه عن غيره من سماته،

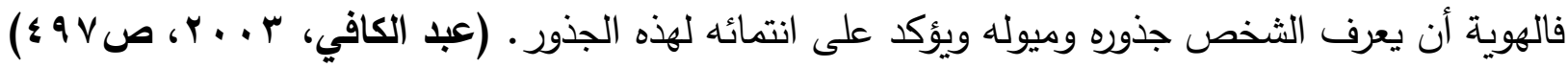
ويطلق مفهوم الهوية على نسق المعايير التي يُعرَف بها الفرد ويُعرّف، وينسحب ذلك على هوية

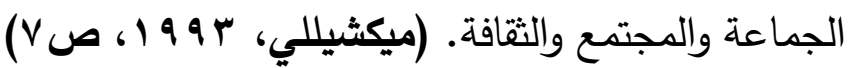

والهوية خاصة بالإنسان والمجتمع، الفرد والجماعة. وهي موضوع إنساني خالص، فالإنسان هو الذي ينقسم على نفسه، وهو الذي يشعر بالمفارقة أو التعالي أو القسمة بين ما هو كائن وما يجب أن يكون بين الواقع والمثال، بين الحاضر والماضي، بين الحاضر والمستقبل. هو الذي يشعر بالفصام، وهو الذي تنقلب فيه الهوية

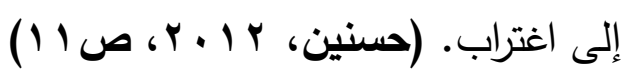

وتتمثل الهوية في: الاعتقاد السائد داخل الفرد بأنه جزء من المنظمة التي يعمل بها ويتأثر بالمنظمة ويكون لايه شعور داخلي بالانتماء للمجتمع الموجود داخل المنظمة وتربطه مع زملائه بالعمل علاقات اجتماعية وكذلك وجود التلاحم والتعاطف القوى بين الأفراد داخل المنظمة وتمتاز العلاقات الاجتماعية بالمتانة والثقة

المتبادلة.

وهنالك تعاطف وتعاون بين الأفراد ووجود صداقات بينهم كل ذلك سوف يعمل على تكوين هوية تتظيمية خاصة بهم ويشير مصطلح الهوية إلى ما يشعر به الأفراد في المنظمة وما يفكرون به ويحملونه من اتجاهات ورؤى مشتركة نحو منظمتهم وبشكل صورة انطباعية في أذهان الأفراد تجاه منظمتهم والتي تعد انعكاسا ديناميكيا لطبيعة الثقافة التتظيمية التي تستند على العلاقات الاجتماعية والتي تبني الهوية التظيمية. (عباس \&

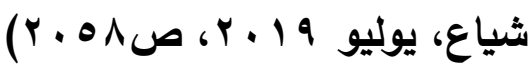
والهوية: هي معرفة وإدراك الذات القومية ومكوناتها من القيم والأخلاق والعادات والتقاليد، وهي سمات وخصائص يتميز بها شعب ما عن غيره من الشعوب، وتربط هذه السمان بالسلوكيات العامة لمجموع الفراد

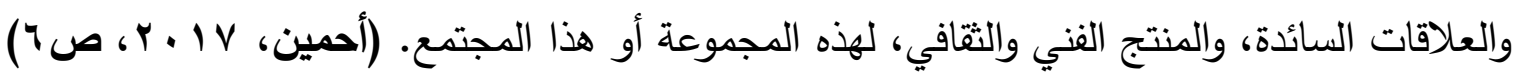
ويمكن تعريف الثقافة بأنها: مصطلح شامل يحدد كل من الأشكال البشرية المتميزة للتكيف والطرق المميزة التي ينظم بها البشر المختلفون حياتهم على الأرض. ولا يلزم مسايرة هذه القواعد عالميًا أو باستمرار، ولكن يتعرف عليها كل الناس، وتعمل عادةً للحد من نطاق التباين في أنماط المعتقدات والتواصل والقيم

والسلوكيات الاجتماعية للبشر • (Zhang, 2018, p162)

والهوية الثقافية تُعني: "أولاً وقبل كل شيء أننا أفراد ننتمي إلي جماعة لغوية محلية أو إقليمية أو وطنية، بما لها من قيم أخلاقية وجمالية تميزها، ويتضمن ذلك أيضًا الأسلوب الذي نستوعب به تاريخ الجماعة وتقاليدها وعاداتها وأسلوب حياتها، وإحساسنا بالخضوع له والمشاركة فيه، أو تشكيل قدر مشترك منه، وتعني الطريقة التي تظهر فيها أنفسنا في ذات كلية، وتعد بالنسبة لكل فرد منا نوعًا من المعادلة الأساسية التي تقرر - 
بطريقة إيجابية أو سلبية - الطريقة التي ننتسب بها إلى جماعتنا والعالم بصفة عامة). (المحروقي، أكتوبر

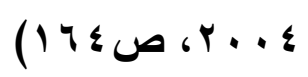

كما تعرف الهوية الثقافية بأنها: "مجموعة المباديء الأصلية السامية والذاتية النابعة من الأفراد أو الشعوب وتلك ركائز الإنسان التي تمثل كيانه الثخصي الروحي والمادي بتفاعل صورتي هذا الكيان، وتمثل

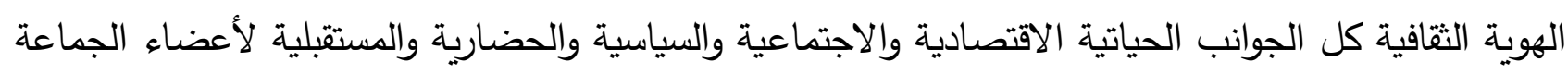

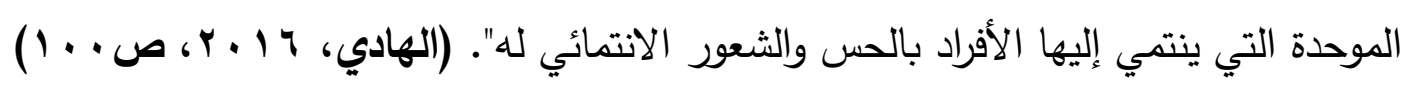
التعربف الإجرائي: 1 - حفاظ الثباب الجامعي على استخدام اللغة العربية والتتسك بها (حديثًا - كتابة). r- تمسك الثباب الجامعي بالقيم (الدينية، الوطنية) وعدم الخروج عنها. r- ب- محافظة الثباب الجامعي على العادات والتقاليد التي يتبناها المجتمع. ع - الخلفية التاريخية المتأصلة لاى الثباب الجامعي وما تتضمنه من (الاهتمام بالمعالم التاريخية- التعرف لهن على التطور التاريخي - الاهتمام بالحضارة القومية). ثالثًا: أهداف الدارسة التهابة - تسعى الدراسة الحالية إلى التوصل إلى مجموعة من الأهداف وهي: 1- تحديد اتجاهات الثباب الجامعي نحو الهندسة الاجتماعية. - - ويمكن تحقيق هذا الهذف من خلال هدفين فرعيين:

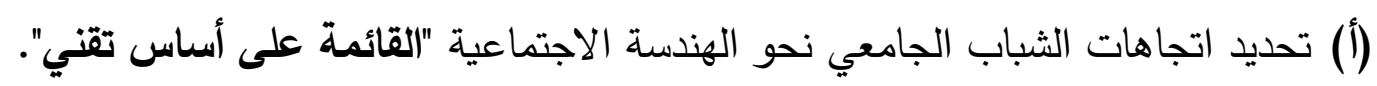

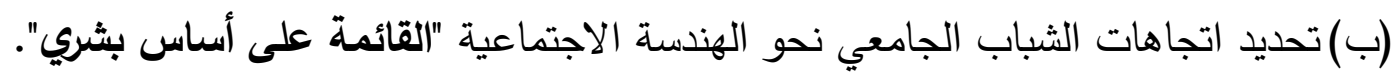

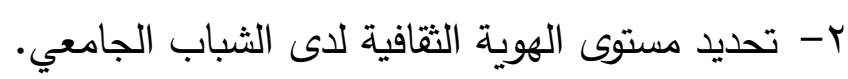
ب- تحديد العلاقة بين اتجاهات الثباب الجامعي نحو الهندسة الاجتماعية ومستوى الهوية الثقافية لديهم.

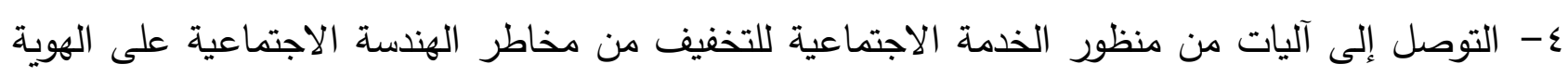
الثقافية للثباب الجامعي. رابعًا: تساؤلات الدراسة

- تسعى الاراسة الحالية إلى الإجابة على مجموعة من التساؤلات وهي:

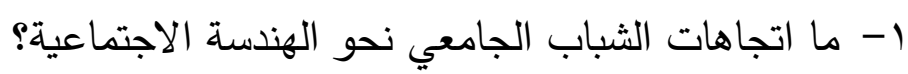
-

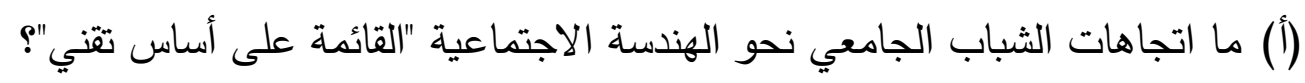

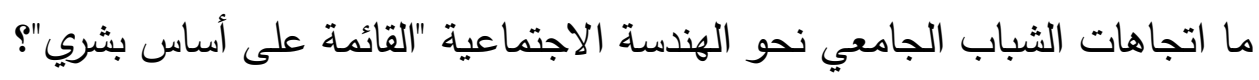


r- ما مستوى الهوية الثقافية لدى الثباب الجامعي؟ ب- ما العلاقة بين اتجاهات الثباب الجامعي نحو الهندسة الاجتماعية ومستوى الهوية الثقافية لديهج؟ خامسا: المنطلق النظري للاراسة - - تنطلق الدراسة الحالية من النظرية المعرفية السلوكية. والنظرية المعرفية السلوكية (Theory Behavioral Cognitive) هي: تعليم الأفراد أن يحددوا أفكارهم ومعتقداتهم ويقيموها، خاصة المرتبطة بالأحداث المؤلمة والاضطرابات السلوكية؛ بهدف تفنيد الأفكار والمعتقدات اللاعقلانية السلبية لدى الفرد وتعديلها، وإبدالها بأفكار ومعتقدات عقلانية إيجابية. (الهلاك \&

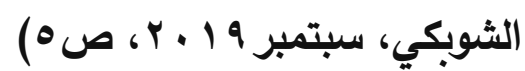
ويرى أصحاب النظرية المعرفية السلوكية أن الإنسان هو الذي يوظف الموقف والمعرفة ويعالجها، ويعيد

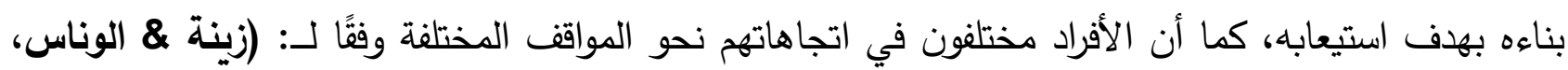

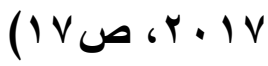

1- طبيعة البنية المعرفية التي كونها الفرد من تفاعلاته النشطة، وخبراته.

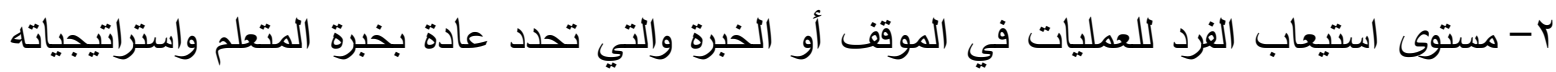
المتطورة ووحدة الزمن المستخدمة لإدخال الخبرة إلى الذهن.

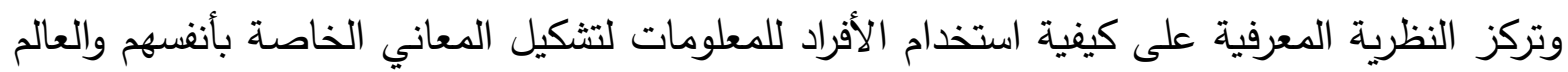
المحيط بهم لبناء المعاني حول هذه الأمور من أجل تفسير ما يواجههم من مشكلات وإمكانية التعامل معها.

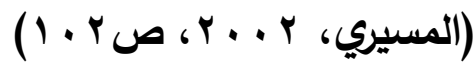
ويمكن الاعتماد على هذه النظرية في الدراسة الحالية باعتبارها من أهم النظريات التي تهدف إلى تفسير

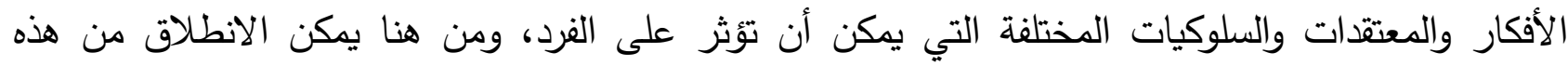

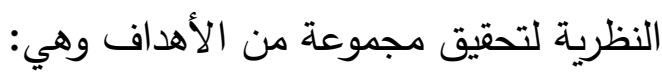

1- إمكانية تفسيرها لاتجاهات الثباب نحو الهندسة الاجتماعية، وكيفية مواجهة المخاطر الناتجة عنها.

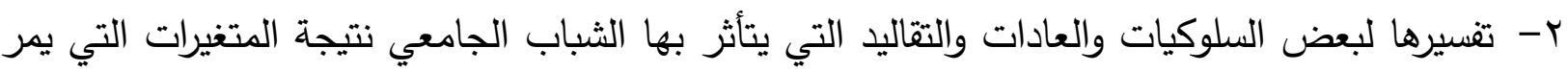
بها المجتمع سواء كانت متغيرات مرتبطة بالنواحي البشرية والمجتمعية أو متغيرات تقنية.

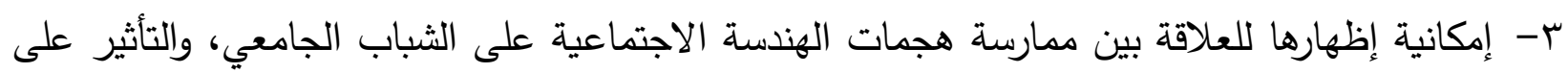
الهوية الثقافية لهم بما تتضمنه من عادات وتقاليد ولغة وقيم دينية ووطنية وتاريخية...إلخ.

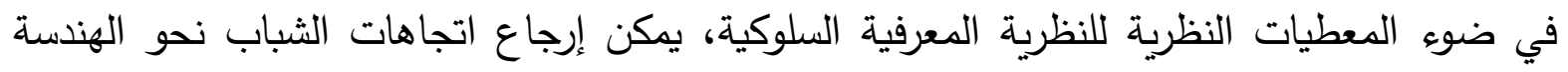
الاجتماعية ووقوعهم ضحايا لهجماتها المختلة، إلى ضعف الوعي لديهم نحو كيفية الحماية من تلك الهجمات

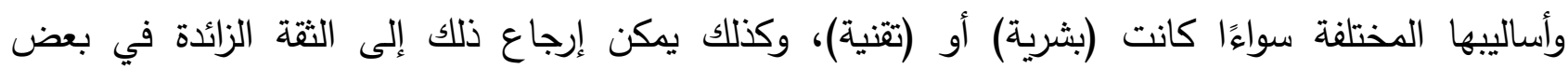
الأشخاص قد يدعون أنهم أصدقاء أو أشخاص مقربين، أو لأنهم يستخدمون أساليب مختلفة كالاحترام الزائد 
للضحية، أو جذب انتباههم بأسلوب معين، أو إظهار ما هو نادر أمامهم..إلخ، كذلك يمكن أن يكون السبب هو

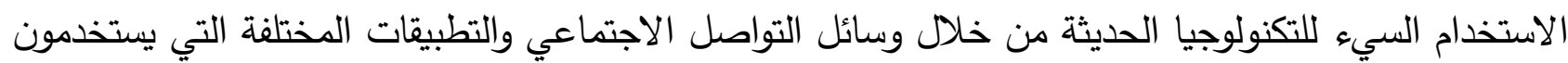
فيها معلوماتهم الثخصية وبريدهم الإكتروني وغيرها من البيانات والمعلومات التي تسهل على المهندس الاجتماعي تتفيذ هجماته للوصول إليهم. كما يمكن تفسير مستوى الهوية الثقافية لدى الثباب الجامعي بأنه يتحدد وفقًا لحفاظهم على المقومات لتهات

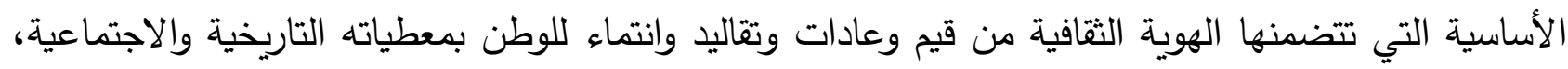
فيمكن إرجاع انخفاض مستوى الهوية لاى الثباب الجامعي إلى العديد من الأسباب والتي في مقدمتها الثورة

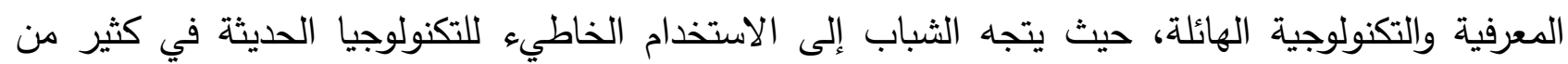
الأحيان عند استخدام وسائل التواصل الاجتماعي والتطبيقات الحديثة، وكذلك ينجرف الثباب وراء الدعايا

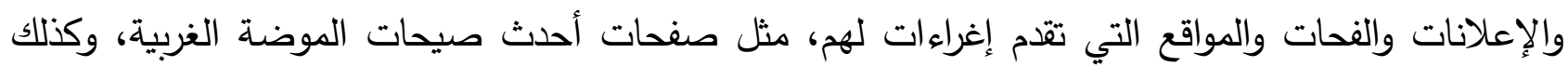

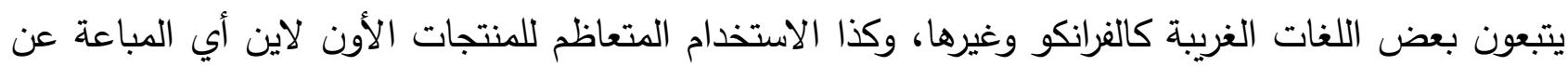

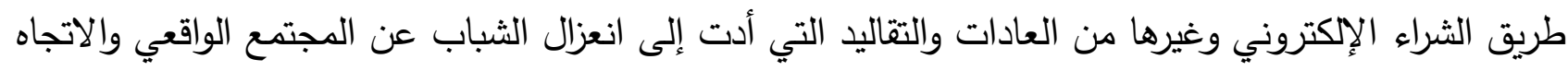

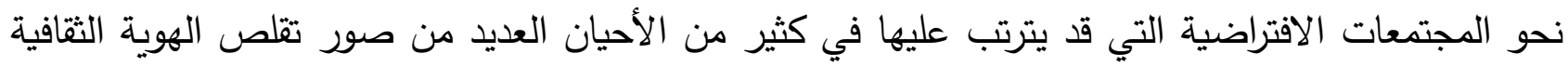
للمجتمعات العربية ومن بينها المجتمع المصري. ومن هنا يتضح أن هناك علاقة وثيقة بين اتجاهات الثباب نحو الهندسة الاجتماعية والهوية الثقافية للشباب الجامعي، حيث أن ممارسة هجمات الهندسة الاجتماعية قد تؤثر على تقلص الهوية الثقافية لهم. سادسًا: الإطار النظري للدراسة

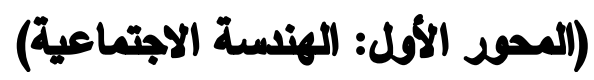
1 - أقسام الهندسة الاجتماعية:

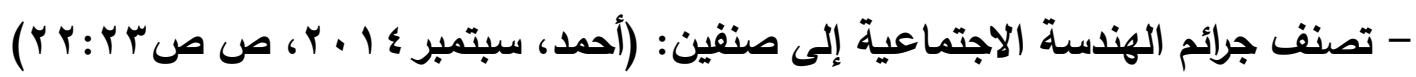
(أ) هندسة قائمة على أساس تقني: وهي برامج وتقنيات تساعد الهاكر للوصول للمعلومة ومن أمثلة ذلك: - الاحتيال الاكتروني(phishing): يعكس هذا المصطلح على رسالة بريد إلكتروني من شركة ائمان أو بنك لكئك وصلتك وتطلب التحقق من معلوماتك وتحتوي هذه الرسالة على وصلة لصفحة ويب احتيالية تظهر مشابهة

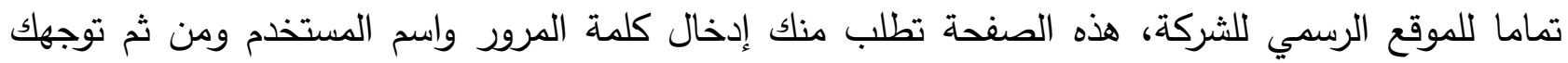

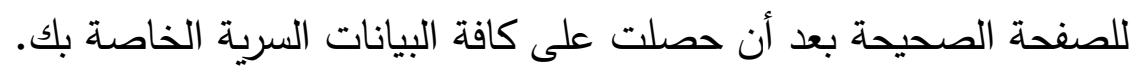

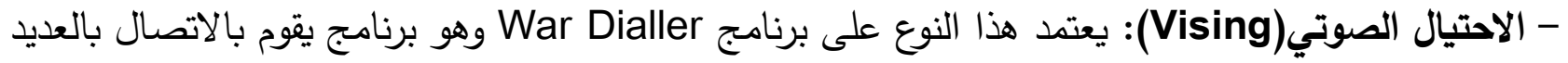

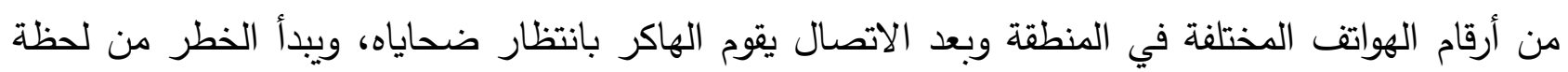

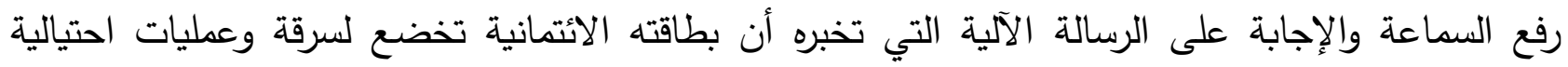
طالب منك رقم البطاقة وبعض البيانات السرية وحينها يحصل الهاكر على ما يريد. 
- الرسائل الاقتحامية المزعجة(Spam): هي رسائل الكترونية بعناوين مشوقة للقراءة مثل تهنئة من صديق

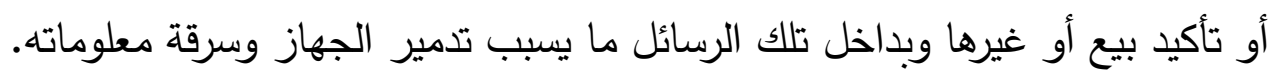
- برامج مهمة: وهي ما نشهده في بعض المواقع من روابط تحميل برامج ولكنها تكون مدعومة بكلمات اقناعية عن أهمية ذالك البرنامج المكر للجهاز والسارق للمعلومات الحساسة. (ب) هندسة قائمة على أساس بثري أو إنساني: وهي جرائم تعتمد على الإنسان، ويمكن القول بأنها جرائم

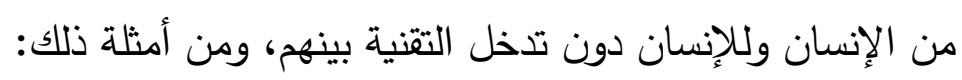

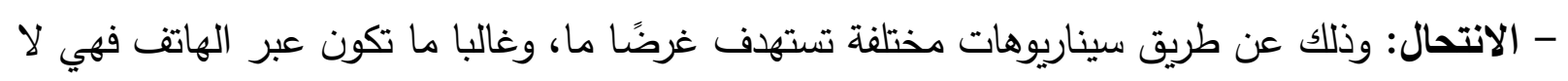
تتطلب الحضور وجها لوجه ولكنها تتطلب بعض المعلومات مثل الاسم أو تاريخ الميلاد وغيرها.

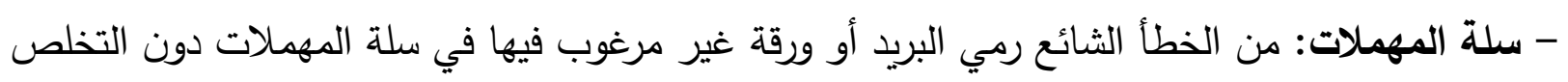

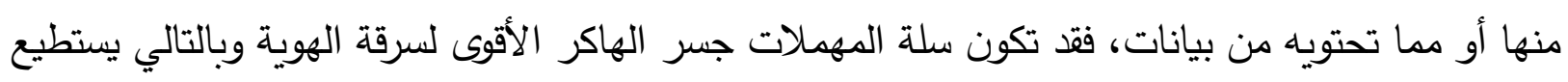

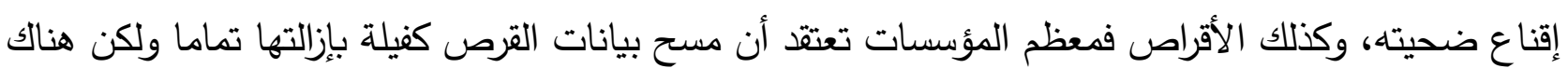
العديد من الطرق الخبيثة لاستعادتها حتى بعد حذفها.

- التجسس والتصنت: يمكن للهاكر سرقة كلمة المرور ومعلومات مهمة عن طريق مراقبة الضحية حين لطادئ

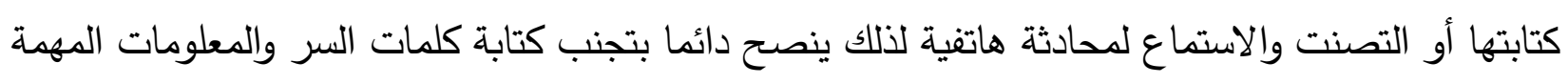
على ورق تحت لوحة المفاتيح أو حتى تبادلها. ץ- خصائص الهنسة الاجتماعية: (Greitzer, 2014, p239) جدول رقم (1)

\begin{tabular}{|c|c|c|}
\hline النتائج/ الآكار المصنملة & المطومات النعونهية المطلوبة & الغماتص البانة \\
\hline 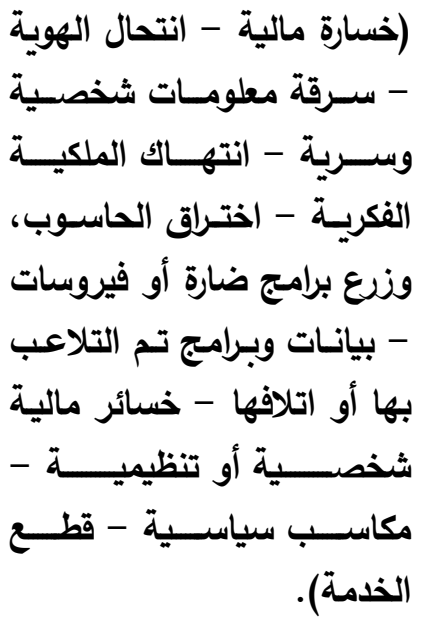 & 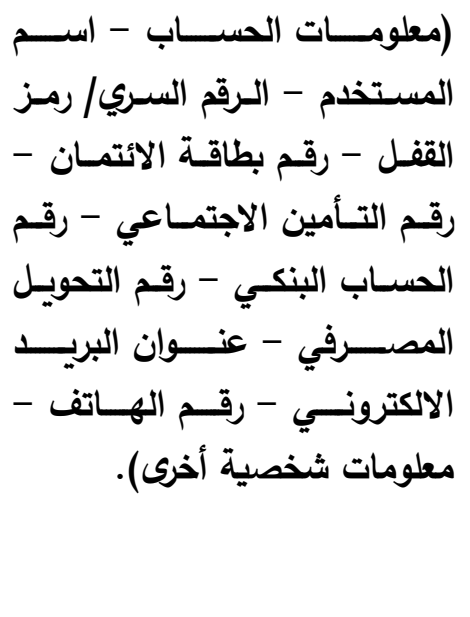 & 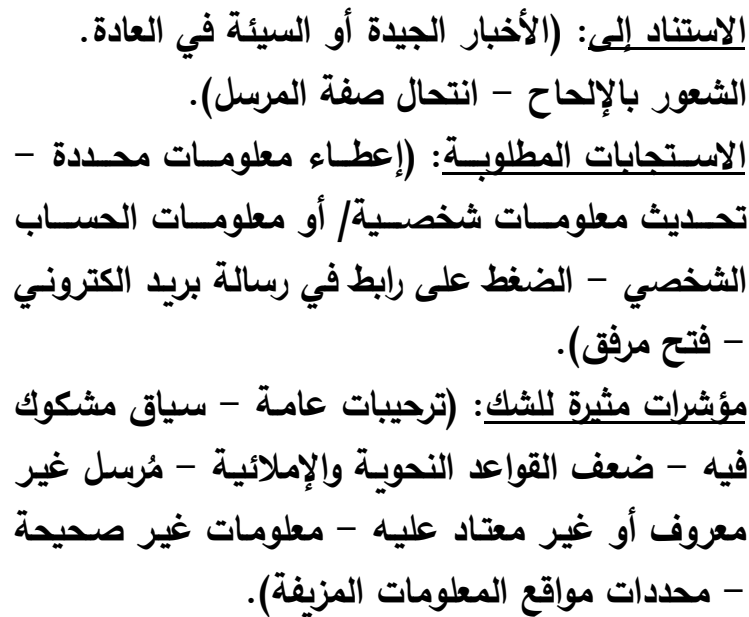 \\
\hline
\end{tabular}




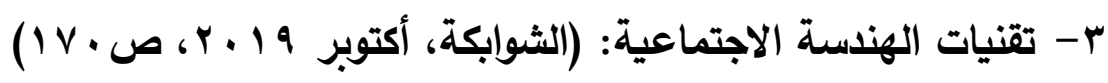

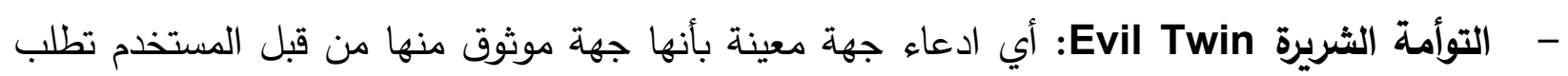
منه استخدام ملف مرفق يكون ضارا. - سرقة الهوية Identify Theft: أي إدعاء جهة معينة بأنها جهة معروفة من قبل المستخدم، بحيث يتم طلب تقديم معلومات منه بشكل مباشر .

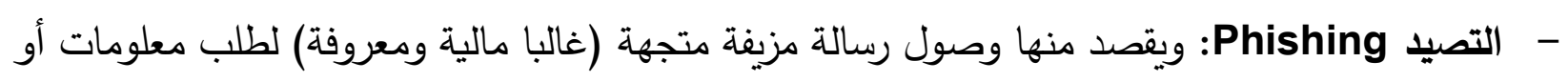
التحقق منها، ولتحقيق ذلك قد تحتوي هذه الرسائل على رابط مزيف لجهة معروفة. ع - مراحل تنفيذ هجمات الهندسة الاجتماعية: - يقوم المهاجم بتنفيذ الهجمات الاجتماعية في شكل تسلسل عبر المراحل التالية: (كمال \& ع عبد الرؤوف،

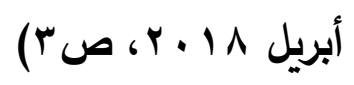

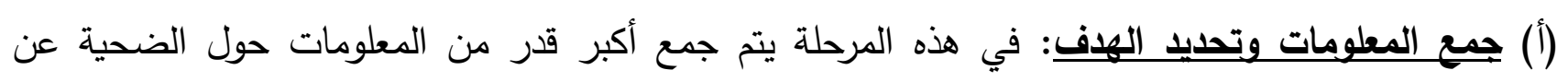

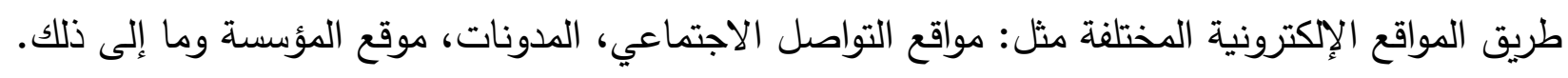

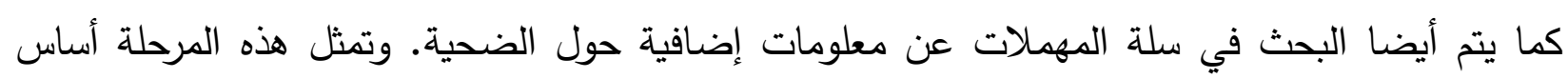

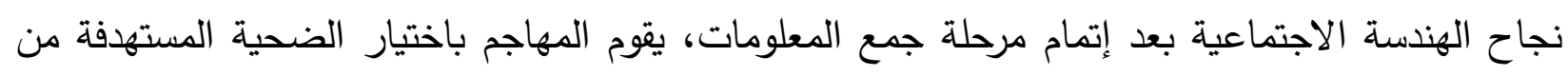
أجل بناء وتطوير العلاقة كمرحلة ثانية. (ب) تطوير العلاقة: يحاول المهاجم خلال هذه المرحلة بناء علاقة مع الضحية المستهدفة والعمل على تلى بلى

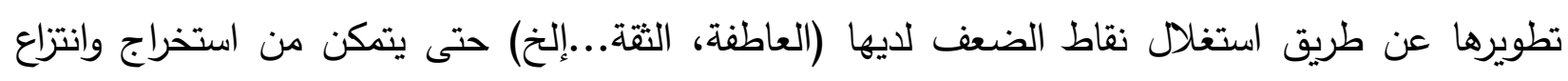

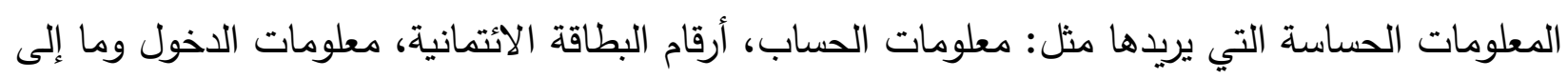
ذلك.

(ج) استغلال العلاقة: يتم استغلال العلاقة بمجرد بناءها، ويتم تطويرها مع الضحية المستهدفة بشكل تدريجي.

التنفيذ والوصول إلى الهيف: في هذه المرحلة يقوم المهاجم بالتنفيذ الفعلي لما خطط له، مع محاولة الوصول إلى الهدف النهائي. وفي حالة عدم وصول المهاجم إلى النتائج المرغوبة، فيمكنه تكرار الخطوات السابقة.

\section{(المحق الثاني: الهوية الثقافية)}

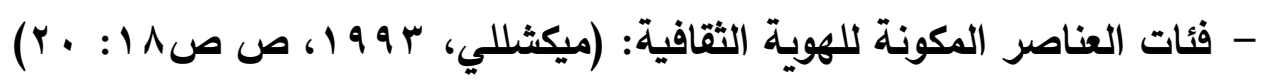

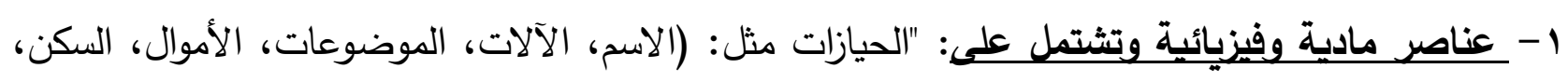

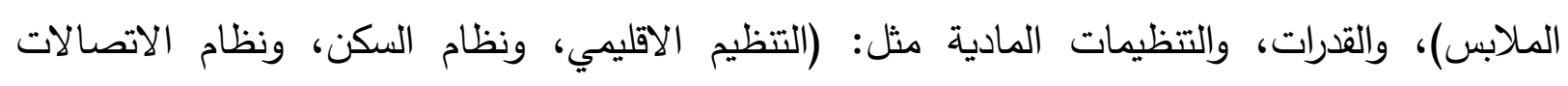

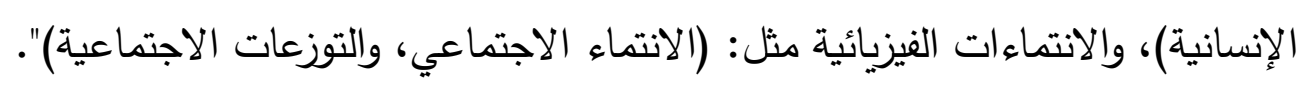


ז- عناصر تاريخية وتتضمن: "الأصول التاريخية مثل: (الأسلاف، الولادة، الاسم، المبدعون، الاتحاد،

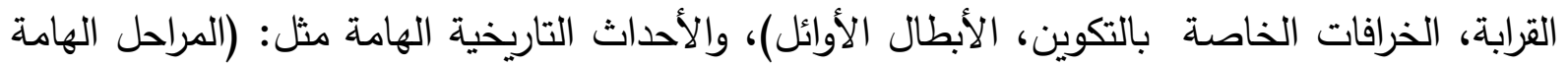
في التطور، التحولات الأساسية، الآثار الفارقة، التربية الاجتماعية)، والآثار التاريخية مثلك: (العقائد

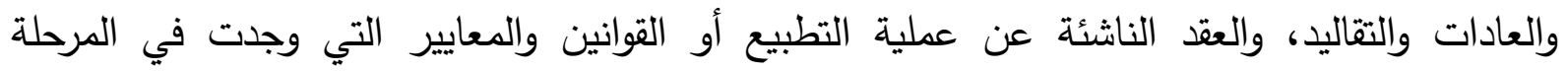
(الماضية). r- عناصر ثقافية نفسية وتثمل: "النظام الثقافي مثل: (المطلقات الثقافية، العقائد، الأديان والرموز

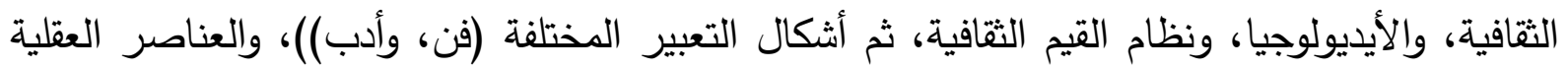

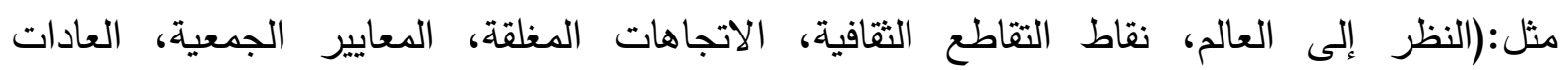
الاجتماعية)، والنظام المعرفي مثل: (السمات النفسية الخاصة، اتجاهات نظام القيم)".

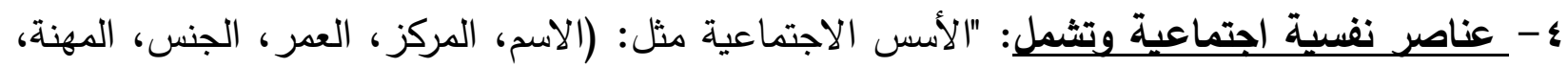
واجبات، أدوار اجتماعية، نشاطات، انتماءات اجتماعية)، والقيم الاجتماعية مثل: (الكفاءة، النوعية،

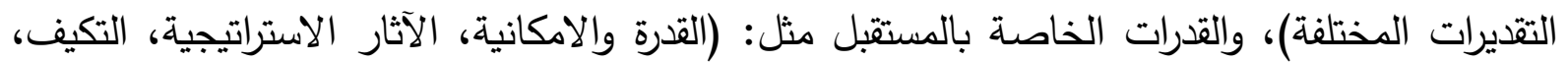
نمط السلوك)". وتتضمن الهوية الثقافية مجموعة من المقومات وهي: (اللغة الوطنية واللهجات المحلية، القيم الدينية

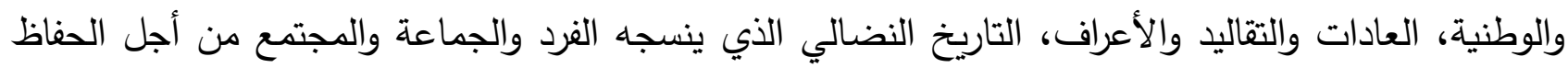

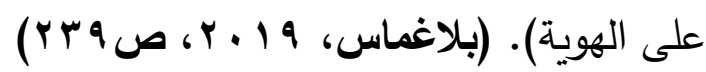
سابعًا: الإجراءات المنهجية للدراسة 1- نوع الدراسة: تنتمي هذه الدراسة إلى نمط الدراسات الوصفية التي تستهدف فيها الباحثة تحديد اتجاهات الثباب نحو الهندسة الاجتماعية، وتحديد مستوى الهوية الثقافية لديهم، من أجل الوقوف على العلاقة بين تلك الاتجاهات ومستوى الهوية الثقافية. ץ- المنهج المستخدم: تستند هذه الدراسة إلى استخدام "المنهج الوصفي"، وذلك باستخدام طريقة المسح الاجتماعي بالعينة لعينة عشوائية بسيطة من الثباب الجامعي "طلاب كلية الخدمة الاجتماعية كنموذج". r- أدوات الدراسة: استتدت الباحثة على أداتين أساسيتين لتحقيق أهداف الدراسة وهما:

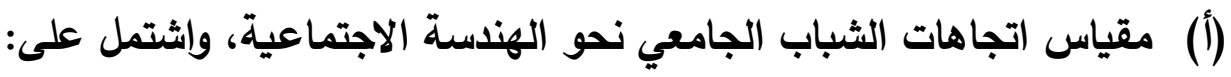
- - البيانات الأولية: وتضمنت أربع أسئلة.

• البعد الأول: اتجاهات الثباب الجامعي نحو الهندسة الاجتماعية القائمة على أساس تقني.

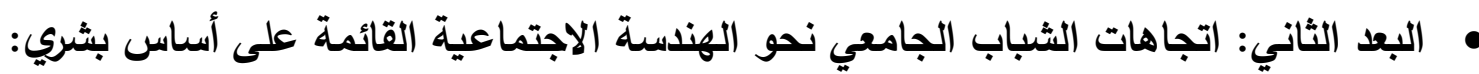

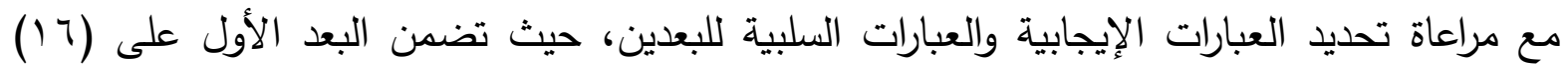

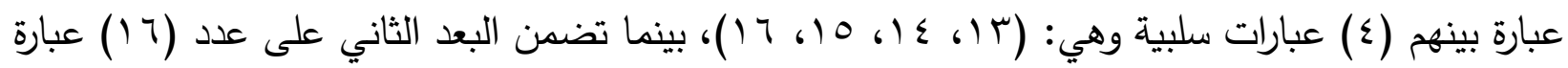




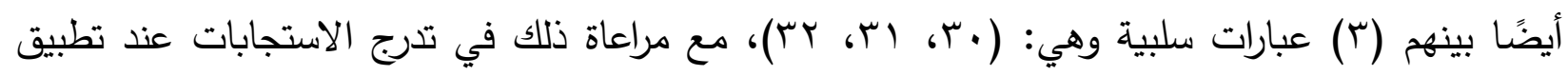
المعاملات الإحصائية. (ب) مقياس مستوى الهوية الثقافية لاى الثباب الجامعي، واشتمل على: - - البيانات الأولية: وتضمنت أربع أسئلة. - ـ ـ ولم يتضمن هذا المقياس على أبعاد، ولكن تمت فيه مراعاة مقومات الهوية الثقافية كاملةً، وتضمن هذا

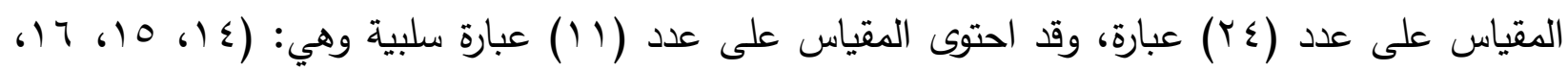

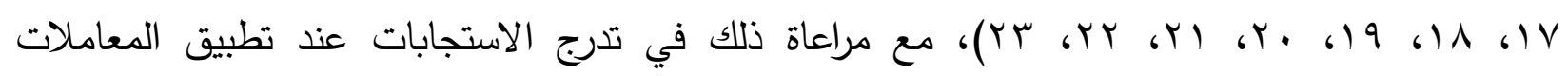
الإحصائية.

\section{-} • الصدق الظاهري (صدق المحكمين): تم عرض مقياسي الدراسة (مقياس اتجاهات الثباب الجامعي نحو الهندسة الاجتماعي - مقياس مستوى الهوية التقافية) على عدد ( • () محكمين من أساتذة كليتي الخدمة الاجتماعية جامعة الفيوم، وجامعة حلوان، وكلية التربية جامعة الفيوم، وبناءً عليه تم تعديل صياغة عبارات المقياسين، وحذف بعض العبارات، وإضافة البعض الآخر، وتم التوصل في النهاية إلى نسبة اتفاق لا تقل عن ( •^\%)، وبالتالي تمت صياغة المقياسين في صورتهما النهائية، وأصبح عدد أبعاد المقياس الأول (بعدان)، والمقياس الثاني لا يحتوي على أبعاد، ولكنه تضمن على كل ما تنطوي عليه الهوية الثقافية من عناصر • صدق المحتوى: معنى صدق المحتوى مدى تمثيل بنود الأداة للمحتوى المراد قياسه، وللتحقق من صدق محتوى أدوات الدراسة تم حساب معامل الارتباط بيرسون للعلاقة بين درجة كل بُعد والدرجة الكلية للأداة.

$$
\text { جدول رقم (r) }
$$

المصفوفة الارتباطية بين أبعاد المقياسين والمجموع الكلي

\begin{tabular}{|c|c|}
\hline المجموع الكلي & الالهماد \\
\hline$* *, v$. & اتجاهات الشباب الجامعي نحو الهندسة الاجتماعية القائمة على أساس تقني \\
\hline$* *, \mathrm{VV}$ & اتجاهات الثباب الجامعي نحو الهندسة الاجتماعية القائمة على أساس بثري \\
\hline$* *, \wedge \varepsilon$ & مقياس اتجاهات الشباب الجامعي نحو الهندسة الاجتماعية ككل \\
\hline$* *, \varepsilon$ & مقياس مستوى الهوية الثقافية لاى الثباب الجامعي ككل \\
\hline
\end{tabular}

يتضح من الجدول السابق ارتباط أبعاد المقياسين ببعضها البعض بمستوى دلالة (1 . • )، وهذا يؤكد أن الأدوات تتمتع بدرجة عالية من الصدق. 


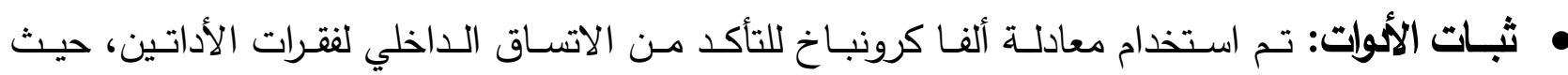

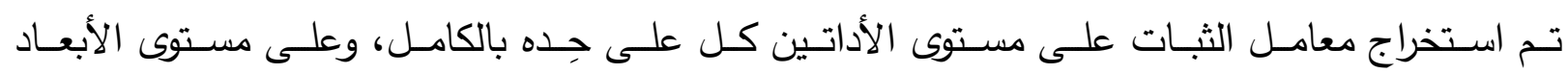

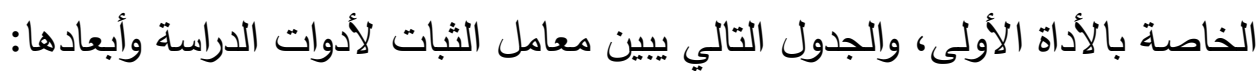

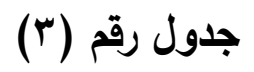

معاملات الثبات للأبعاد باستخدام معادلة ألفا كرونباخ وللأداة ككل

\begin{tabular}{|c|c|}
\hline معامل الثبات & الالجعاد \\
\hline$\cdot, 70$ & اتجاهات الثباب الجامعي نحو الهنسسة الاجتماعية القائمة على أساس تقني \\
\hline , vo & اتجاهات الثباب الجامعي نحو الهندسة الاجتماعية القائمة على أساس بشري \\
\hline$\cdot, \mathrm{\vee V}$ & |مقياس اتجاهات الثباب الجامعي نحو الهندسة الاجتماعية ككل \\
\hline (0, & مقياس مستوى الهوية الثقافية لاى الثباب الجامعي \\
\hline
\end{tabular}

وبالنظر إلى النتائج الموجودة بالجدول السابق يتضح أن معامل ثبات بالنسبة لمحاور الأداة الأولى والثانية

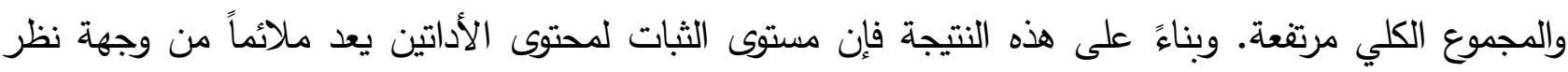

$$
\text { ع - مجالات الدراسة: }
$$

(أ) المجال البشري: تم التطبيق على عينة عشوائية بسيطة من الثباب الجامعي (طلاب كلية الخدمة الاجتماعية - جامعة الفيوم نموذجًا)، وفيما يلي بيان تفصيلي للمجال البشري وكيفية اختيار العينة:

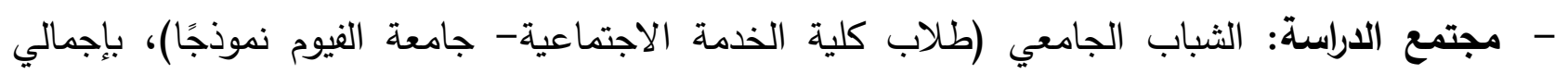

\begin{tabular}{|c|c|c|c|c|c|}
\hline الإجمالي & الرابعة & الثالثة & الثانية & الأولى & المركة \\
\hline$\varepsilon q \wedge r$ & \&OV & VII & ivio & $r \cdot \leqslant q$ & اللعد \\
\hline
\end{tabular}

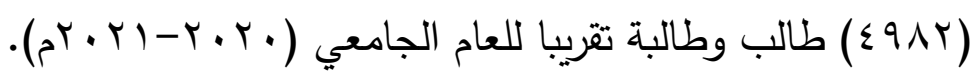

$$
\begin{aligned}
& \text { - - إطار المعاينة: }
\end{aligned}
$$

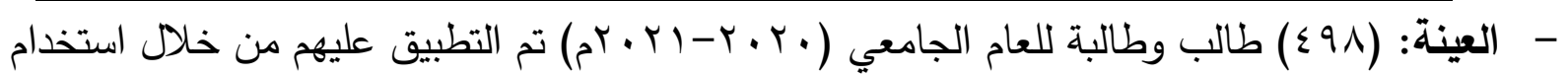
نماذج جوجل للتطبيق الإلكتروني "google forms".

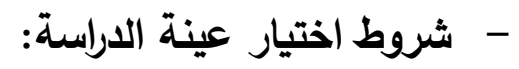
1- أن تكون من طلاب كلية الخدمة الاجتماعية باعتبارهم نموذج للشباب الجامعي.

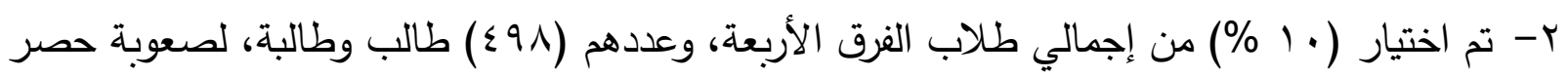
جميع الطلاب. (ب) المجال المكاني: كلية الخدمة الاجتماعية. 


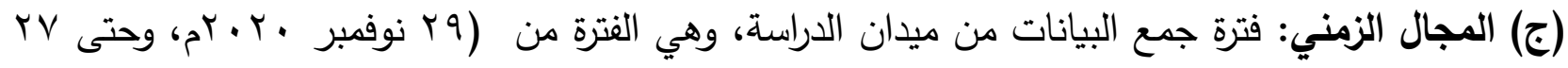

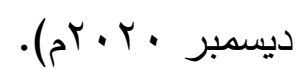

ه- المعالجات الإحصائية:

استخدمت الباحثة مجموعة من الاختبارات الإحصائية خلال الدراسة من خلال استخدام برنامج الحزم الإحصائية للعلوم الاجتماعية (SPS 26)، وشملت:(الوزن المرجح، القوة النسبية، النسب المئوية معامل الارتباط بيرسون، معامل ألفا كرونباخ).

ثامنًا: التحليل الكمي والكيفي لنتائج الدراسة:

\section{1- البيانات الوصفية لعينة الدراسة:}

تقوم هذه الدراسة على عدد من المتغيرات المتعلقة بالخصائص الشخصية لأفراد عينة الدراسة، وفي ضوء هذه المتغيرات يمكن تحديد خصائص أفراد عينة الدراسة كالتالي: جدول (ع)

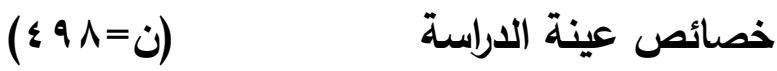

\begin{tabular}{|c|c|c|c|c|c|c|c|}
\hline المئوية & 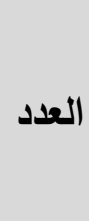 & الفئسة & الالمتموجرافيةات & المئوية & العدد العد & الفئة & الالمتغيرات \\
\hline $09,7 \varepsilon$ & rqv & ريف & \multirow[t]{2}{*}{ محل الإقامة } & $r \varepsilon, 1 \varepsilon$ & 18 & 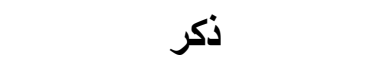 & \multirow{2}{*}{ النوع } \\
\hline$\varepsilon$ & $r \cdot 1$ & 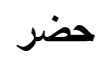 & & $\curlyvee 0, \wedge \uparrow$ & rrA & أنثى & \\
\hline$r \leqslant, r$. & $|r|$ & الأولى & \multirow{4}{*}{ الدراسية } & $\leqslant 1,17$ & $r . Q$ & من ^ا لأقل من • ب سنة & \multirow{4}{*}{ 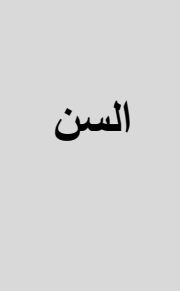 } \\
\hline$r \leq, 1$. & ir. & الثانية & & $\varepsilon ., 07$ & $r \cdot r$ & من · r لأقل من r r rننة & \\
\hline$r r, \cdot q$ & 11. & الثالثة & & \multirow{2}{*}{$I \Lambda, r V$} & \multirow{2}{*}{91} & \multirow{2}{*}{ r r r سنة فأكثر } & \\
\hline$r q, \diamond r$ & $1 \leqslant V$ & الرابعة & & & & & \\
\hline
\end{tabular}

يوضـح الجدول السـابق توزيـع مفردات عينـة الاراسـة وفقـاً للمتغيرات الاديموجرافيـة التي تناولتها الاراسة الحالية، حيث جاءت كما يلي:

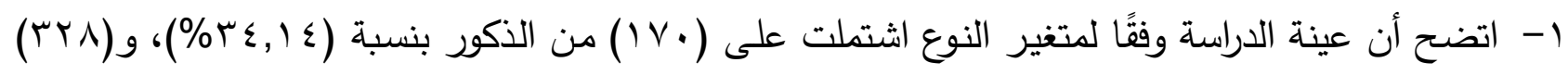
من الإناث بنسبة (7,人,1\%\%)، وهو ما يوضح أن الغالبية العظمى للعينة كانت من الإناث.

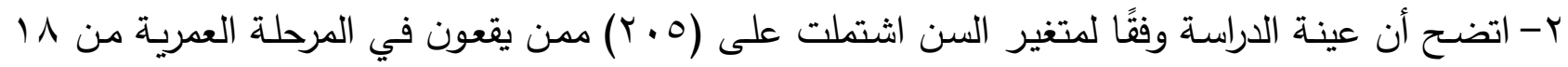

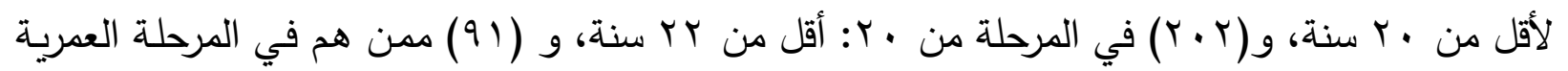
من r r سنة فأكثر ، وهو ما يوضح أن الغالبية العظمى للعينة كانت في الفئتين العمريتين الأولى والثانية أي

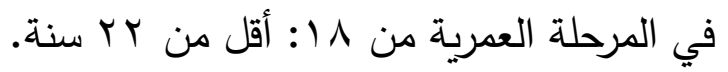




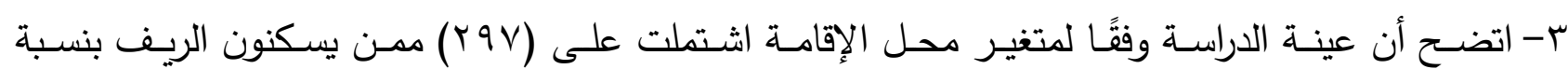

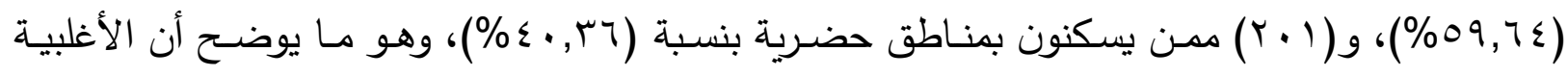

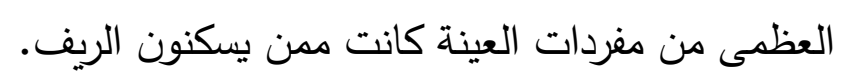

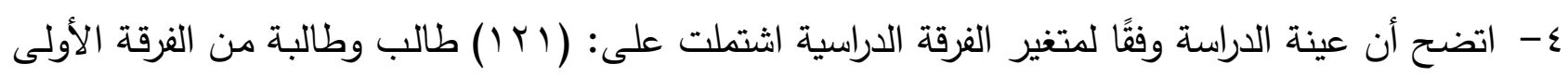

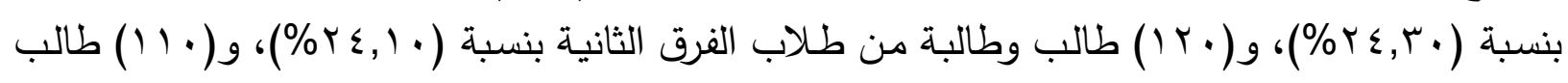

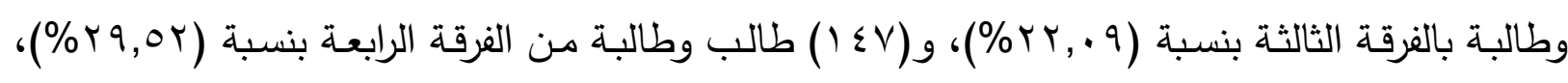

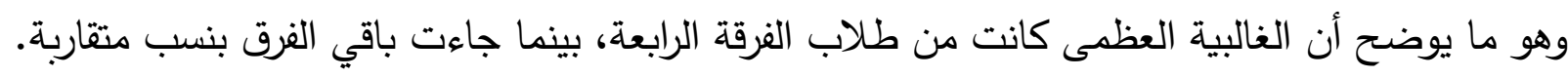




\section{2-2 تصليل وتفسير نتائج الدراسة:}

(أ) نتائج مقياس اتجاهات الثباب الجامعي نحو الهندسة الاجتماعية

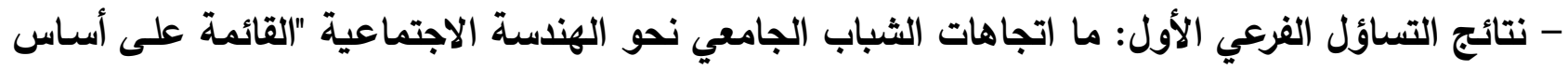
جدول رقم (0)

اتجاهات الثباب الجامعي نحو الهندسة الاجتماعية "القائمة على أساس تقني" (ن = 9 ؛ ؛)

\begin{tabular}{|c|c|c|c|c|c|c|c|c|c|c|c|c|}
\hline \multirow{2}{*}{ 司。 } & \multirow{2}{*}{ 雅 } & \multirow{2}{*}{5} & \multirow{2}{*}{ 牙 } & \multirow{2}{*}{ 氞 } & \multicolumn{2}{|c|}{$y$} & \multicolumn{2}{|c|}{ إلى حد ما } & \multicolumn{2}{|c|}{ نعم } & \multirow{2}{*}{ العبــــــــــــارة } & \multirow[b]{2}{*}{$p$} \\
\hline & & & & & $\%$ & ك & $\%$ & ك & $\%$ & s & & \\
\hline - & 7,87 & rAq,rr & VA, IA & 1171 & $17, \varepsilon V$ & Ar & rr,or & 178 & $01, .$. & roz & 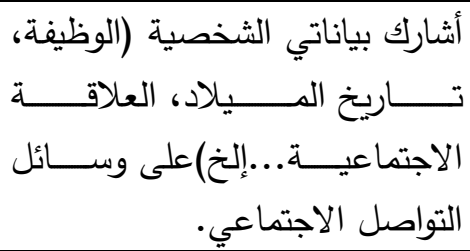 & 1 \\
\hline$\varepsilon$ & $v_{0}, 7$ & $\varepsilon \cdot \gamma, r r$ & $\wedge 1,09$ & $|r| q$ & $1 \cdot, \varepsilon \varepsilon$ & or & $r \varepsilon, r \varepsilon$ & $|v|$ & $00, Y Y$ & rro & 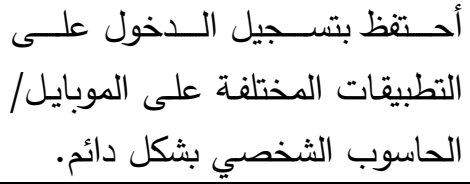 & $r$ \\
\hline 1 & $V, A V$ & \&or,rr & $91, .4$ & (rצ. & $\varepsilon, \pi$ & r & IV,TV & $\mathbf{\wedge} \boldsymbol{\Lambda}$ & $\checkmark Y, Y I$ & rav & 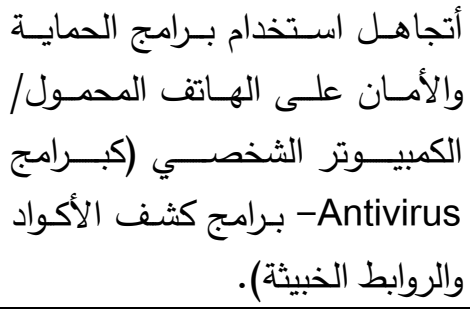 & $r$ \\
\hline$r$ & $\mathbf{V}, \mathbf{A l}$ & $\varepsilon \varepsilon q, \uparrow \vee$ & $9 \cdot, Y 9$ & $1 r \varepsilon q$ & $0, \wedge Y$ & rq & $I Y, \varepsilon V$ & AV & VY,YI & rar & 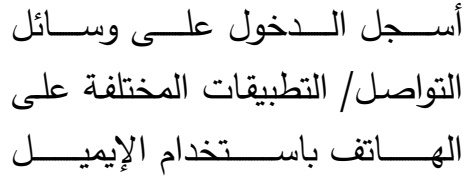 & $\varepsilon$ \\
\hline $1 \varepsilon$ & $0, \ldots$ & YAY,IV & OY,YY & ATr & $0, \varepsilon$. & YOI & Yo,9. & Ira & $r r, 7 q$ & 111 & 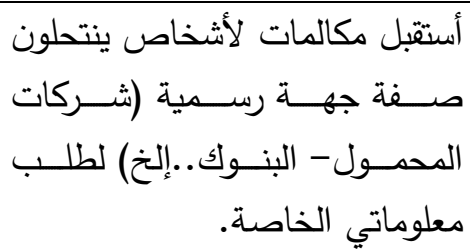 & 0 \\
\hline ir & $0, Y Y$ & r..,rrr & $7 \cdot, r)$ & 9.1 & ro,9\& & IV9 & $\varepsilon V, 19$ & rro & $17, \wedge \mathrm{V}$ & $\wedge \varepsilon$ & ألتواصل الأخبار الرائجة عبر وسائل & $y$ \\
\hline$v$ & 7,09 & rvq,rr & $v \eta, I V$ & IIrA & $17, \mathrm{rV}$ & Al & rA,97 & $19 \varepsilon$ & $\varepsilon \varepsilon, \vee \wedge$ & rYr & 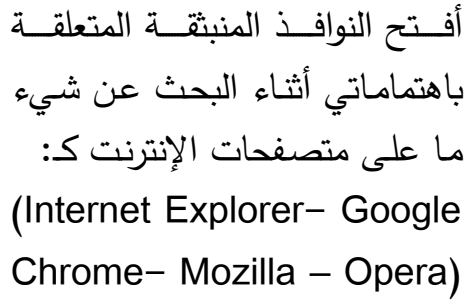 & $\checkmark$ \\
\hline
\end{tabular}




\begin{tabular}{|c|c|c|c|c|c|c|c|c|c|c|c|c|}
\hline \multirow{2}{*}{ 司。 } & \multirow{2}{*}{ 牙 } & \multirow{2}{*}{ :3 } & \multirow{2}{*}{ 武 } & \multirow{2}{*}{ 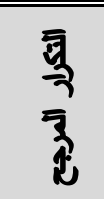 } & \multicolumn{2}{|c|}{$y$} & \multicolumn{2}{|c|}{ إلى حد ما } & \multicolumn{2}{|c|}{ نعم } & \multirow[b]{2}{*}{ العبـــــــــــارة } & \multirow[b]{2}{*}{$p$} \\
\hline & & & & & $\%$ & ك & $\%$ & ك & $\%$ & ك & & \\
\hline 1. & 7,19 & rot,rr & $v 1,00$ & 1.79 & $Y V, M$ & iro & ri,ir & 100 & $\varepsilon 1, V \vee$ & $r \cdot \Lambda$ & 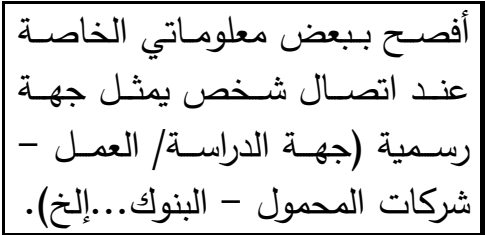 & $\wedge$ \\
\hline$r$ & $v, 0 \varepsilon$ & $\varepsilon r \varepsilon, r r$ & AY,YY & ir.r & $\mid \varepsilon, Y\}$ & vI & $9, \wedge \varepsilon$ & $\varepsilon 9$ & vo,q. & rYA & 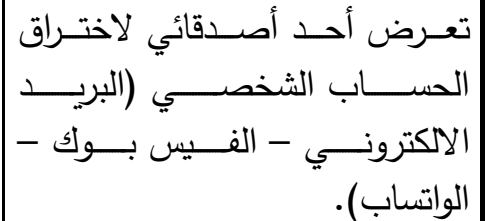 & 9 \\
\hline 9 & $Y, Y \varepsilon$ & roq,rr & VY,IT & $1 . \mathrm{VA}$ & $r \varepsilon, q$. & IrE & $r r, v r$ & 171 & $\varepsilon 1, r v$ & $r \cdot Y$ & 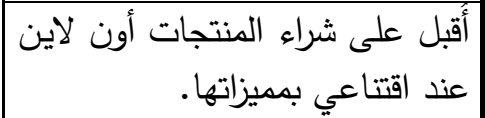 & 1. \\
\hline 7 & $7, V Y$ & rАT,TV & $Y Y, T \varepsilon$ & 117. & $10, .7$ & vo & rq,90 & $1 \wedge \varepsilon$ & $\varepsilon Y, १ 9$ & rra & 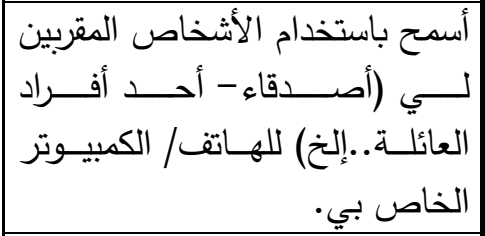 & 11 \\
\hline$\Lambda$ & 7,89 & rrr,ir & vo,.r & $|1 r|$ & $r \cdot, \& A$ & $1 . r$ & Pr,q\& & 179 & $\varepsilon 0,0 \wedge$ & rYr & 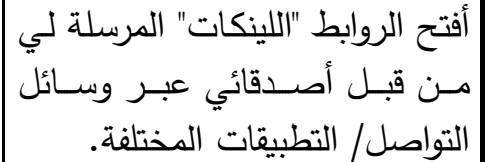 & ir \\
\hline 17 & $\varepsilon, 71$ & rro,TV & or,ro & vav & 19,11 & 99 & $r \cdot, r \Lambda$ & 1.1 & $\triangle ৭, \wedge \varepsilon$ & rqA & 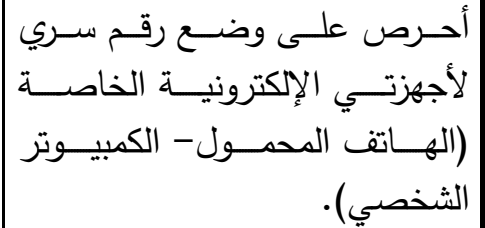 & ir \\
\hline 10 & $\varepsilon, 7 r$ & rาT,rr & or, \&A & v१9 & $\mid r, \varepsilon 0$ & IV & rr,or & 178 & or,. 1 & YT\& & 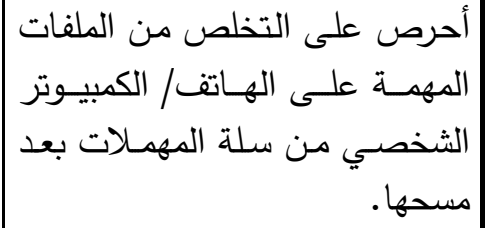 & $1 \varepsilon$ \\
\hline 11 & $0,9 Y$ & $r \varepsilon 1, \ldots$ & $\checkmark \Lambda, \varepsilon \vee$ & 1.rr & rr,vr & 171 & $r v, 90$ & 119 & $r A, r)$ & $|\varepsilon|$ & 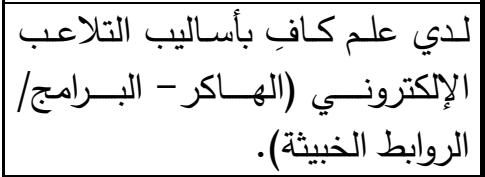 & 10 \\
\hline ir & $0, r \varepsilon$ & $r \cdot v, q v$ & $71, \mathrm{VA}$ & arr & Yr,\&q & $11 \mathrm{~V}$ & rA,ro & 191 & $r A, 10$ & 19. & 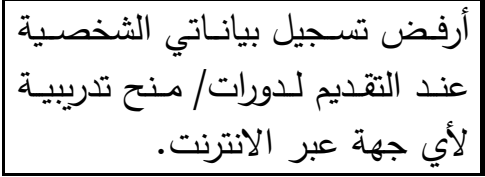 & 17 \\
\hline \multicolumn{2}{|c|}{ القوة النعبية } & \multicolumn{2}{|c|}{ مجموع الاونلن } & \multicolumn{2}{|c|}{ مجموع التكرارات } & \multicolumn{3}{|c|}{ العتوبط العسابي } & \multicolumn{2}{|c|}{$\begin{array}{l}\text { المتوسط } \\
\end{array}$} & \multirow[t]{2}{*}{ المؤر ككل } & \\
\hline VY & , Yo & oyor & & & & & $r \varepsilon, r \Lambda$ & & $1 . v 9$ & $\varepsilon \varepsilon$ & & \\
\hline
\end{tabular}


باستقراء بيانـات الجدول السـابق رقم (0) يتضـح أن (اتجاهـات الثـباب الجـامعي نحسو الهندسـة

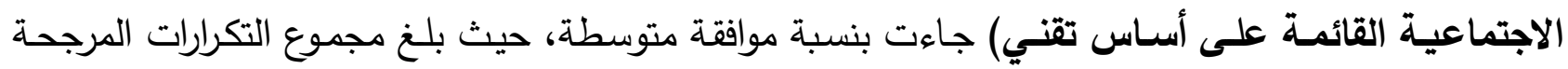

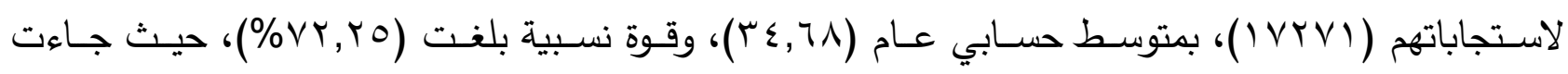

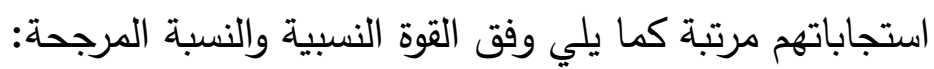

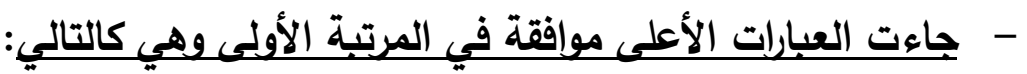

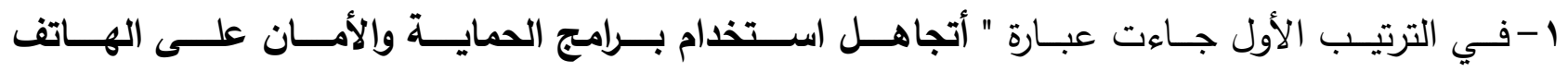

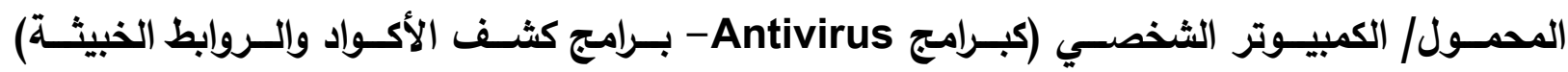

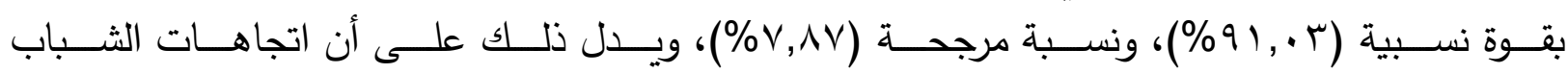

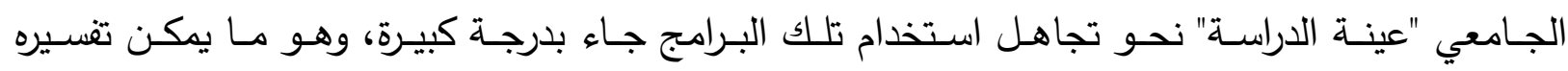

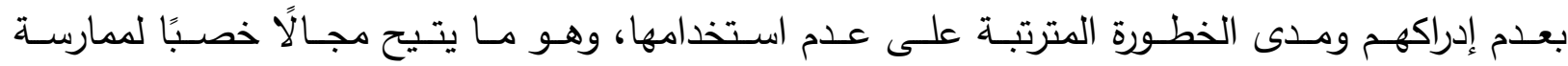
أساليب الاحتيال والاختراق وغيرها من أساليب الهنسة الاجتماعية التقنية عليهم.

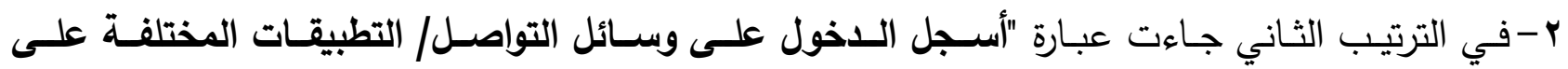

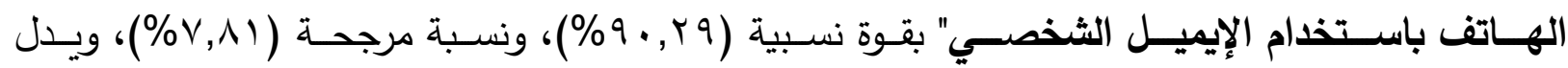

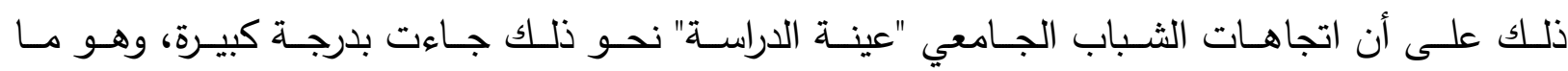

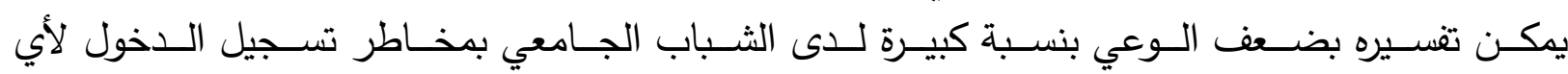

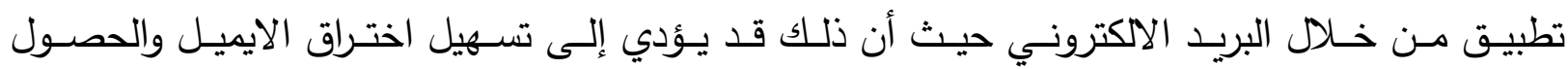
على بيانات ومعلومات عن الثخص قد تؤدي إلى وقوعه كضحية.

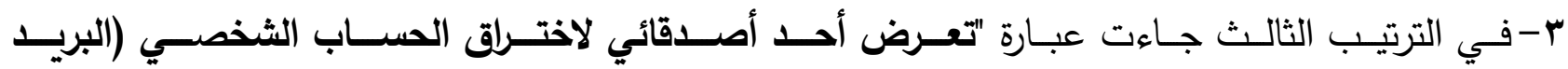

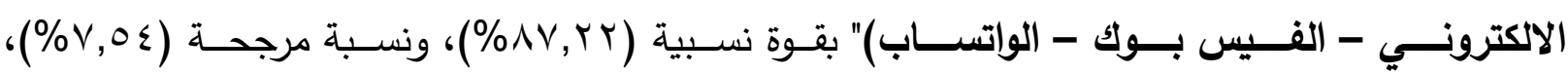

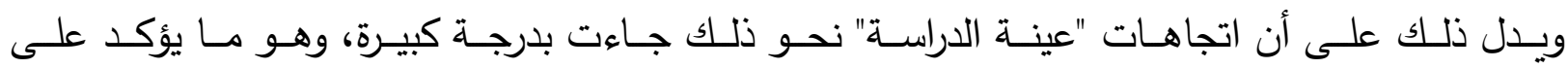

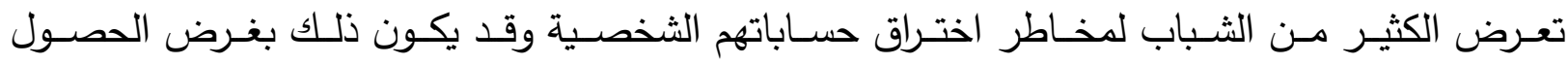

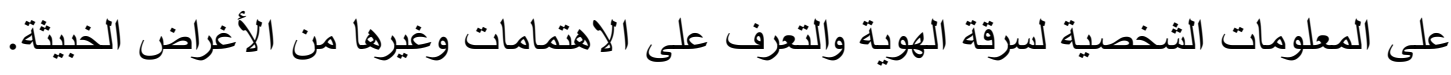

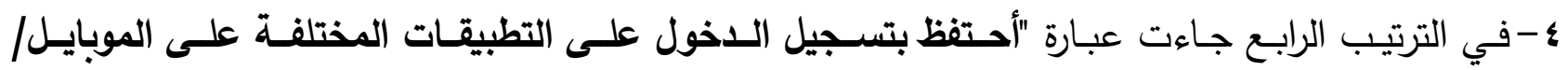

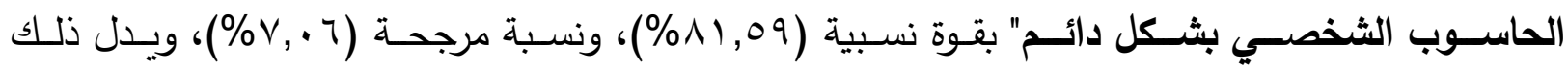

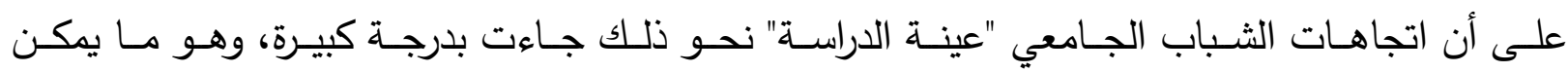

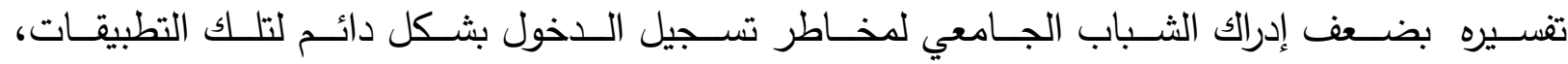

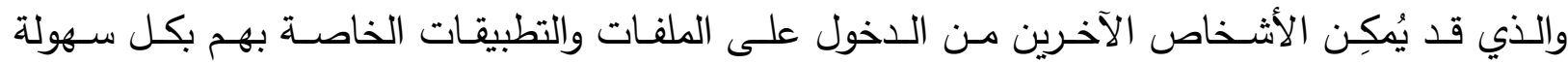
من أجل الحصول على ما يرغبون به من معلومات وغيرها لتحقيق الغاض الغراض معينة.

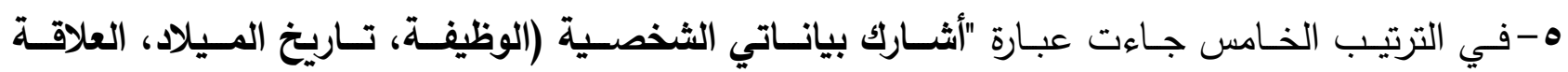

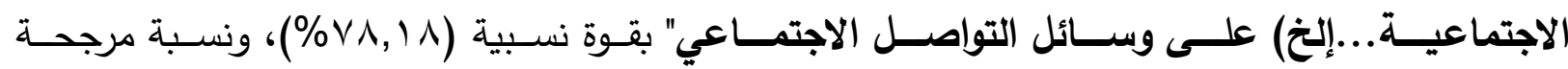

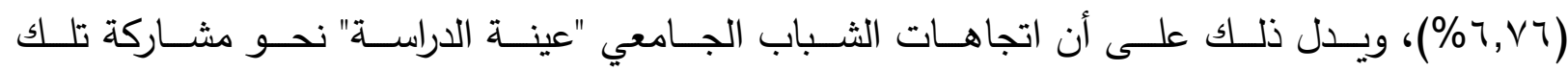
البيانـات جـاء بدرجـة كبيـرة، وهـو مــا يمكـن إرجاعـهـ إلـى عـدم الاسـتيعاب الكـافِ لمخـاطر مشـاركة 


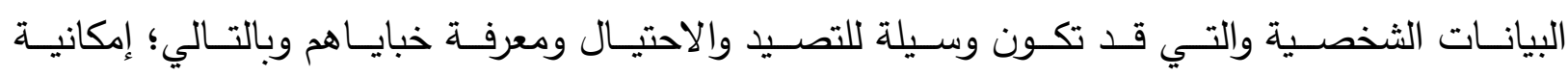
التدرج لإيقاعهم كضحايا واختراق حياتهر وطرق تفكيرهم.

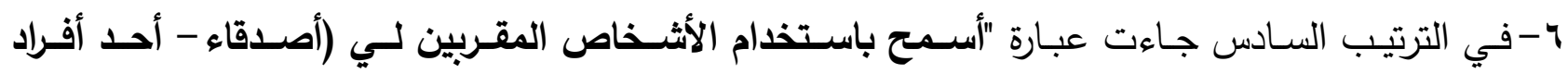

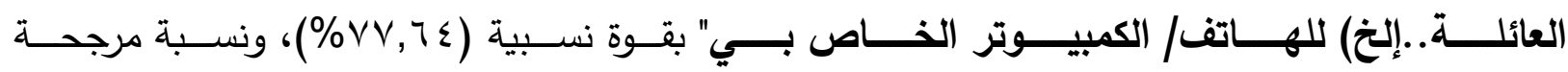

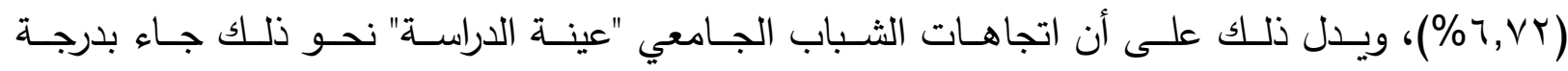

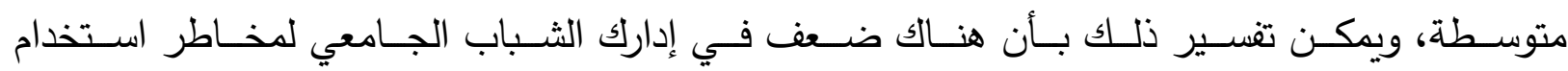

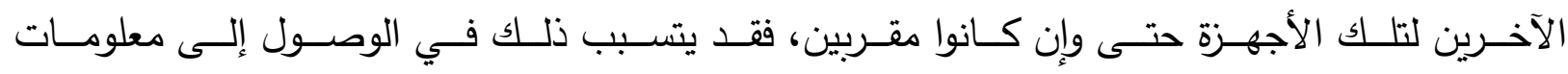

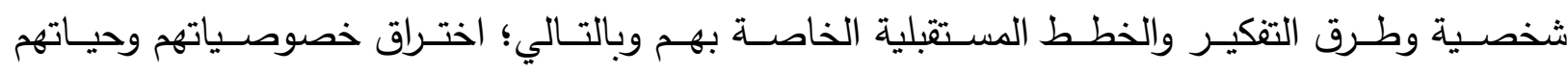
الشخصية واستغلالها.

\section{- - ينما جاءت العبارات الأقل موافقة في المرتبة الأخيرة وهي كالتالي:}

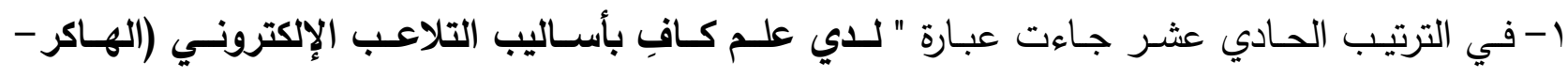

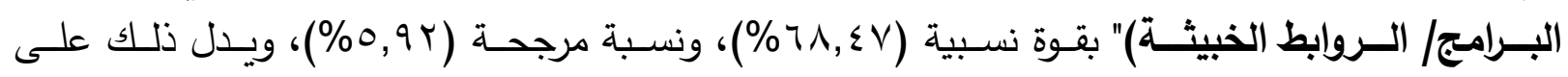

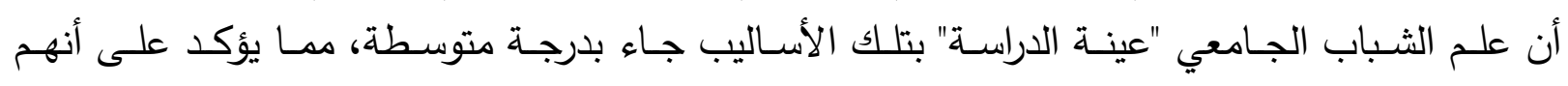

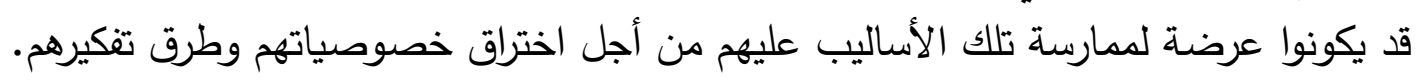

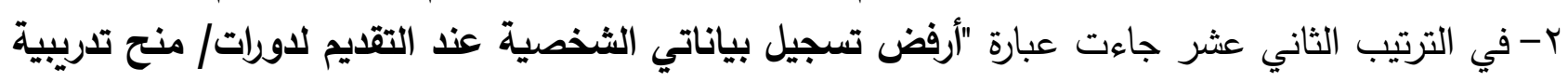

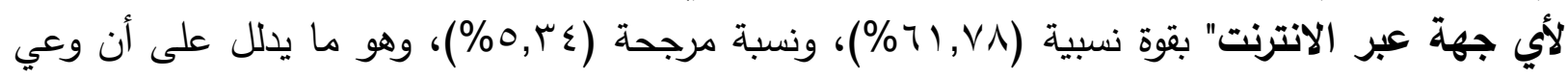

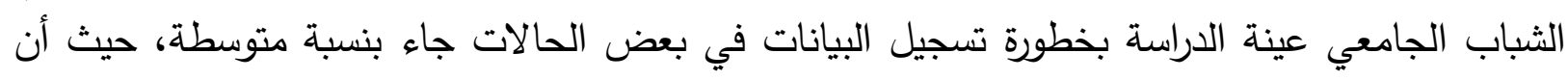
هناك العديد من الصفحات التي تتنحل صفة جهات رسمية تمنح دورات وغيرها، قد تكون وسيلة لاختراق حسابات من يقومون بالتسجيل فيها.

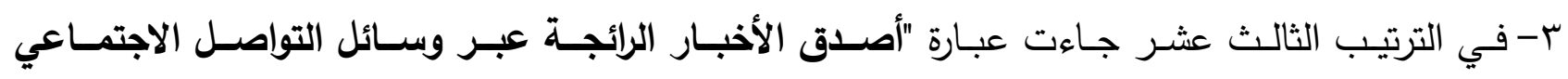

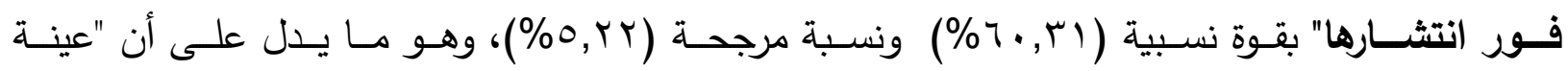

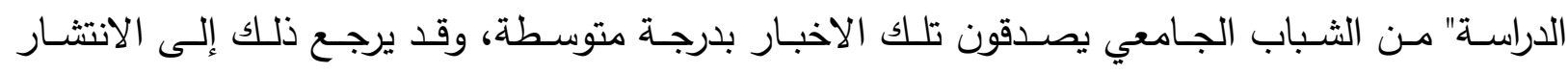

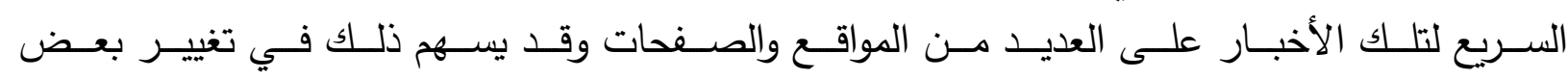
اتجاهاتهم وترسيخ بعض الأفكار لديهم وهو من أهم ما تستهدفه الهندسة الاجتماعية.

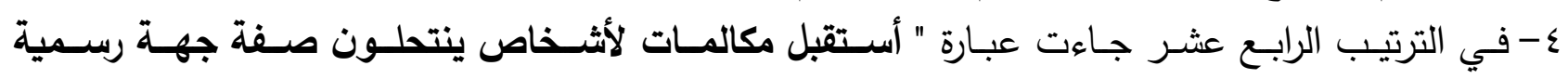

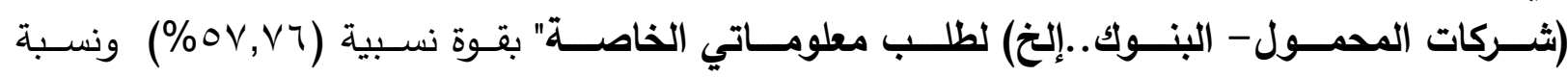

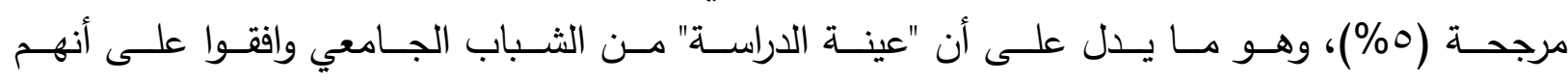

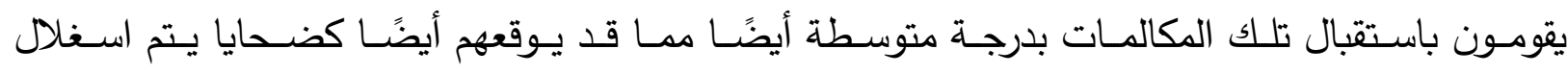
بياناتهم الثخصية لأغراض التصيد والاحتيال.

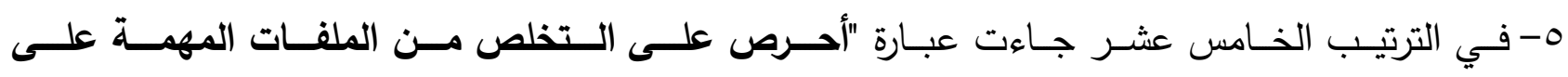

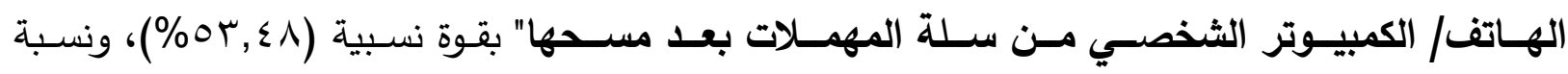

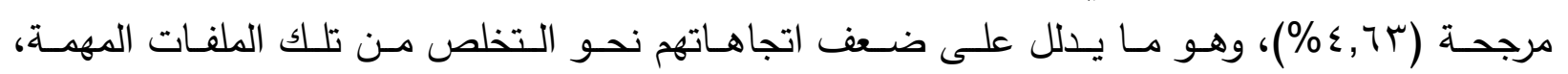




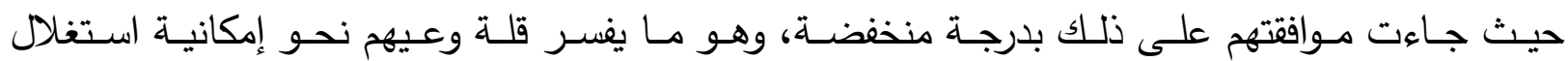

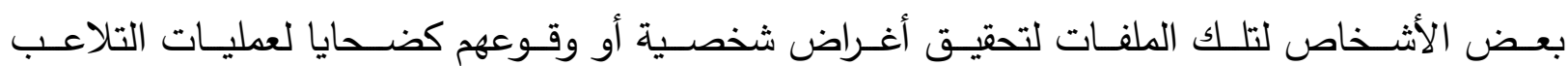
والاحتيال.

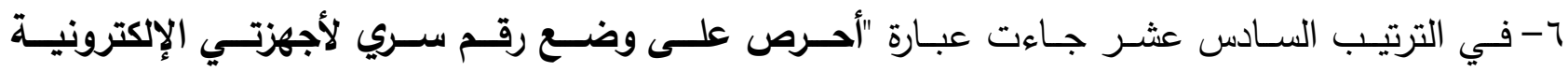

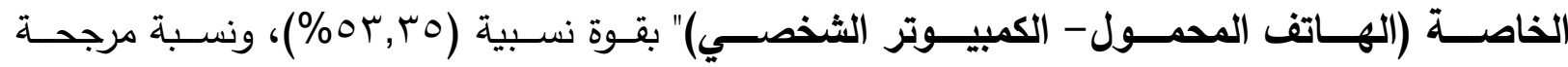

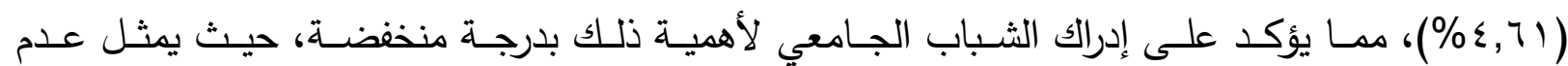

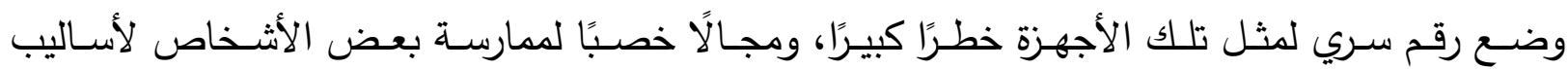
الاحتيال والاختراق وغيرها من أساليب الهندسة الاجتماعية التقنية. وترى الباحثة منطقية نتائج الدراسة واتساقها مع نتائج الدراسات السابقة، ويمكن تفسير ذلك بعداء توفر الخلفية الكافية لدى الثباب الجامعي حول الهندة الاجتماعية التقنية والأساليب المختلفة المستخدمة

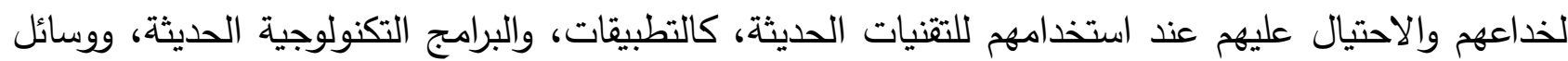
التواصل الاجتماعي سواء كان ذلك من خلال الهاتف الدحمول، أو باستخدام أجهزة الكبيوتر وغيرها.

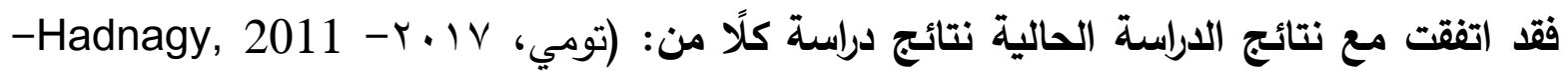
Holz, et. al, 2011 - Uebelacker \& Quiel, 2013

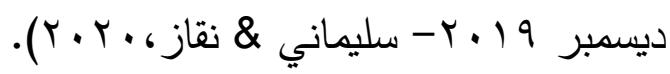

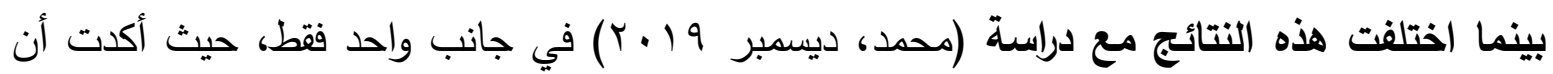
مجتمع الدراسة كانوا يقومون بحماية بياناتهم الثخصية على شبكات التواصل الاجتماعي بشكل تلقائي وبمعدل مرتفع.

وهو ما يؤكد ضرورة توجيه الثباب وتتمية وعيهم بأساليب الهنسة الاجتماعية التقنية التي قد تواجههم،

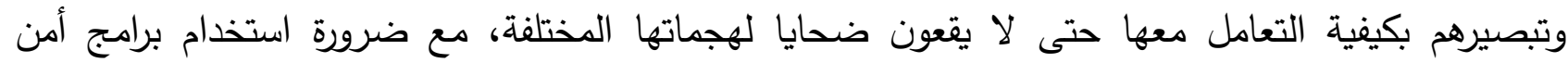
المعلومات والحماية من البرامج الخبيثة. 
- نتائج التساؤل الفرعي الثاني: ما اتجاهات الثباب الجامعي نحو الهندسة الاجتماعية "القائمة على أساس

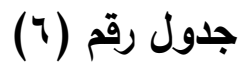

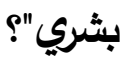

اتجاهات الثباب الجامعي نحو الهندة الاجتماعية "القائمة على أساس بشري" (ن = 9^ ؛) )

\begin{tabular}{|c|c|c|c|c|c|c|c|c|c|c|c|c|}
\hline \multirow{2}{*}{ 雪! } & \multirow{2}{*}{$\frac{7}{3}$} & \multirow{2}{*}{$\begin{array}{l}5 \\
5 \\
5 \\
2\end{array}$} & \multirow{2}{*}{ 零 } & \multirow{2}{*}{$\begin{array}{l}\text { 氧 } \\
\overline{3}\end{array}$} & \multicolumn{2}{|c|}{ y } & \multicolumn{2}{|c|}{ إلى حد ما } & \multicolumn{2}{|c|}{ نعم } & \multirow[b]{2}{*}{ العبـــــــــــارة } & \multirow[b]{2}{*}{$p$} \\
\hline & & & & & $\%$ & ك & $\%$ & ك & $\%$ & ك & & \\
\hline$r$ & $r_{1},$. & $\varepsilon 10, .$. & Ar,rr & $1 Y \leqslant 0$ & $T, Y Y$ & r & $r v, 00$ & IAV & ri, & YA. & 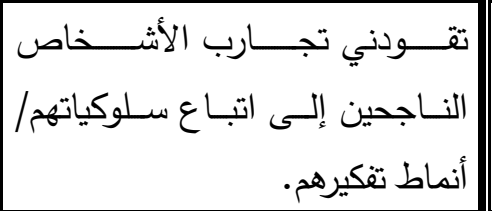 & iv \\
\hline $1 \varepsilon$ & 0,01 & rrI,... & $7 \pi, \varepsilon V$ & 994 & rr,or & ITr & rr,or & ITV & $r r, q r$ & $17 \varepsilon$ & 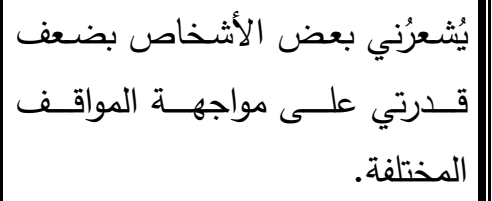 & 11 \\
\hline 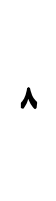 & T,YY & rYI, IV & $v \varepsilon, \pi r$ & 1110 & 10,77 & VA & $\varepsilon \varepsilon, Y \wedge$ & rrr & ra,or & 198 & 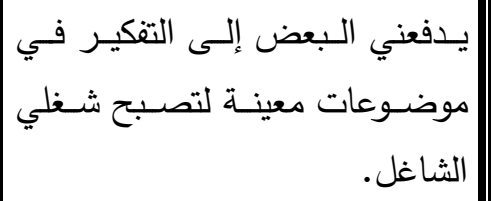 & 19 \\
\hline 11 & 7,11 & rir, rr & vr,or & 1.99 & $r 1, \cdot \Lambda$ & 1.0 & $r v, 10$ & 110 & $\varepsilon 1, V \gamma$ & $r \cdot A$ & 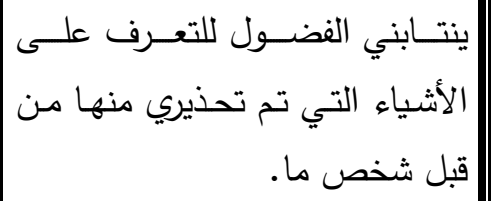 & r. \\
\hline 1. & 7,19 & $r q v_{1} .$. & vr, Tq & 11.1 & $r \cdot,{ }^{\prime}$ & 1.1 & ru,ro & 191 & $\varepsilon 1, \Gamma v$ & r. & أكتشف في كثير من الأحيان أني & Y \\
\hline 9 & $7, Y 1$ & $r{ }^{\prime} \Lambda, i v$ & $v \varepsilon, \cdot r$ & 11.4 & $r \cdot, \wedge$ & 1.8 & $r(, 1 \varepsilon$ & iA. & $\varepsilon r, q \gamma$ & $r \mid \varepsilon$ & 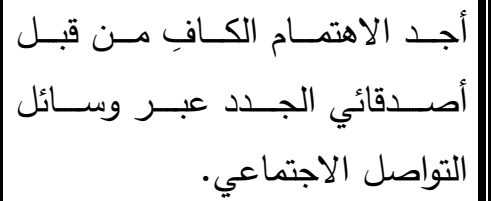 & rr \\
\hline$r$ & V,IT & \&rr,.. & $\Lambda \varepsilon, q \varepsilon$ & Irrag & r,Ar & rq & ra,or & $1 \& V$ & & rir & التُجبرني الأشخاص الذين الاحترام على الثقة بهم. & rr \\
\hline 1 & $7, \pi$ & rar,iv & $V \wedge, \wedge 0$ & llYA & $9,7 \varepsilon$ & \&A & $\{\varepsilon, 1 \wedge$ & $r r$. & $\varepsilon 7,11$ & rr. & 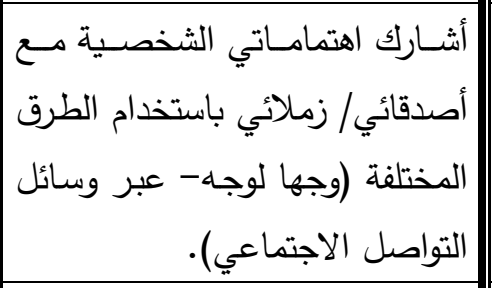 & 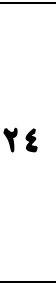 \\
\hline$\varepsilon$ & 8,79 & rav,... & Yq,YY & 1191 & $v, \tau$ & rA & $\{0,01$ & rrr & $\varepsilon 7, Y q$ & rrr & 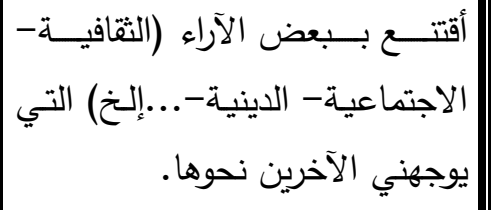 & ro \\
\hline
\end{tabular}




\begin{tabular}{|c|c|c|c|c|c|c|c|c|c|c|c|c|}
\hline \multirow{2}{*}{ 氞。 } & \multirow{2}{*}{$\frac{7}{3}$} & \multirow{2}{*}{ :3 } & \multirow{2}{*}{ 氞 } & \multirow{2}{*}{$\begin{array}{l}\text { 氙 } \\
\overline{3} \\
\overline{2}\end{array}$} & \multicolumn{2}{|c|}{$y$} & \multicolumn{2}{|c|}{ إلى حد ما } & \multicolumn{2}{|c|}{ نعم } & \multirow{2}{*}{ العبــــــــــارة } & \multirow[b]{2}{*}{$p$} \\
\hline & & & & & $\%$ & ك & $\%$ & ك & $\%$ & ك & & \\
\hline 10 & $0,1 Y$ & $r \cdot 7,7 v$ & 71,01 & 9 . & $\varepsilon r, \mid Y$ & rio & YA,9Y & $1 \varepsilon \varepsilon$ & $Y Y, q)$ & ira & 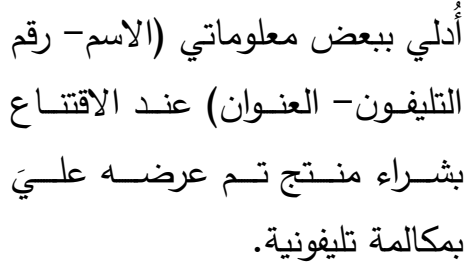 & rq \\
\hline 1 & $V, \varepsilon V$ & $\varepsilon \varepsilon r, r r$ & $\Lambda 9, \cdot Y$ & irr. & r,AY & 19 & ro,r. & IYY & $V \cdot, \wedge \Lambda$ & ror & أهـتم بـالحوار مـع الأشـخاص ذأسوو الجذاب في التعامل. & rr \\
\hline • & $7,7 Y$ & rar,.. & VA,qr & 1189 & ir,ro & 77 & rq,vo & lar & $0 ., \ldots$ & $r \leqslant 9$ & 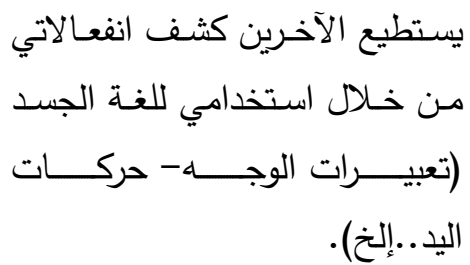 & rA \\
\hline$\checkmark$ & $7, r Y$ & rvo,.. & vo,r. & $11 r 0$ & $|A, A|$ & $9 \varepsilon$ & rq, ro & $|A|$ & $\varepsilon \varepsilon, \vee \wedge$ & rrr & أهتم بالحصـول على الأشياء نـادرة & rq \\
\hline ir & 7,19 & rro,rr & Vrr,rq & 1.94 & $\varepsilon r, O r$ & riv & rr,qr & 178 & $r r, \varepsilon q$ & 118 & 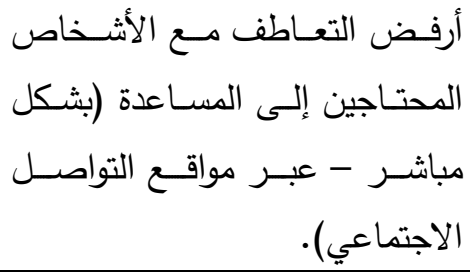 & $r$. \\
\hline 17 & $\varepsilon, \varepsilon\}$ & YY\&,TV & or,10 & va६ & IY,YO & 71 & $r \varepsilon, q \varepsilon$ & IVE & Or,Al & צו & 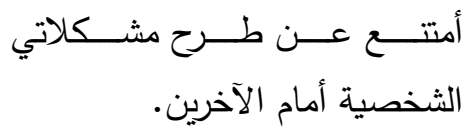 & 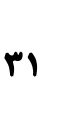 \\
\hline ir & $0,9 r$ & ror,... & $v_{0,7 u}$ & 1.04 & ro,0₹ & IVV & $\varepsilon \cdot, 94$ & $r \cdot \varepsilon$ & $r r, \varepsilon q$ & IIr & 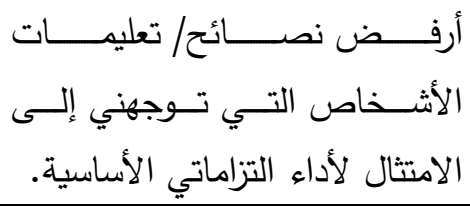 & rr \\
\hline \multicolumn{2}{|c|}{ القوة النعبية } & \multicolumn{2}{|c|}{ مجموع الاونلن } & \multicolumn{2}{|c|}{ مجموع التكرارات } & \multicolumn{3}{|c|}{ المتوسط الحسابي } & \multicolumn{2}{|c|}{ المتوجط } & \multirow[t]{2}{*}{ المؤشر ككل } & \\
\hline \multicolumn{2}{|c|}{$\vee \varepsilon, \varepsilon 0$} & \multicolumn{2}{|c|}{ هarr,rr } & \multicolumn{2}{|c|}{ irvar } & \multicolumn{3}{|c|}{ 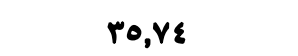 } & \multicolumn{2}{|c|}{$\||r, r|$} & & \\
\hline
\end{tabular}

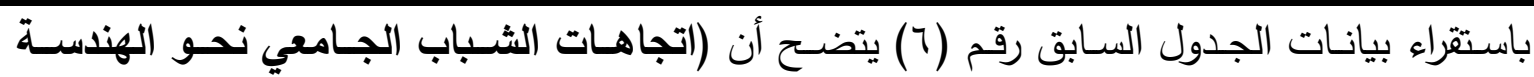

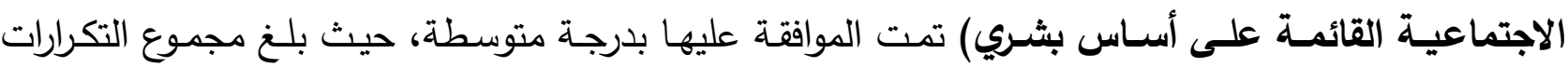

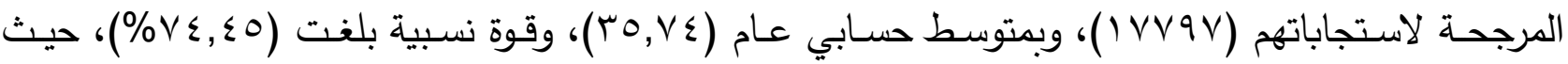
جاءت استجاباتهم مرتبة كما يلي وفق القوة النسبية والنسبة المرجحة: 
- جاءت العبارات الأعلى موافقة في المرتبة الأولى وهي كالتالي:

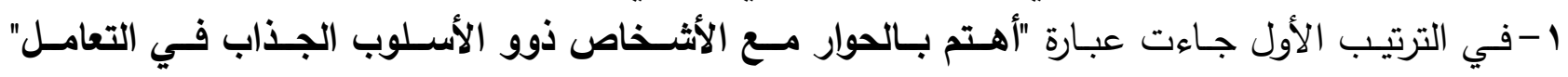

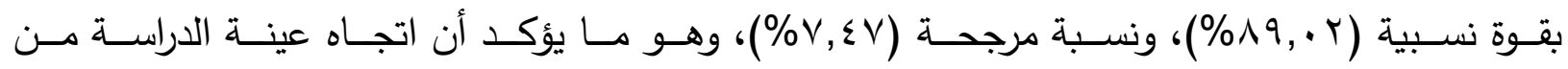

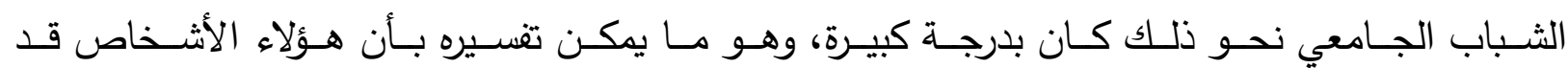

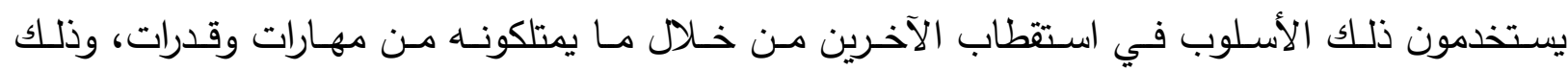

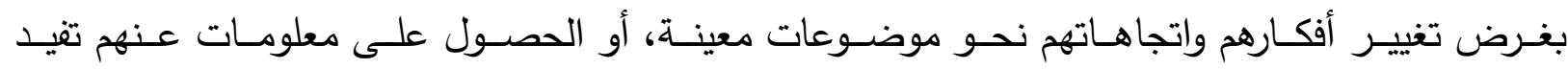

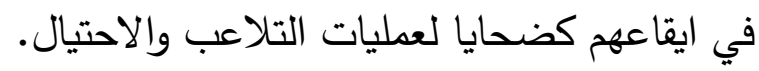

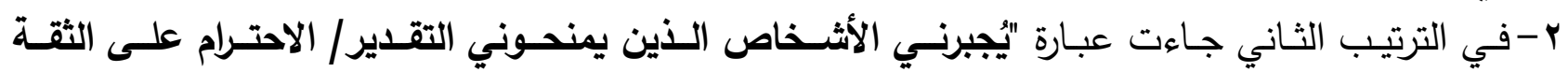

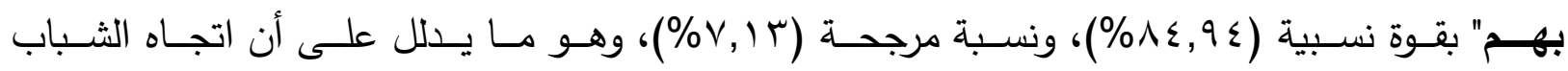

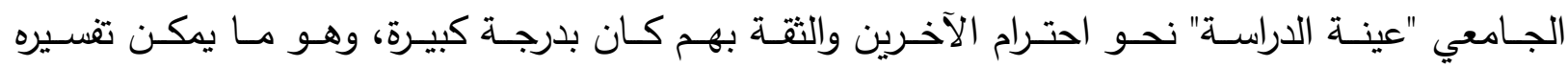

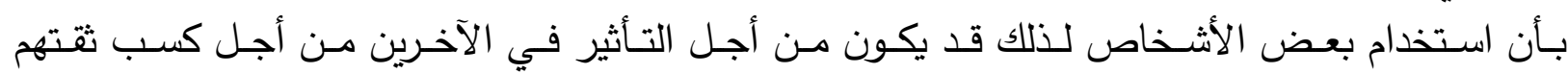

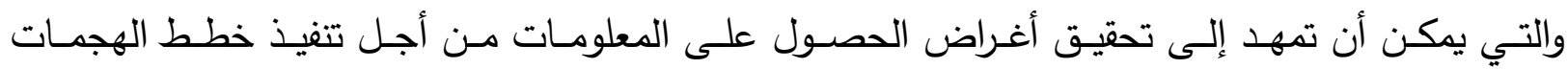
المختلفة للاحتيال والتلاعب بهن بهر.

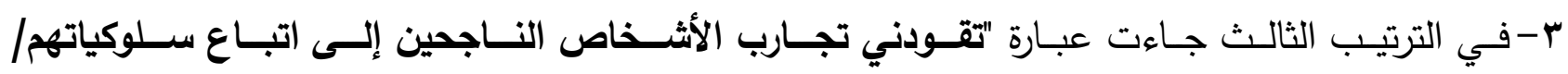

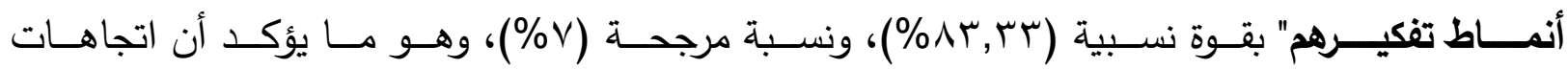

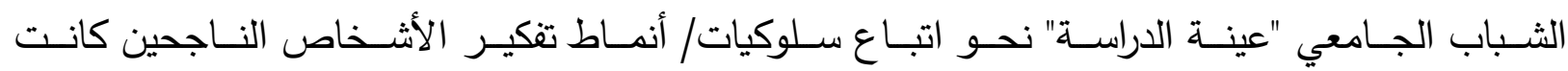

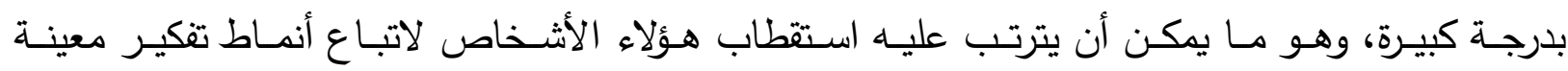

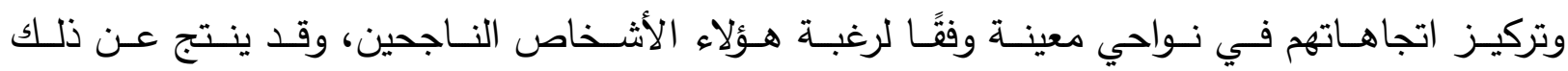
العديد من المخاطر على هؤلاء الثباب.

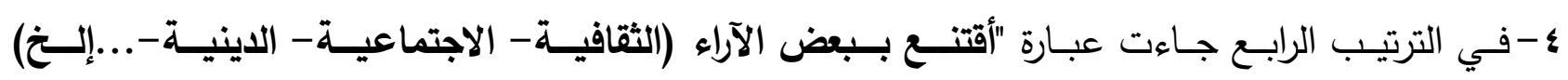

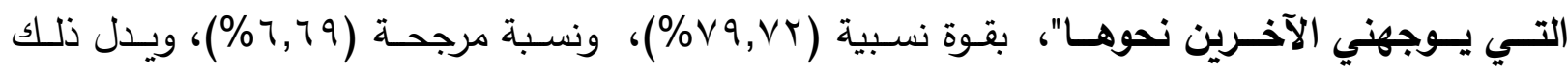

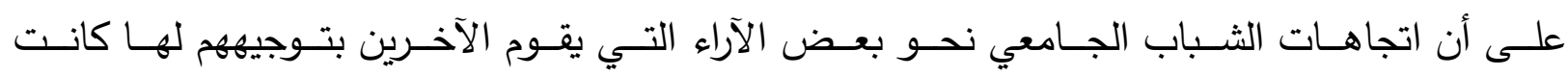

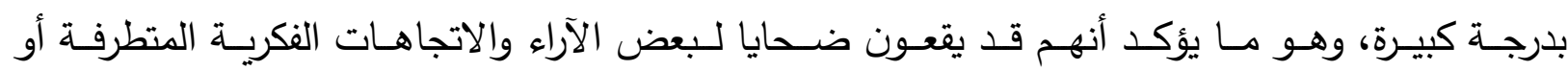

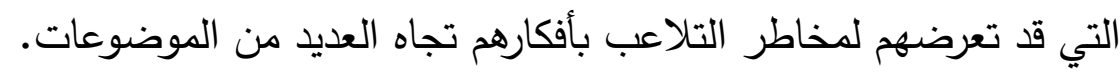

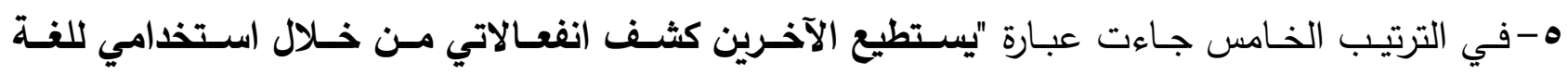

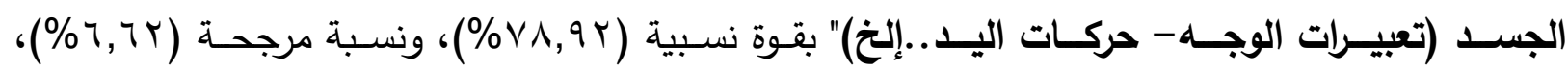

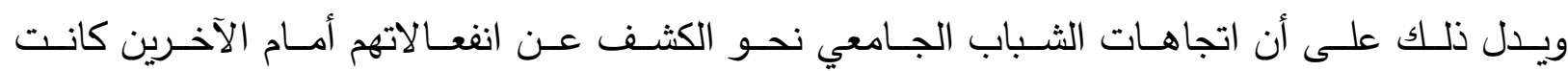

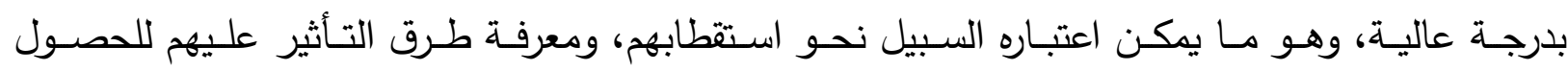
على المعلومات المختلفة عنهم، وبالتالي وقوعهم كضحايا.

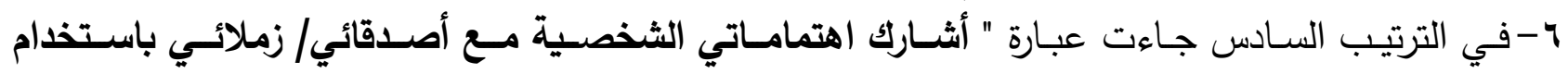

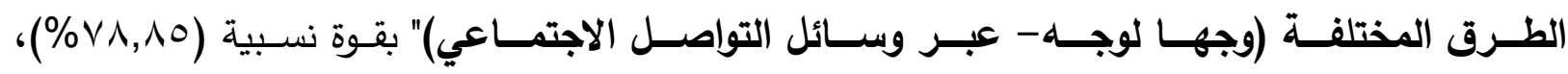

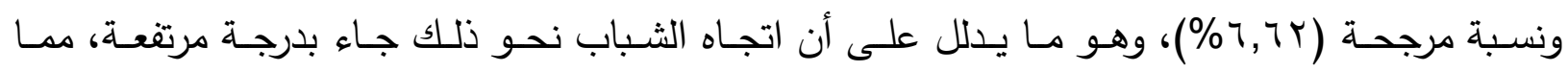




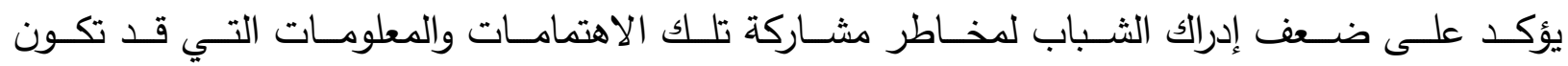
وسيلة للتصيد من أجل ايقاعهم كضحايا والتلاعب بهم من قبل البعض لتحقيق أغراض معينة.

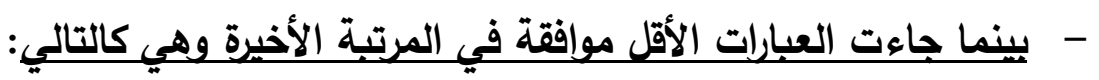
ا- في الترتيب الحـادي عشر جـاءت عبـارة "ينتـابني الفضــول للتعـرف علـى الأثـياء التـي تـم تحــيري

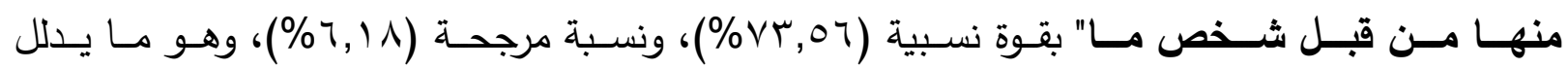
الشـباب الجـامعي "عينـة الدراسـة" على ذلك بنسـبة متوسـة، وهـو مـا يؤكد أن معظمهم يكـون لـديهم هـذا الفضـول، والـذي قـد يـوقعهم كضـــايا أو يتسـبب في إيـذائهم مـن قبـل هـؤلاء الـذين تـم تحـذيرهم منهم، أي يمكن تقسير ذلك باعتباره وسيلة لاستفزازهم من أجل تحقيق أغراض ما قد تضر بهم.

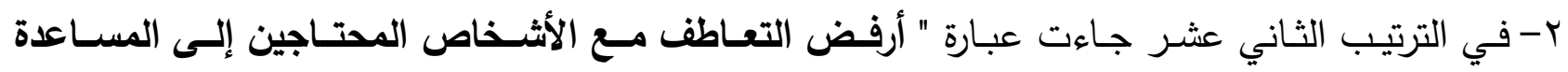

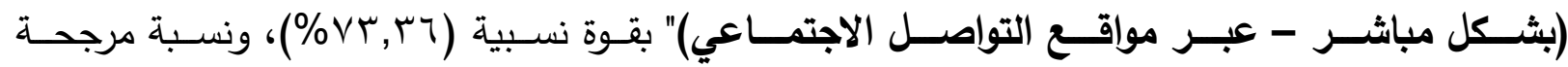

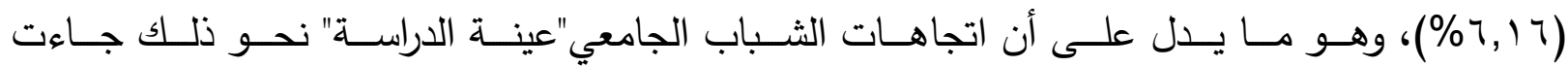

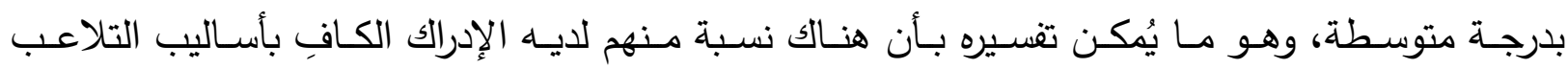
والاستعطاف التي يمارسها البعض للحصول على المال وغيرها من أساليب الاحتيال.

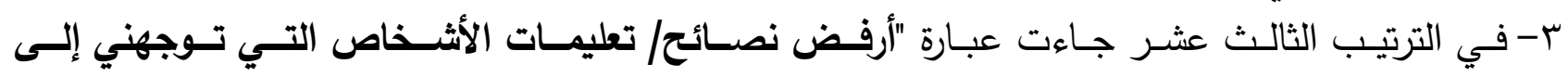

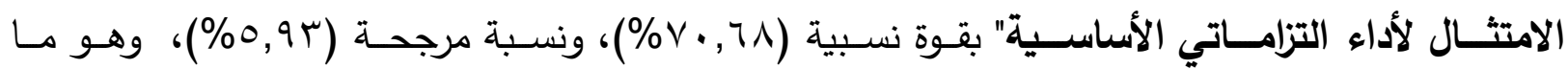

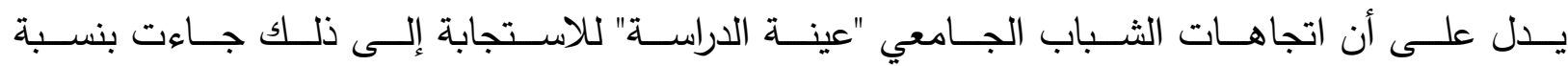
متوسـطة، وهـو مـا يمكن تفسـيره باسـتيعاب عـد كبيـر مـنهم لمخـاطر الإنسـياق وراء أشـخاص آخـرين

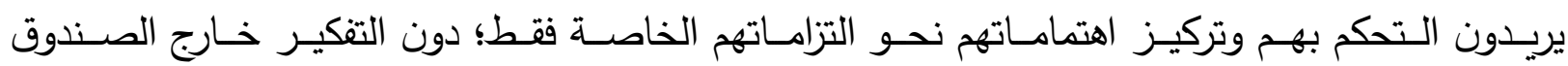
أو ما هو معتاد من أجل تطوير أنفهه والإنفتاح الفكري الإيجابي.

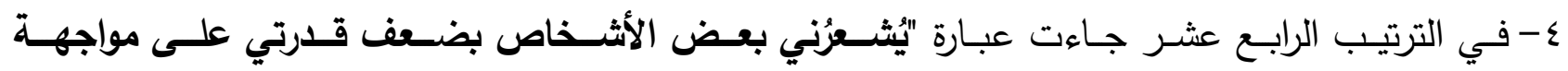

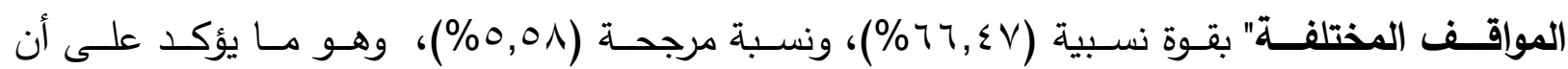

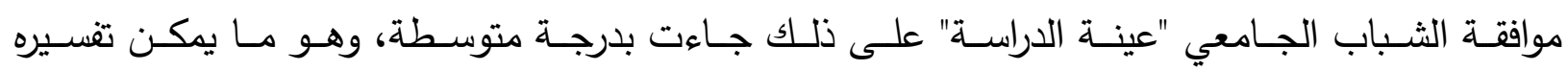
باعتبـار ذلك وسـيلة للتأثير على عدد كبير مـنهم مـن قبـل أثـخاص آخـرين يكـون غرضـهم الأساسـي

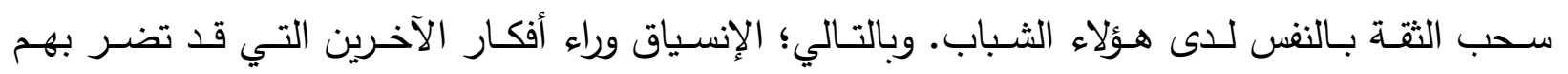
وتجعلهم ضحايا لهؤلاء الأشخاص الذين يرغبون في تسييرهم والتحكم بهم في كثير من الأحيان. ه- في الترتيـب الخـامس عشر جـاءت عبـارة "أدلــي بـبعض معلومـاتي (الاستـم - رقـم التليفـون - العنـوان)

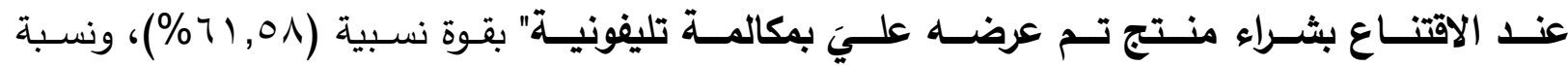

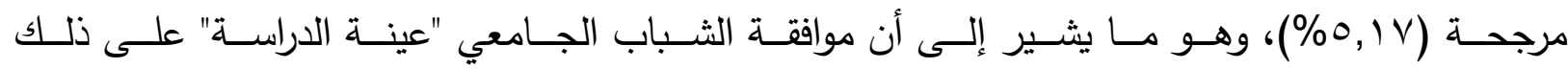

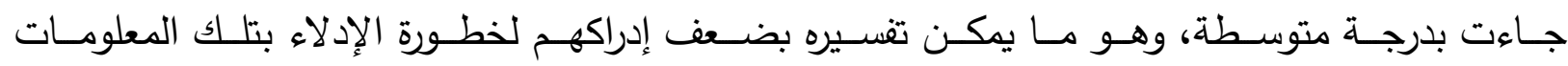
لأي جهــة غيـر موثوقـة مـن خـلال المكالمـات التليفونيـة، والتهي قد تكـون وسـيلة للتصـيد والاسـتغلال من أجل تحقيق أغراض خبيثة لتلك الجهات. 


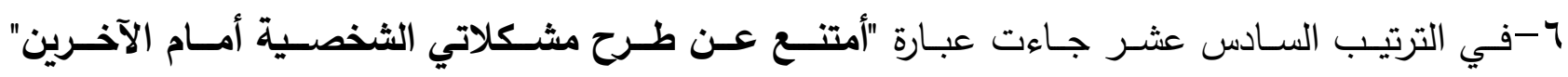

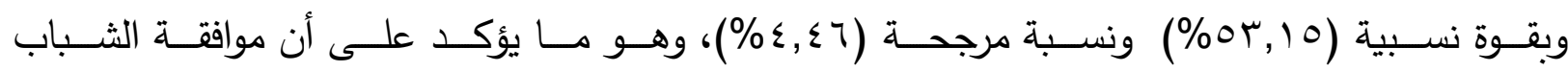

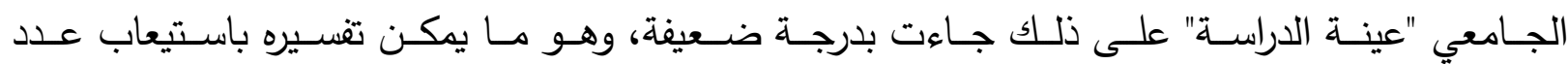

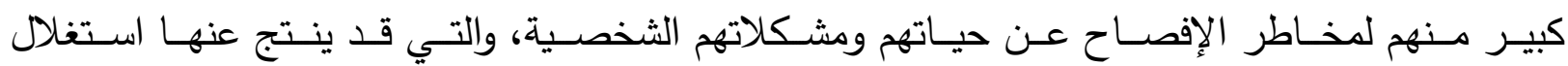
البعض لنقاط الضعف لديهم وممارسة أساليب التلاعب وغيرها من الأغراض الخبيثة.

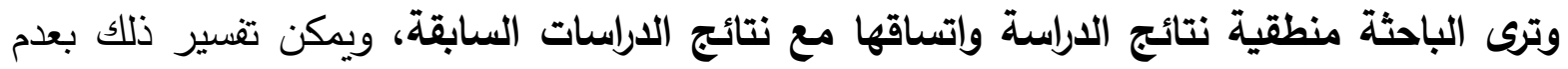
إدراك الثباب الجامعي بثكل كافِ لمخاطر الهندسة الاجتماعية البشرية، والأساليب المختلفة المستخدمة

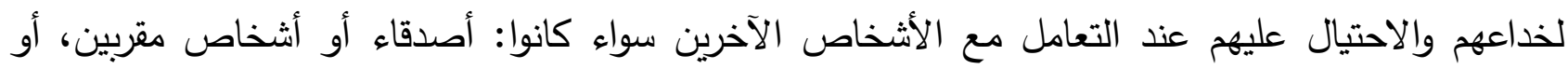
أشخاص ليس لايهح معرفة سابقة بهم.

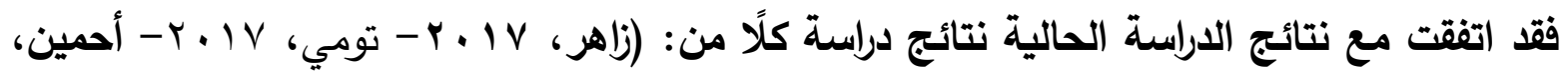
Holz, et. - Uebelacker \& Quiel, 2013 -Hadnagy, 2011 -Bengt, et. al,2012 - r. IV al, 2011

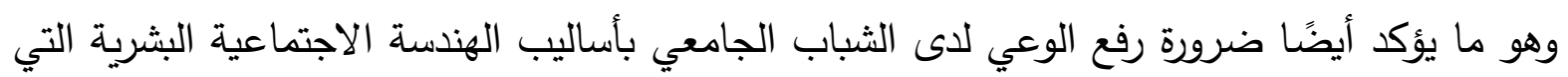

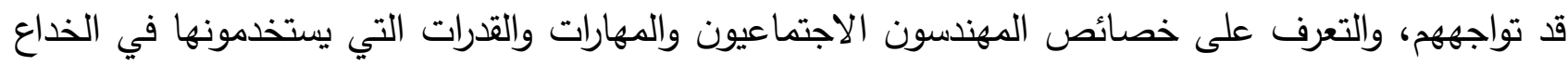
والاحتيال، وتبصيرهم بكيفية التعامل معهم، حتى لا يقعون ضحايا لهجماتها المختلفة. 
(ب) نتائج مقياس مستوى الهوبة الثقافية لدى الثباب البامعي:

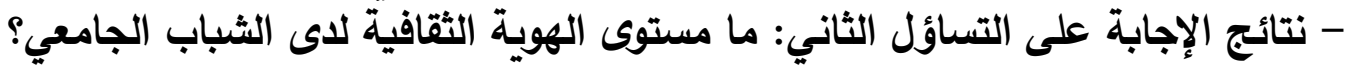

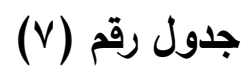

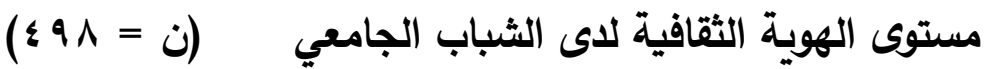

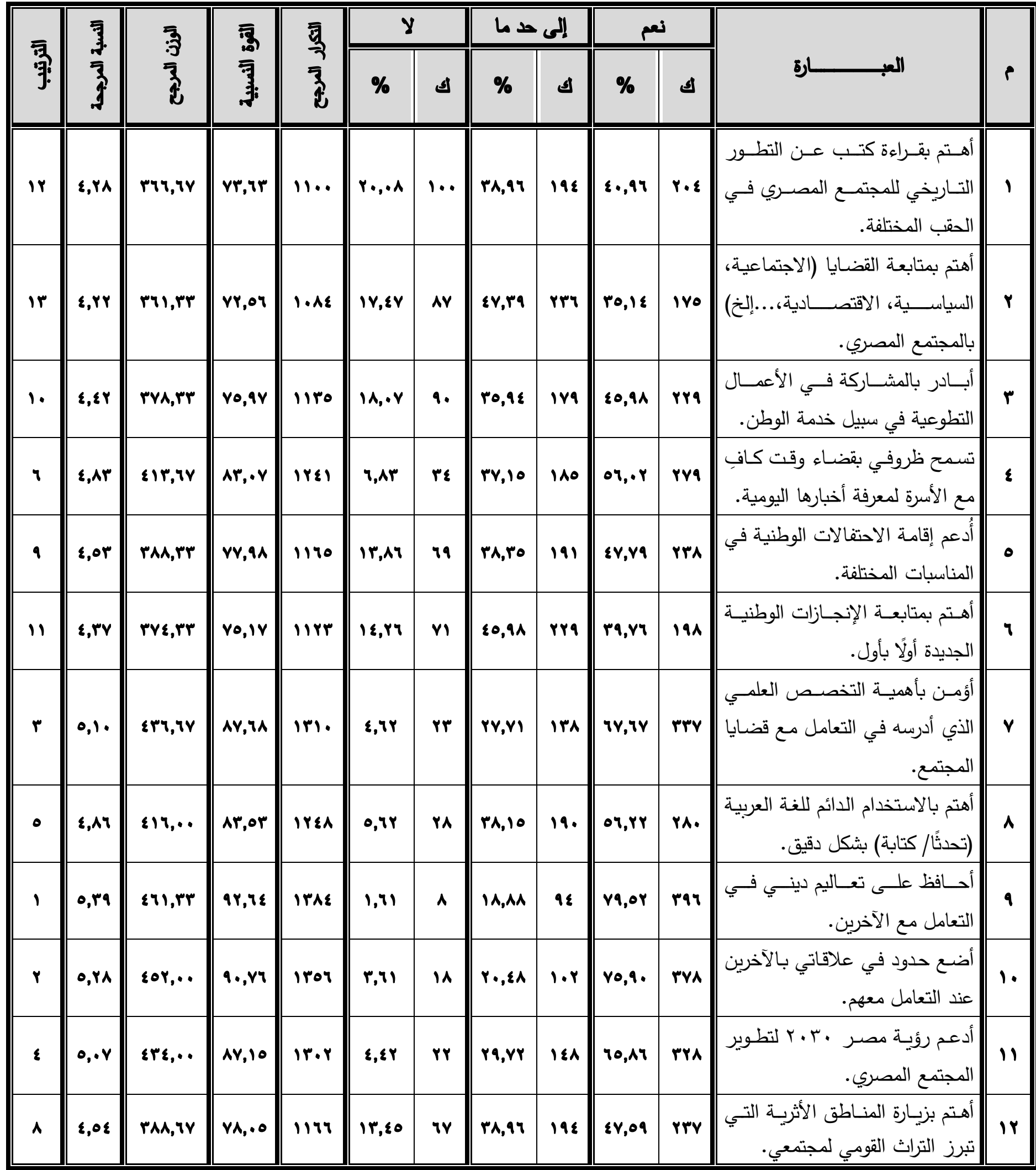




\begin{tabular}{|c|c|c|c|c|c|c|c|c|c|c|c|c|}
\hline \multirow{2}{*}{ 司。 } & \multirow{2}{*}{$\frac{3}{3}$} & \multirow{2}{*}{ :3 } & \multirow{2}{*}{ 雪 } & \multirow{2}{*}{$\begin{array}{l}\text { 氞 } \\
\text { दे }\end{array}$} & \multicolumn{2}{|c|}{$y$} & \multicolumn{2}{|c|}{ إلى حد ما } & \multicolumn{2}{|c|}{ نعم } & \multirow[b]{2}{*}{ العبــــــــــارة } & \multirow[b]{2}{*}{ p } \\
\hline & & & & & $\%$ & ك & $\%$ & ك & $\%$ & ك & & \\
\hline$\checkmark$ & $\varepsilon, v r$ & $\varepsilon \cdot 0, r r$ & Al,rq & IYIT & $1 \cdot, \cdot \varepsilon$ & ०. & 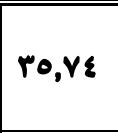 & IVA & $0 \varepsilon, Y Y$ & rv. & 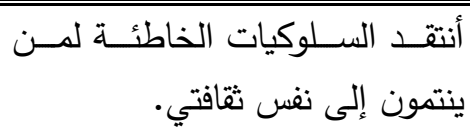 & ir \\
\hline r. & r,rA & YA9,TV & OA,IV & A79 & rr,tq & IIr & Y9,IY & 180 & $\{A, 19$ & $r \varepsilon$. & 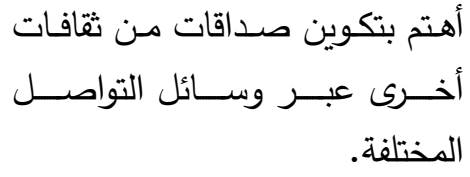 & $1 \varepsilon$ \\
\hline 17 & $r, \wedge \varepsilon$ & rrq,rr & rr, & 911 & $r Y, Y)$ & IrA & $\varepsilon Y, 9 Y$ & YIE & rq,rY & $1 \varepsilon 7$ & 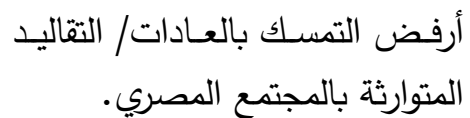 & 10 \\
\hline rr & $r, .7$ & rTY,rr & OY,TA & VAV & $1 \%, .0$ & 7. & rr,qq & 179 & $0 \varepsilon, \cdot Y$ & rาq & خلال اليوم. على الانترنت لفترات طويلـة & 17 \\
\hline Yr & $r, 11$ & PYY,TY & $\bullet \varepsilon, v_{0}$ & १וA & $9, \varepsilon \varepsilon$ & $\varepsilon V$ & $\varepsilon 0, r \wedge$ & rYY & $\varepsilon 0,11$ & rYo & 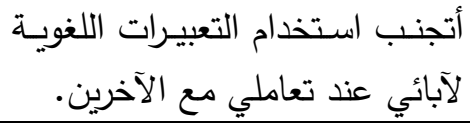 & iv \\
\hline 11 & $r, v \varepsilon$ & $r r \cdot, r r$ & T\&,YY & 971 & $r \Lambda, 0)$ & $1 \varepsilon Y$ & ro, qq & IV9 & ro,0\& & IVY & 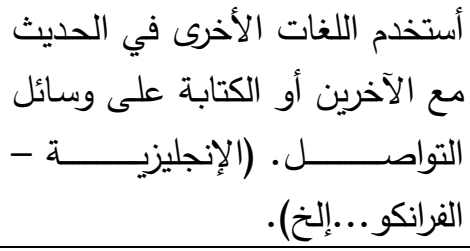 & in \\
\hline Y乏 & r, 70 & PrY,rY & 80,70 & TAY & r,AY & 19 & rq,rr & $1 \& 7$ & IY,AY & rrr & 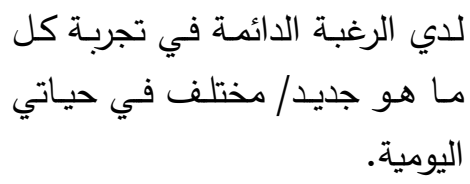 & 19 \\
\hline Y & r,rr & YA $\varepsilon, . \cdot$ & Or,or & AOY & 10,14 & vq & rq,rq & 197 & $\varepsilon \varepsilon, \vee \wedge$ & rrr & أهتم بمتابعة (الأفلام/ المسلسلات/ التليفزيونية) غير العربية. & r. \\
\hline 19 & $r, \varepsilon \varepsilon$ & rq\&,rr & 09,1 . & AAr & rr, Tq & IIr & ri,9r & 109 & $\varepsilon 0, r \wedge$ & YYY & 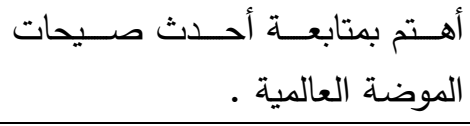 & Y \\
\hline iv & r,AY & rYY,TV & $70, \Lambda$. & १Ar & ri,vr & 101 & rr,qq & 179 & $r \varepsilon, r \varepsilon$ & $|v|$ & 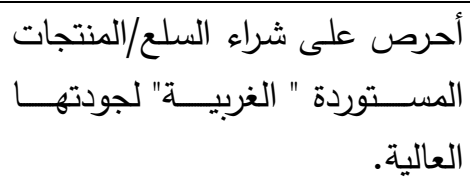 & $r r$ \\
\hline $1 \varepsilon$ & $\varepsilon, 1 Y$ & ror,ir & $r \cdot, A r$ & 1.01 & $\varepsilon \varepsilon, \Gamma \wedge$ & YYI & rr,tq & 111 & ri,qr & 109 & 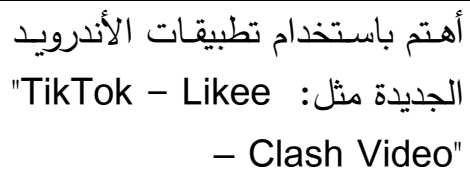 & $r r$ \\
\hline 10 & $r, \wedge 0$ & rr.,.. & $7 \%, Y Y$ & १9. & $r \varepsilon, q \varepsilon$ & IVE & YA,9Y & $1 \varepsilon \varepsilon$ & m, $1 \varepsilon$ & 1A. & 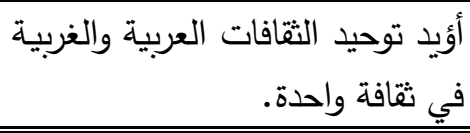 & YE \\
\hline \multicolumn{2}{|c|}{ القوة النسبية } & \multicolumn{2}{|c|}{ مجموع الاونلن } & \multicolumn{2}{|c|}{ مجموع التكرارات } & \multicolumn{3}{|c|}{ المتوسط المعابي } & \multicolumn{2}{|c|}{$\begin{array}{l}\text { المتوسط } \\
\end{array}$} & \multirow[t]{2}{*}{ الموشر ككل } & \\
\hline \multicolumn{2}{|c|}{$v 1,7 \Lambda$} & \multicolumn{2}{|c|}{ 10Tr,... } & \multicolumn{2}{|c|}{ rov.1 } & \multicolumn{3}{|c|}{01,71} & \multicolumn{2}{|c|}{$1 \cdot v \cdot, \wedge \Lambda$} & & \\
\hline
\end{tabular}


باستقراء بيانات الجدول السابق رقم (0) اتضح أن (مستوى الهويـة الثقافية لاى الثباب الجامعي)

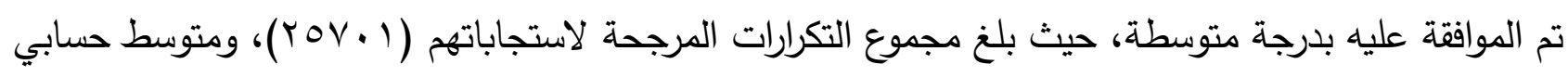

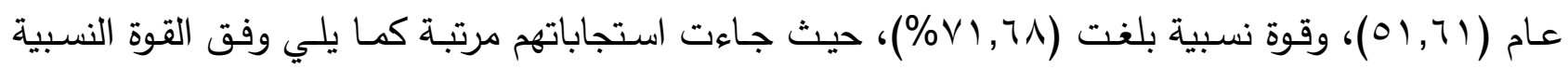

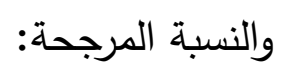
- - جاءت العبارات الأعلى موافقة في المرتبة الأولى وهي كالتالي:

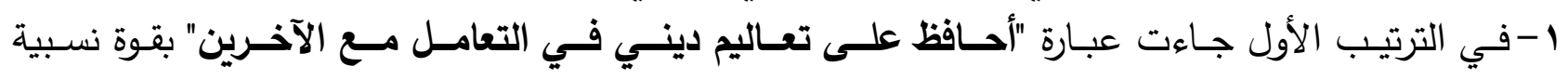

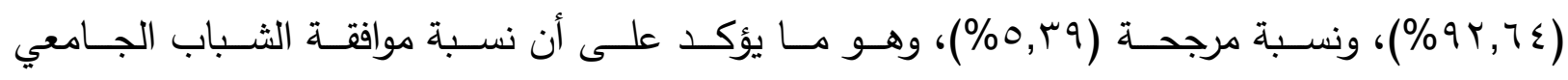

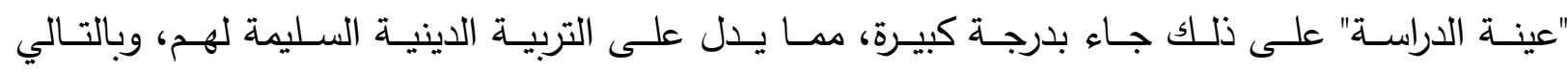

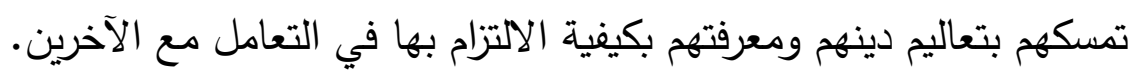

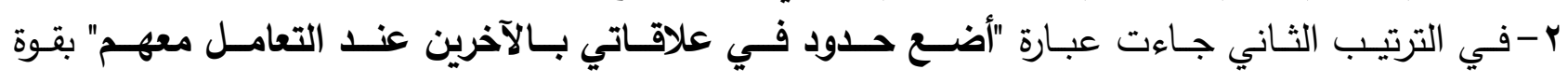

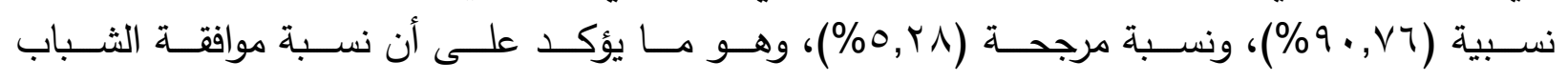

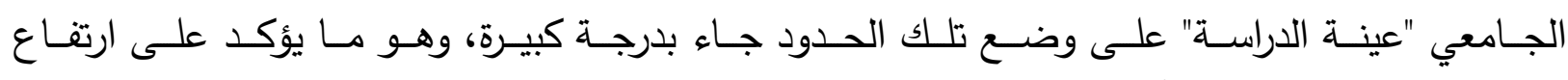

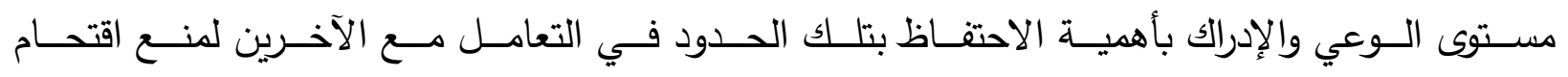
الآخرين لخصوصياتهم.

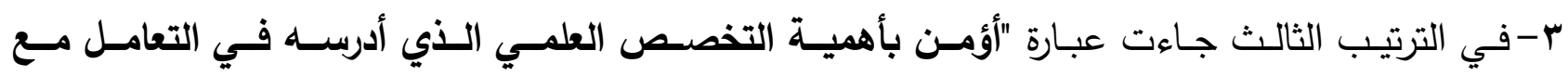

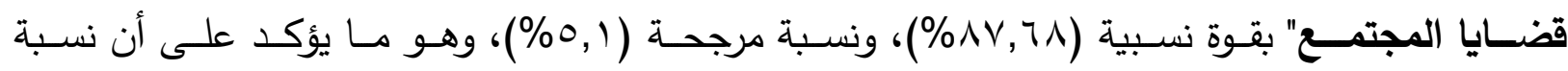

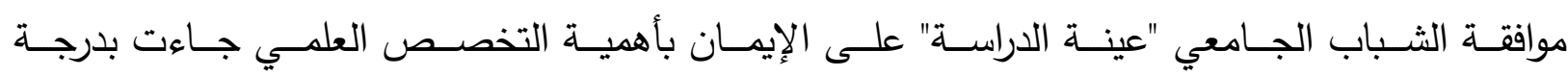

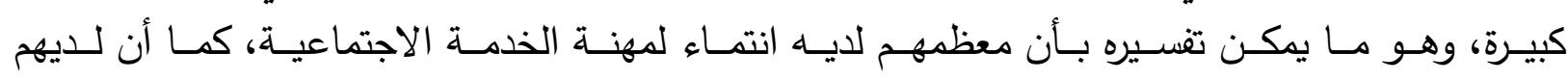

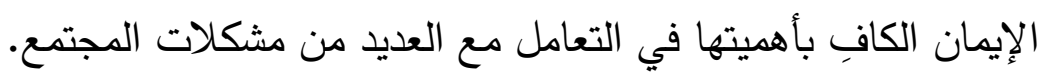

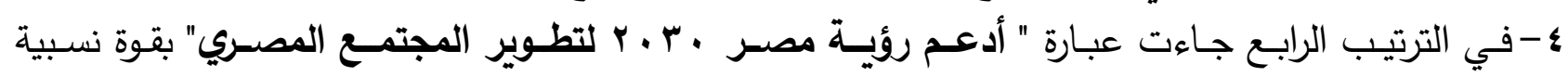

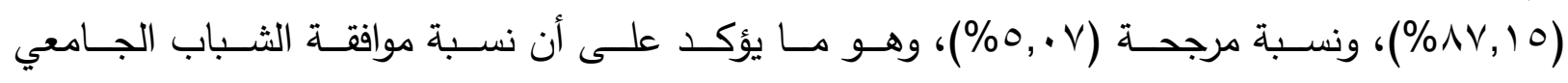

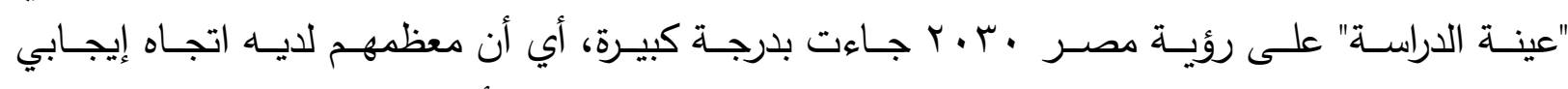

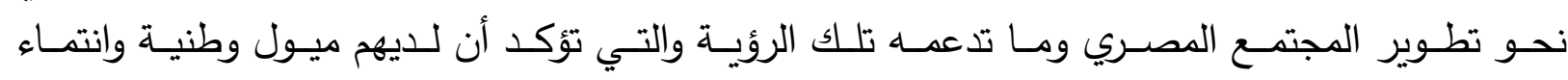
نحو مجتمعهم.

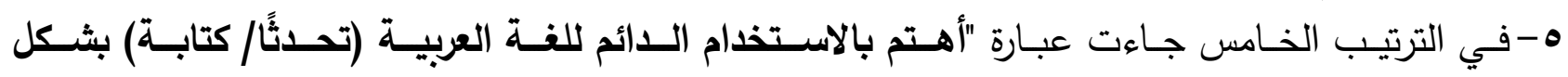

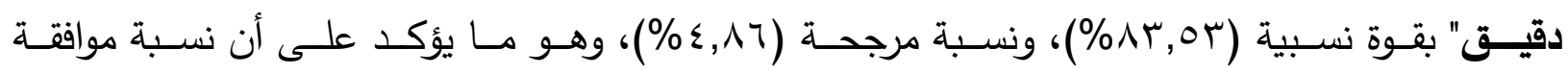

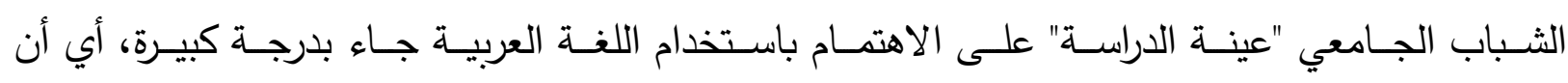

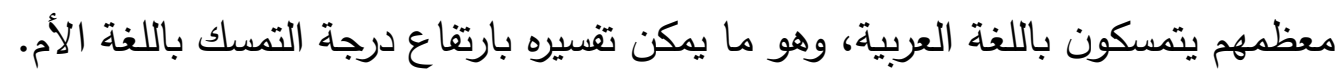

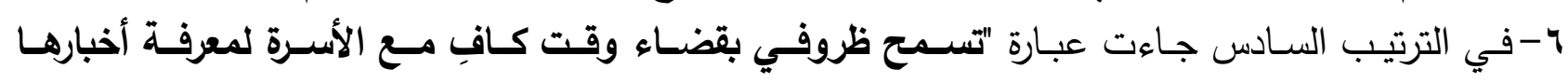

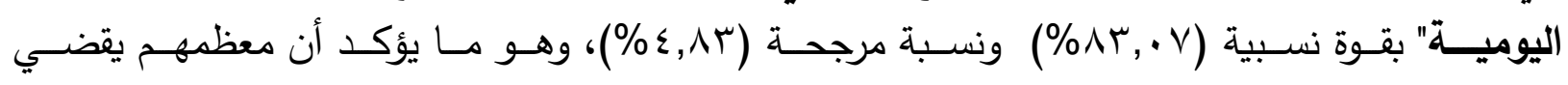

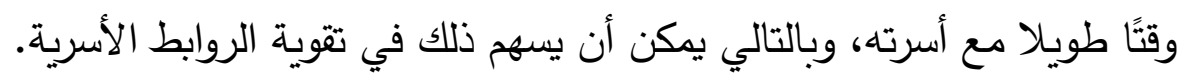




\section{- - بينما جاءت العبارات الأقل موافقة في المرتبة الأخيرة وهي كالتالي:}

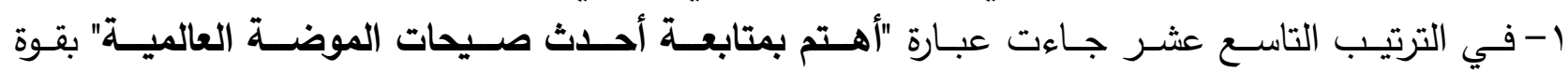

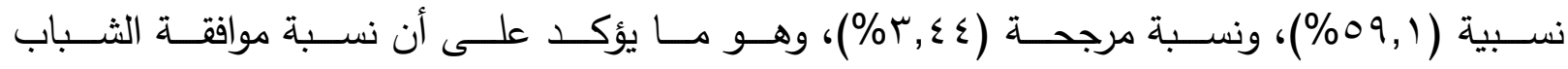

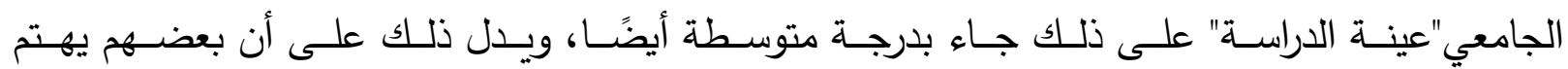

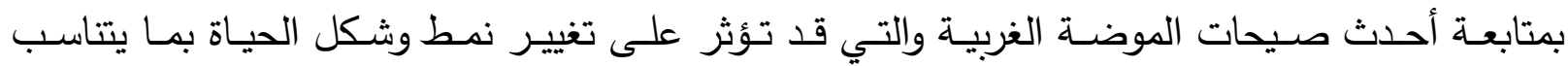

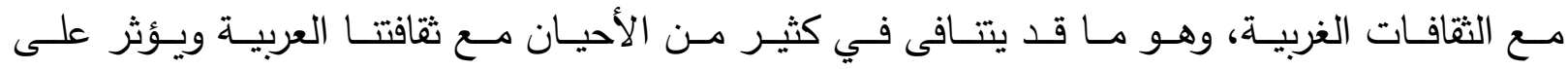
مستوى الهوية الثقافية لدينا.

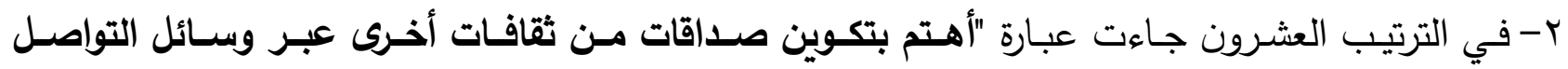

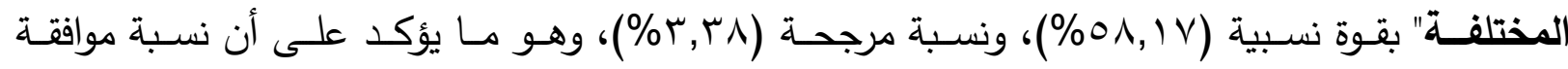

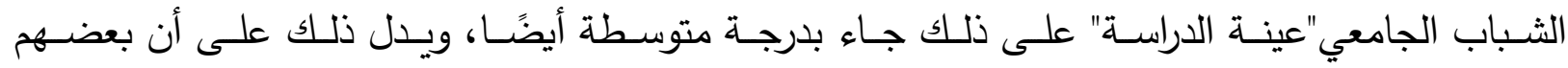

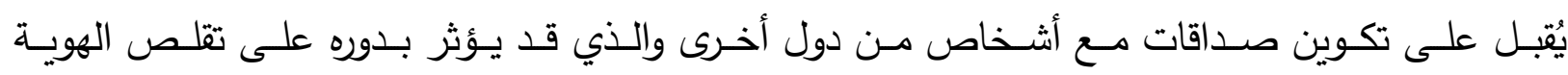
الثقافية لايهم.

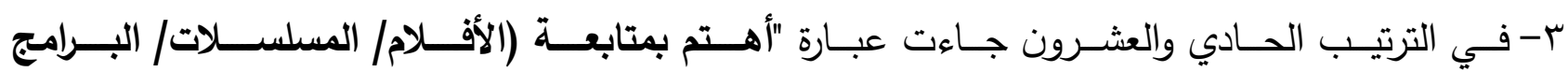

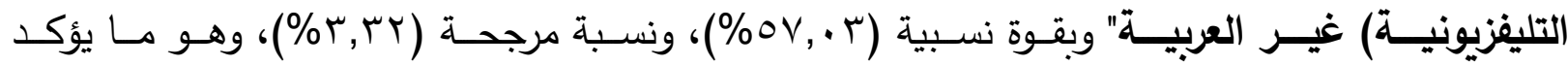

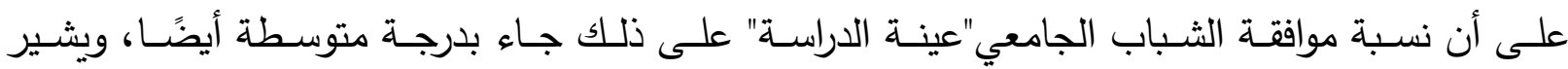

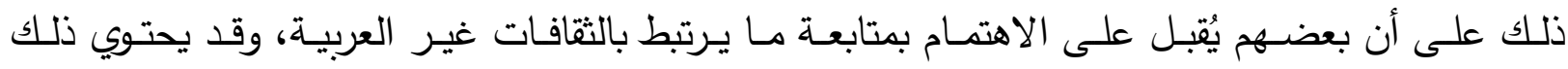

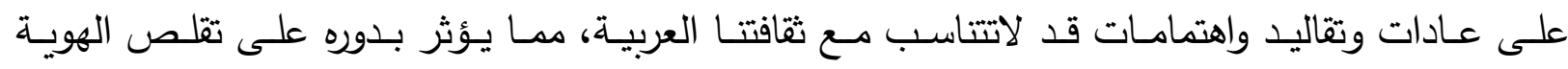
الثقافية لايهم.

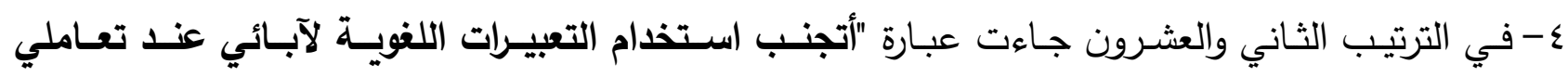

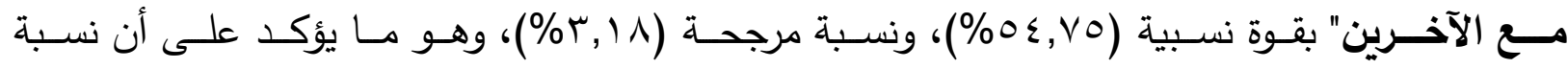

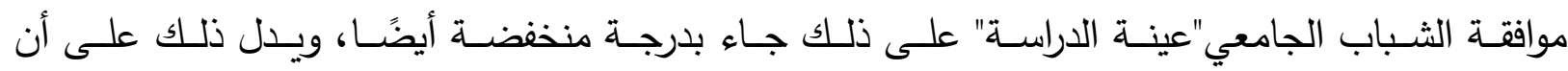

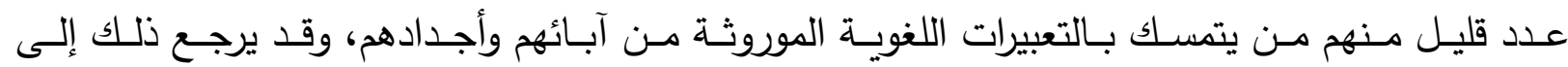

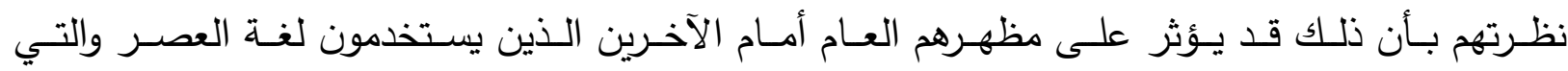

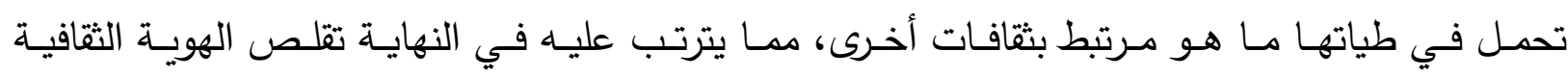
لديهم.

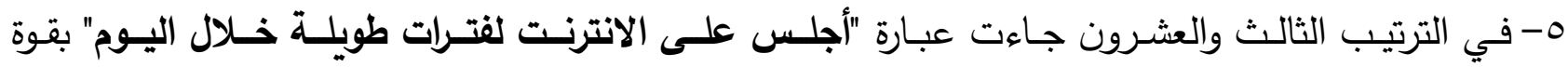

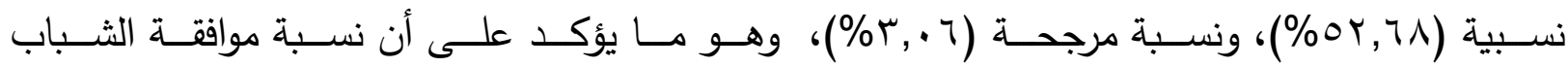

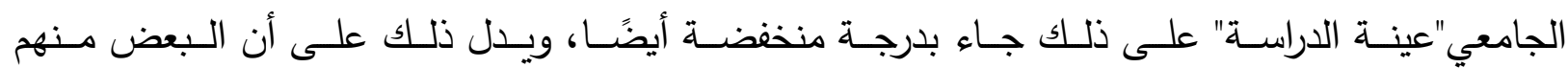

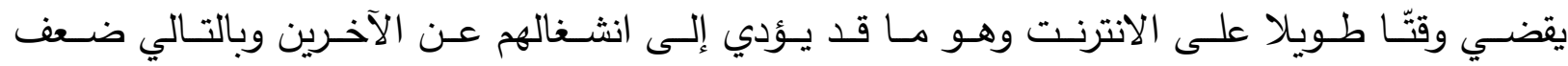

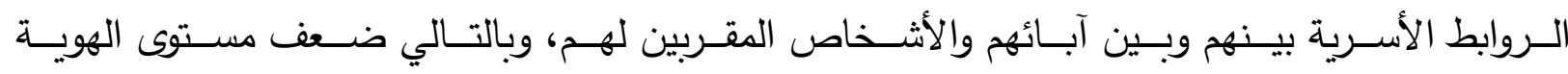




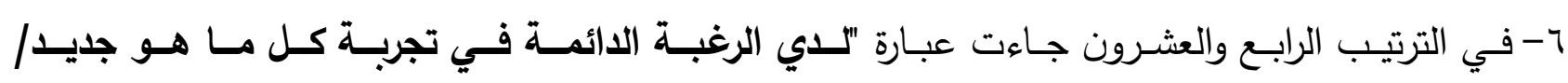

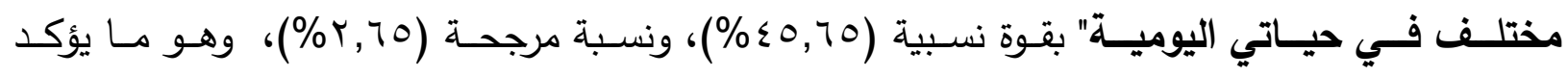

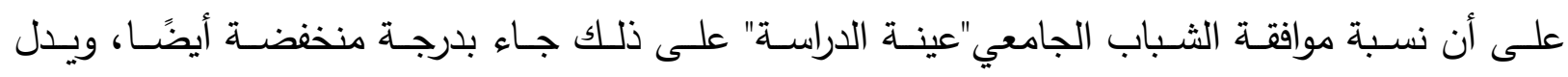

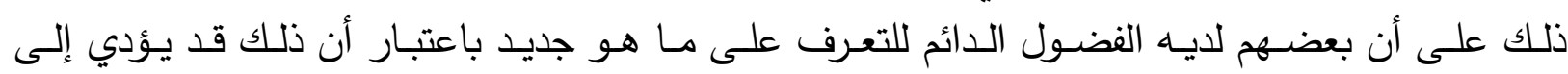

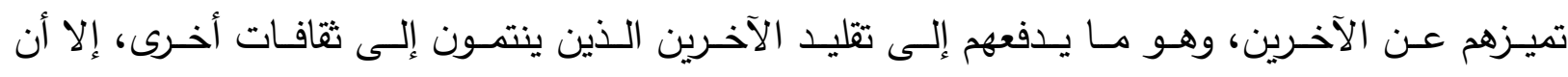

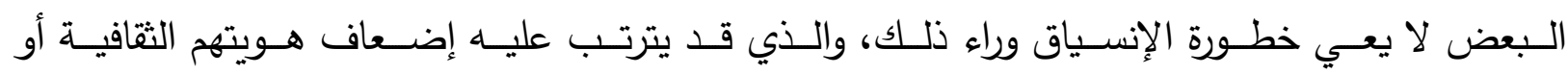
التأثير على أبعادها المختلفة.

وترى الباحثة منطقية نتائج الدراسة واتساقها مع نتائج الداراتات السابقة، ويمكن تفسير بزيادة

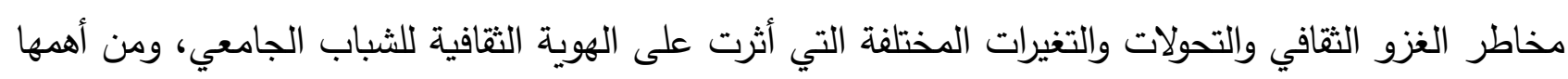

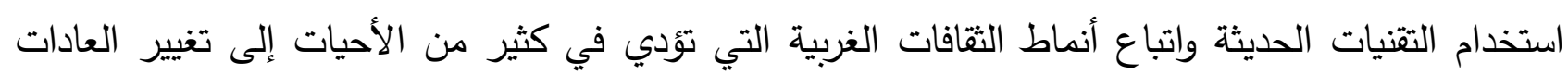

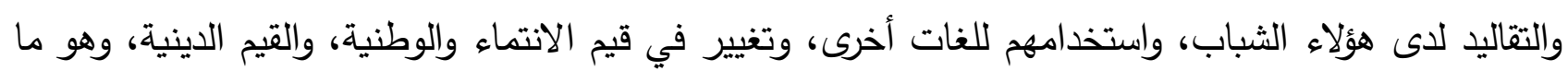
تتضح مظاهره في وقتنا الراهن.

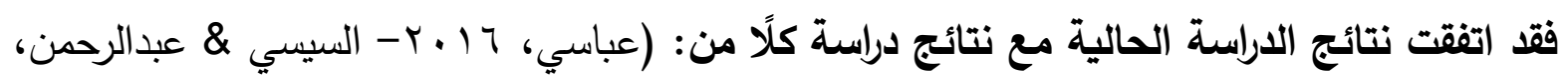

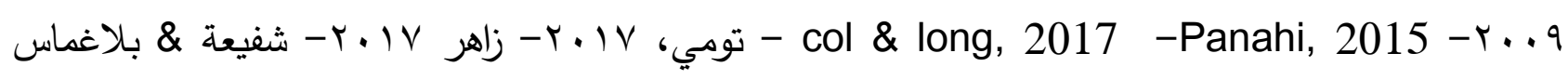

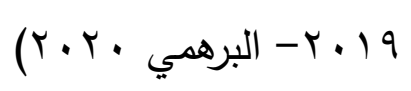

وهو ما يؤكد أيضًا ضرورة رفع الوعي لدى الثباب الجامعي بمخاطر الغزو الثقافي والآثار المترتبة

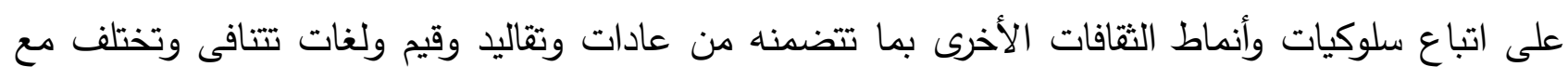
هويتنا الثقافية العربية، مع ضروريات وانماط اتباع أنماط سلوكية للحفاظ عليها. 
- - نتائج الإجابة على التساؤل الثالث: ما العلاقة بين اتجاهات الشباب الجامعي نحو الهندسة الاجتماعية ومستوى الهوية الثقافية لايهم؟

جدول رقم (^)

الارتباط بين مقياس اتجاهات الثباب الجامعي نحو الهندسة الاجتماعية ككل ومقياس مستوى الهوية

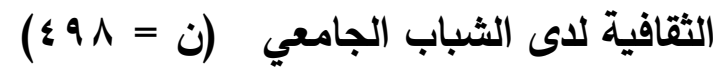

\begin{tabular}{|c|c|c|c|c|c|}
\hline الهوية الثقافية لاسى مستوى & الحقباب الجامعي & 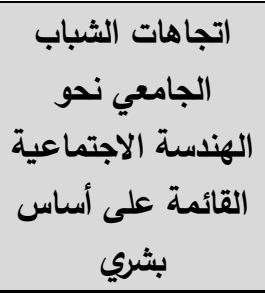 & 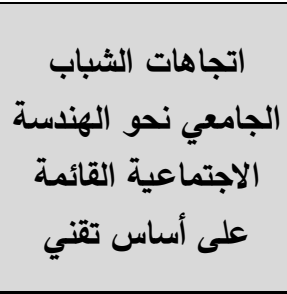 & المحور & b \\
\hline$* *,, 1 \leq V-$ & $* *,, \Lambda \leq \mu$ & $* *,, 00 \varepsilon$ & $\bar{T}$ & الاجاهات الثباب الجامعي نحو الهندسة & 1 \\
\hline$* *_{,}, 10 \leq-$ & $* *,, 910$ & - & $* *,, 0 \bullet \leq$ & الاجتاهات الثباب الجامعي نحو الهندسة & $r$ \\
\hline$* *,|,| \vee 1=$ & 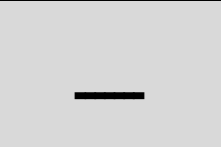 & $* *, 910$ & $* *,, \wedge \leq \Psi$ & الهنيسة الاجتماعية ككل الجات الثباب الجامعي نحو & $r$ \\
\hline- & $* *,, \mid \vee 1=$ & $* *, 10 \leq-$ & $* *,, 1 \leq V$. & مقيـاس مسـتوى الهويـة الثقافيـة لـدى & $\varepsilon$ \\
\hline
\end{tabular}

يتضح من الجدول السابق "وجود علاقة ارتباطية عكسية" بين مقياس اتجاهات الشباب الجامعي نحو

الهندسة الاجتماعية ككل، ومقياس مستوى الهويـة الثقافية لدى الشباب الجامعي، وهو ما يؤكد أنـه كلما زادت اتجاهات الثباب الجامعي نحو الهندسة الاجتماعية كلما انخفض مستوى الهويـة الثقافية لديهم، وهو ما يوضـح أن للهندسة الاجتماعية ومخاطرها انعكاس كبير للتأثير على الهوية الثقافية للشباب الجامعي بشكل سلبي وذلك

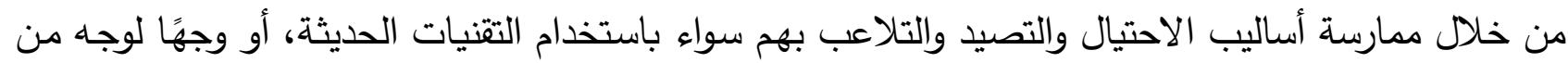

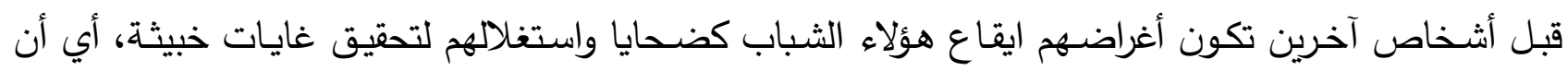
مخاطرها المختلفة يمكنها أن تضعف الهويـة الثقافية لديهم بشكل كبير ، فقد يترتب عليهاء انفلات هؤلاء الشباب

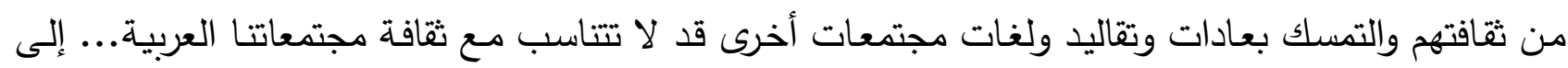
غير ذلك من مخاطر الغزو الثقافي الأخرى. 
تاسعًا: آليات مقترحة من منظور الخدمة الاجتماعية للحد من مخاطر الهندسة الاجتماعية على الهوية

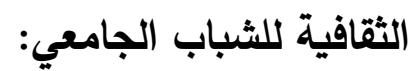
انطلاقًا مما سبق عرضهاب، وبالإطلاع على الإطار النظري للدراسة وما يرتبط بها من كتابات ودراسات

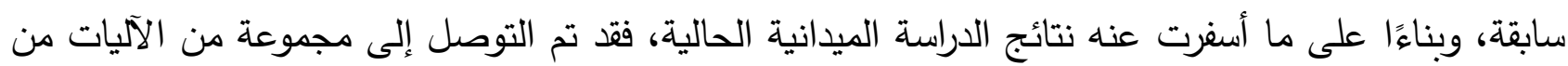

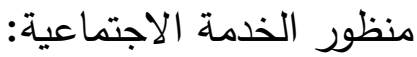

- - وفيما يلي عرض لبعض المحاور التي تم اقتراح الآليات من خلالها: 1- الأسس التي تقوم عليها الآليات المقترحة:

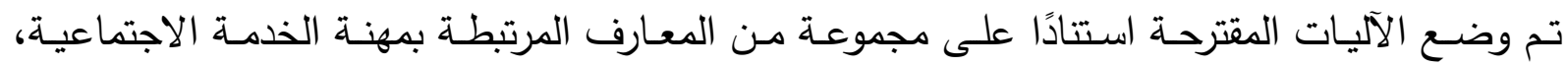
والمعارف المرتبطة بموضوع الهندسة الاجتماعية والهوية الثقافية، والتي نشأت من: - الإطار النظري للدراسة بصفة عامة، والنظرية المعرفية السلوكية.

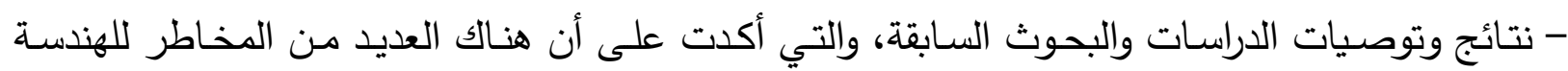

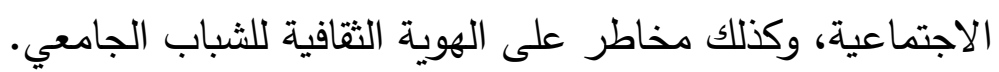

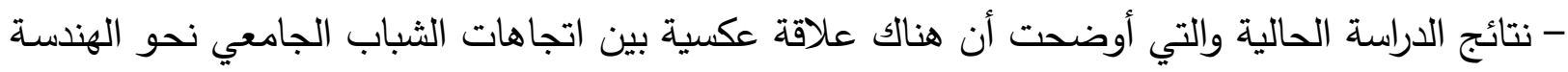

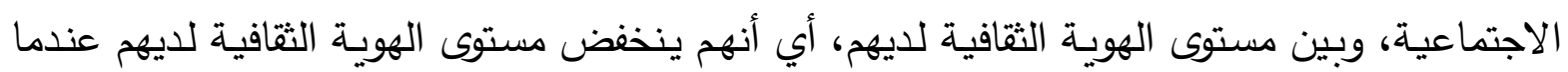

$$
\text { يتعرضون لهجمات الهندسة الاجتماعية. }
$$

- مقابلة الباحثة مع الخبراء في مجال الخدمة الاجتماعية، وفي التخصصات الآتماعة الأخرى. r - المسلمات التي تنطلق منها الباحثة في وضع الآليات:

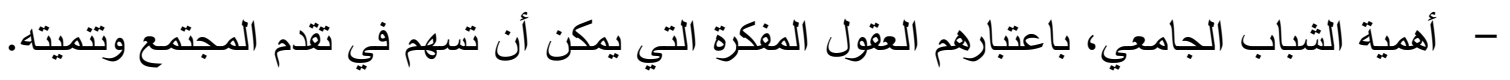

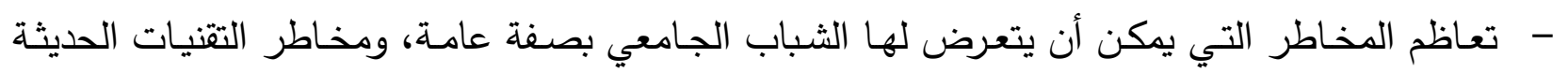
واتجاهاتهم نحو استخدامها والتأثر بها، وانعكاسات ذلكرضك على الهوية الثقافية مما قد يؤدي إلى تقلصها. - ضعف الوعي الكافِ للشباب الجامعي بمخاطر الهندسة الاجتماعية وتقنياتها المختلفة (البشرية - التقنية) المستخدمة للتلاعب بهم والاحتيال عليهم.

$$
\text { r- ب أهداف وضع الآليات المقترحة: }
$$

يتحدد الهدف الرئيسي من وضع الآليات هنا في محاولة الحد من مخاطر الهندسة الاجتماعية (البشرية

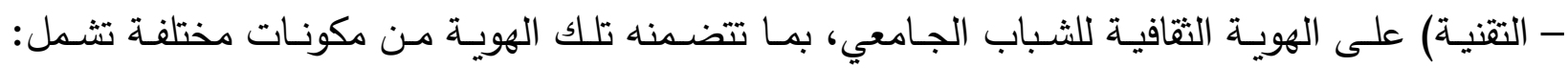

$$
\text { (العادات والتقاليد- اللغة- القيم الدينية والوطنية - الخلفية التاريخية...إلخ). }
$$

ع - المنطلق النظري:

تم الاعتمـاد على "النظريـة المعرفيـة السلوكية" باعتبارهـا من النظريـات التي تسـاعد في تحليل

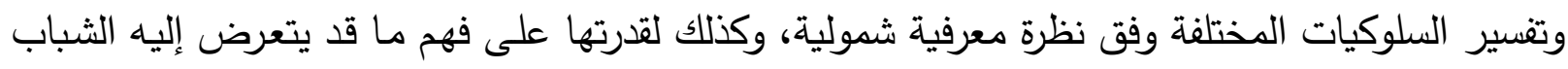

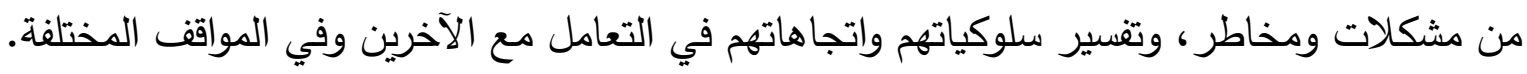




\section{الههف من استخدام النظرية:}

- مساعدة الأخصائي الاجتماعي في تقسير وتحليل السلوكيات المختلفة للشباب الجامعي.

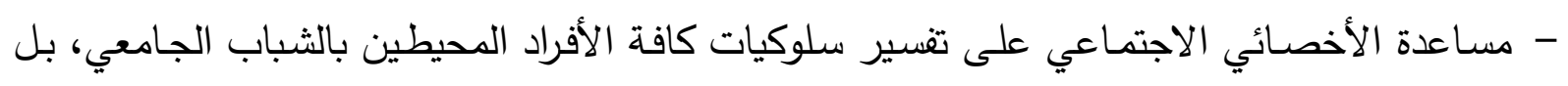

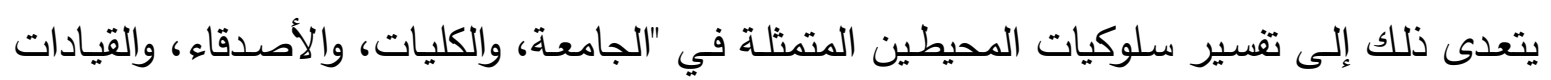
الجامعية، وأعضاء هيئة التدريس...إلخ". ه - الأدوات المستخدمة لتحقيق الآليات المقترحة:

-

צ- أدوار الأخصائي الاجتمـاعي في الحـد من مخـاطر الهندسـة الاجتماعيـة على الهويـة الثقافيـة للثباب الجامعي: الباحـث Researcher: حيث يقوم الأخصـائي الاجتمـاعي بعمل أبحـاث دوريــة ومستمرة حـول احتياجات الثباب الجامعي وما يعانون من مشكلات، وما يواجههم من مخاطر .

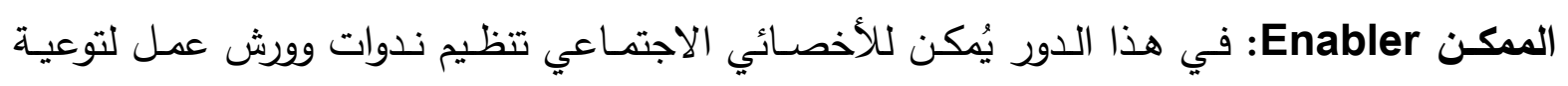

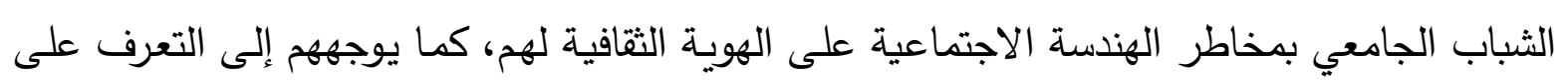
الحقوق والواجبات الدينية والوطنية التي يجب أن يلتزموا بها في إطار المجتمع الجامعي وخارجه.

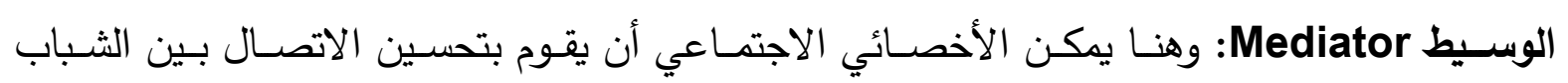

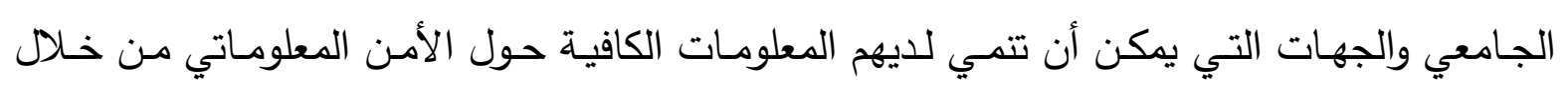
تعريفهم بها وبما تقدمه لهم من خدمات ودورات تدريبية.

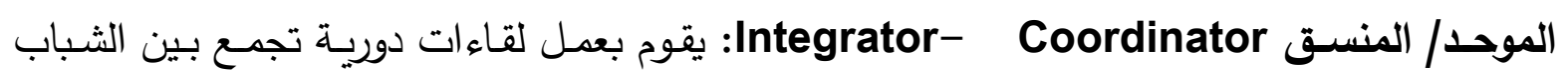

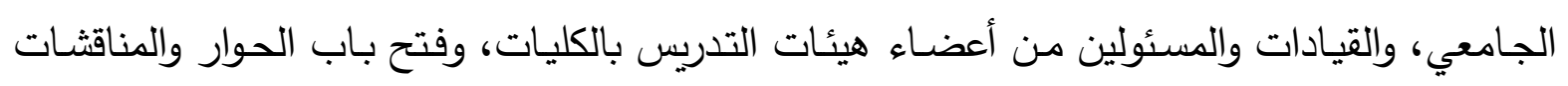

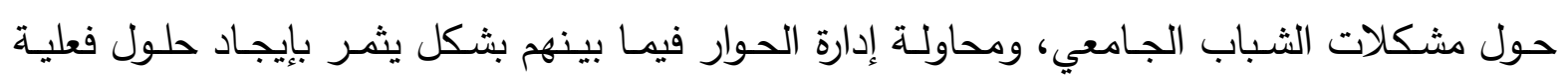
وواقعية تحد من وقوعهم كضحايا لمتغيرات العصر الحديث أو التأثير على الهوية الثقافية لهم. لهان.

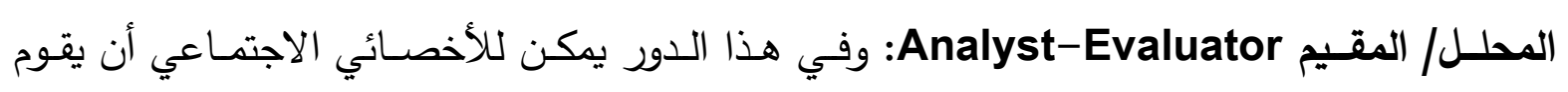
بالتقويم المستمر لدور الجامعة بما تتضمنه من كليات في توفير الدعم الكافِ للشباب الجامعي وتوفير

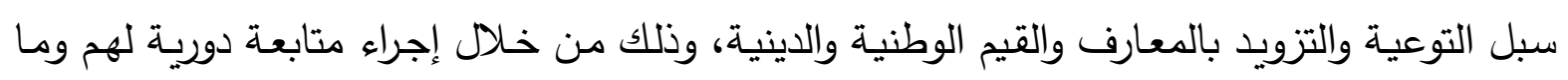

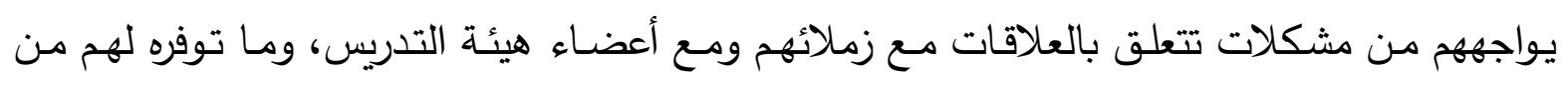

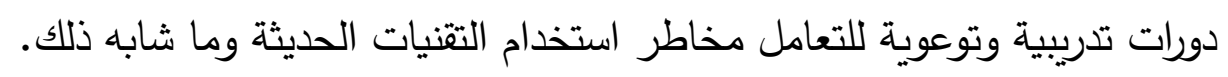

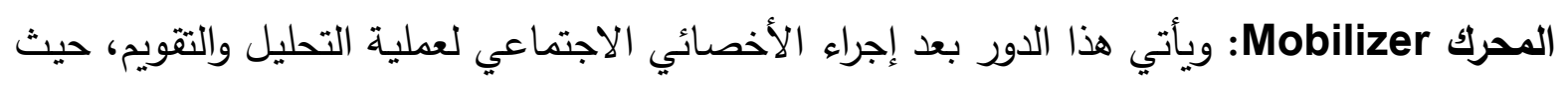

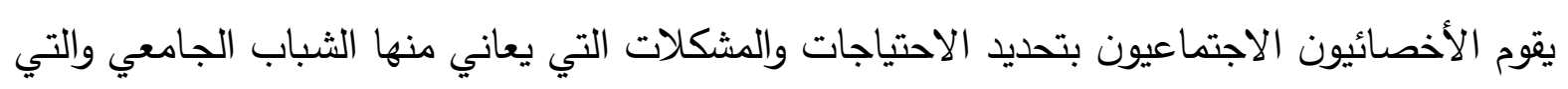


يمكن أن تؤثر على هويتهم الثقافية، وكذا المخاطر المرتبطة بالهندسة الاجتماعية، ومن ثم يقوم بطرح تلك المشكلات على كل من يمكنه الإسهام في حلها، فعلى سبيل المثال: طرح تلك المخاطر على عمداء الكليات لكي يقومـوا باتخـاذ الإجـراءات اللازمـة مثل: (عقد دورات تدريبيـة - عمل منشـورات توعوية - تضمين مقررات جديدة حول الأمن المعلوماتي وأخرى لتدعيم قيم الولاء والانتماء والمواطنة وتعميق الهوية الثقافية لدى الشباب وذلك ضمن لوائح الكليات العملية والنظرية). V- الآليات المقترحة للحد من مخاطر الهندسـة الاجتماعية على الهويـة الثقافية للشباب الجامعي من منظور الخدمة الاجتماعية:

\begin{tabular}{|c|c|c|}
\hline أدوات تتفيذها & الآلية & |لتصنيف \\
\hline ن & 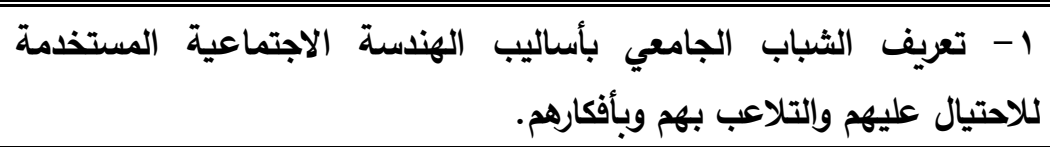 & \\
\hline ندوات ومحاضرات & 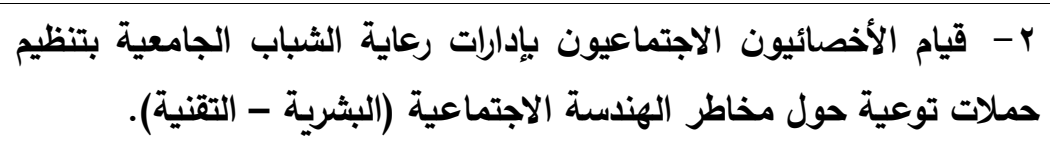 & \\
\hline الأمن المعلوماتي. تدربية عن & 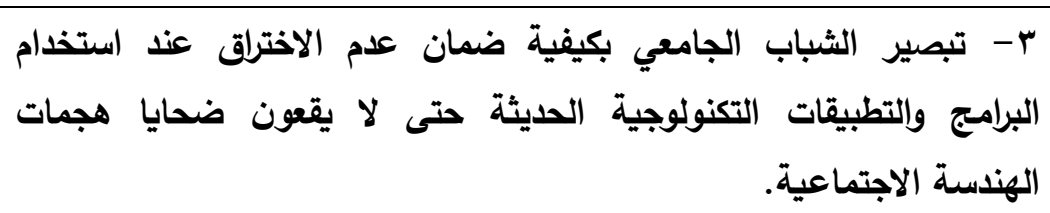 & 及 \\
\hline مقابلات مع خبراء & ع - تنمية مهارات وقدرات الثباب الجامعي على كيفية التصدي لهجمات & दें \\
\hline دورات تدريبية. & 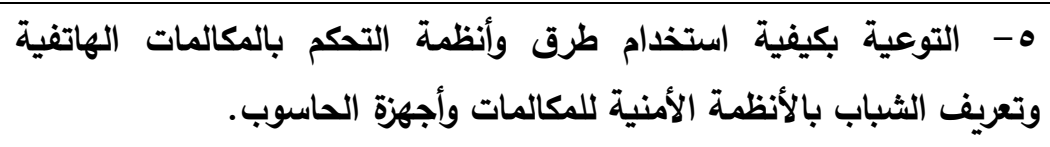 & - \\
\hline ندوات توعويـة. & لو - لضمان عدم استخدامها للخداع والتلاعب. الحفاظ على الخصوصية وعدم نشر معلومات شخصية & 5 \\
\hline مقررات دراسية عن & المعلومات. تبصير الثباب الجامعي بكل ما يتعلق بالأساليب الدايثة لأمن & \\
\hline ورش عمل إرشادية & 1 القديمة التي تحتيهم على كيفية اتلاف جميع الأجهزة والملفات الورقية والإكترونية & \\
\hline دوش عمل- دورات تدريبية & 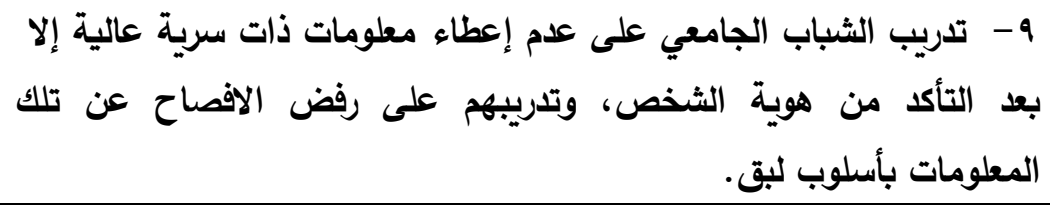 & \\
\hline دورات تدريبية-- & الهندسة الاجتماعية بكافة أثكالها. & \\
\hline
\end{tabular}




\begin{tabular}{|c|c|c|c|}
\hline إصدار قرار بذلك. & 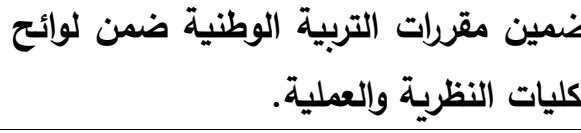 & -1 & \multirow{8}{*}{ 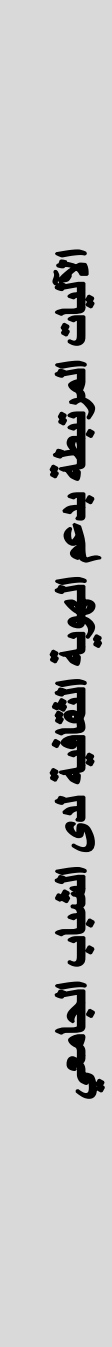 } \\
\hline منشورات، ندوات & ثقافي واتباع الثقافات الغربية. حول مخاطر الغزو & $-r$ & \\
\hline محاضرات تثقيفية & بوية الثقافية للمجتمع الجابعي بكيفية الحفاظ على & $-r$ & \\
\hline محاضرات & غزبية ينتمون إلثى ثلى التعامل بحذر مع الخآخرين & $-\varepsilon$ & \\
\hline رحلات & 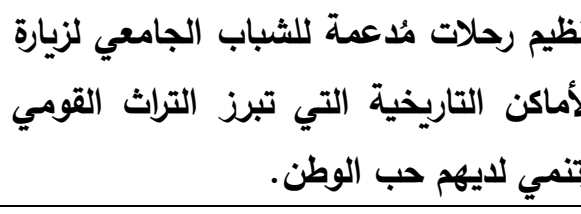 & -0 & \\
\hline اتصالات تليفونية- & فال فير نظم الرقابة والمتابعة الدورية للشباب & -9 & \\
\hline ندوات - دورات تدريبية & كليها، ومحاولة الثباب بأهمية اللغة العربية والحفاظ & $-v$ & \\
\hline ندوات & معلاقات الاجتماعية داخل وخارج حول أسس وضوابط الجامعة. & $-\Lambda$ & \\
\hline
\end{tabular}




\section{المراجع الستخدمة:}

للمراجي العربية:

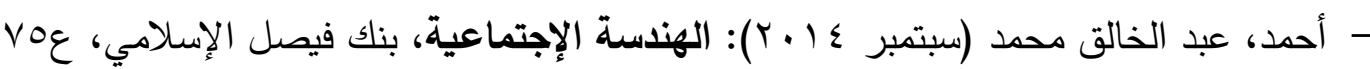

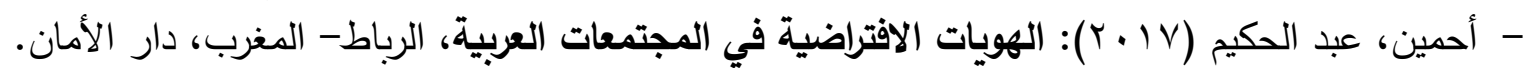

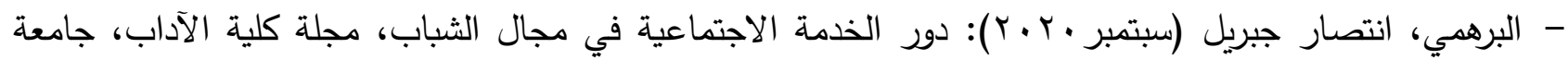

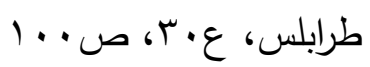

- الجهاز المركزي للتعبئة العامة والإحصاء: النشرة السنوية للطلاب المقيدين وأعضاء هيئة التدريس بالتعليم العالي

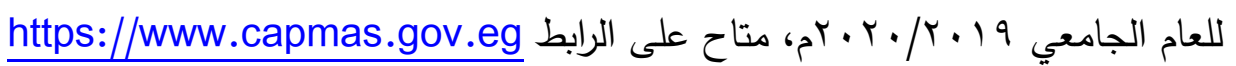

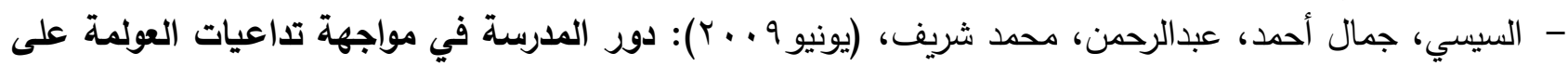

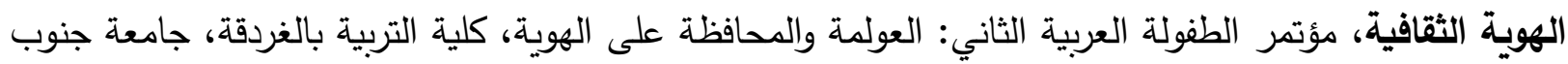
الوادي. - الثوابكة، عدنان عواج (أكتوبر 9 ( ـ ب): دور إجراءات الأمن المعلوماتي في الحد من مخاطر أمن المعلومات في

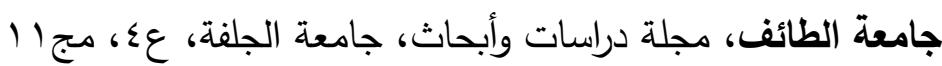

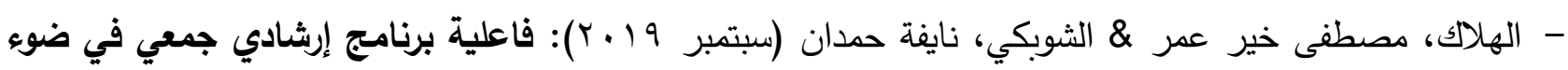
النظرية المعرفية السلوكية في خفض مستويات أعراض الاكتئاب واضطراب ضغط ما بعد الصدمة لاى عينة من

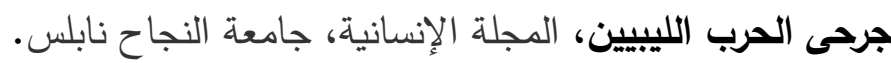

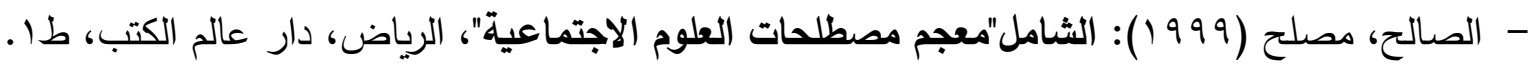

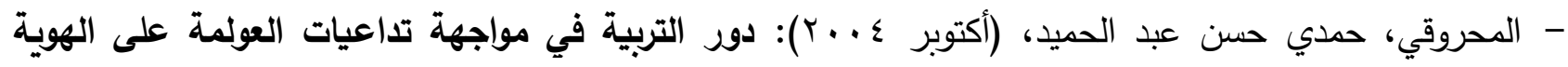

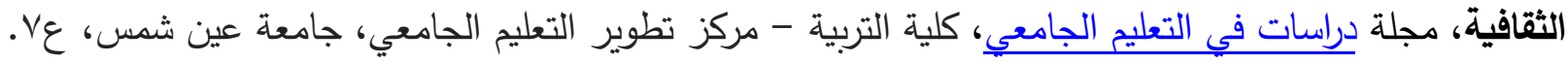

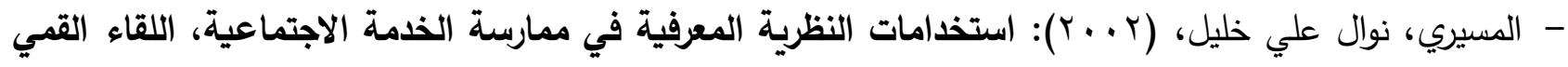
الثاني - قضايا ممارسة الخدمة الاجتماعية في المجتمع السعودي، كلية الخدمة الاجتماعية، وكالة كليات البنات. - شفيعة، حداد \& بلاغماس، أسماء (يوليو 9 ( • ب): تأثير العولمة في بعدها الثقافي الهوياتي على الهوية الثاية الثقافية

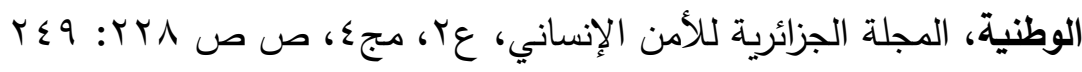

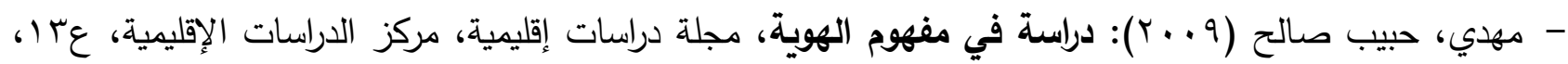
مجن.

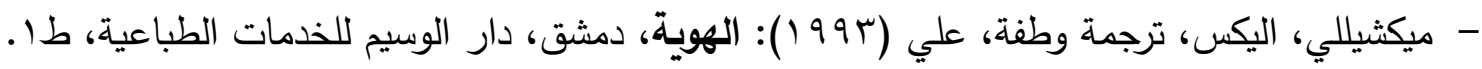

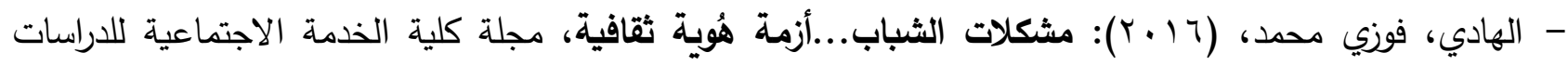

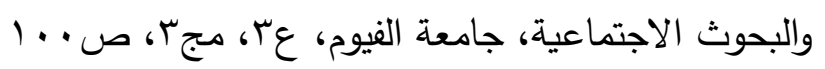

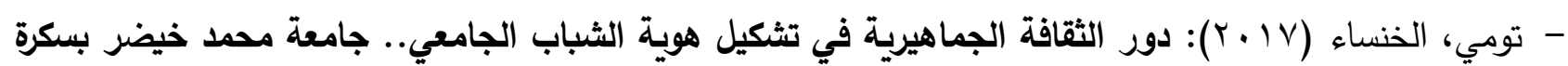

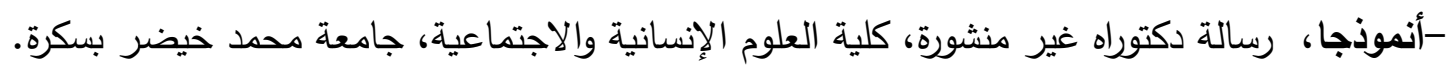

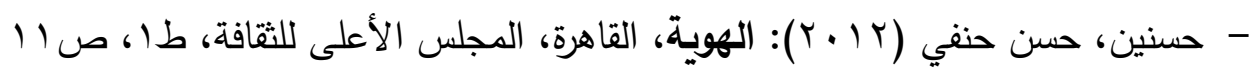

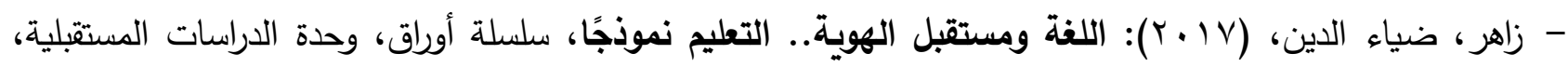

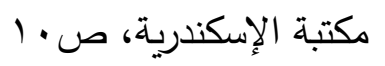

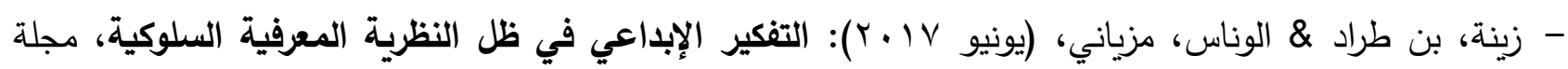

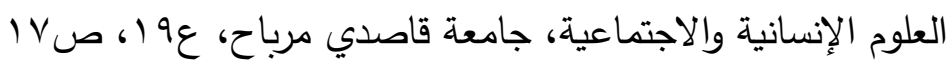


- سليماني، خديجة \& نقاز ، أحمد (·r ·r): الهندسة الاجتماعية لارتكاب الاحتيال ودور التدقيق الداخلي للحد من

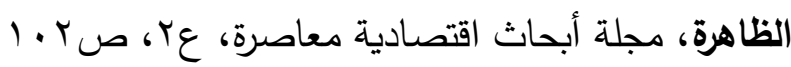

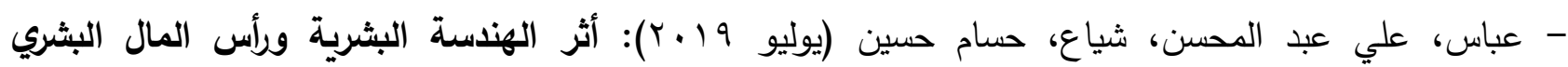
كمتغيرين وسيطين في العلاقة بين القيادة الخدمية ورأس المال الاجتماعي، المؤتمر العلمي الدولي العاشر تحت

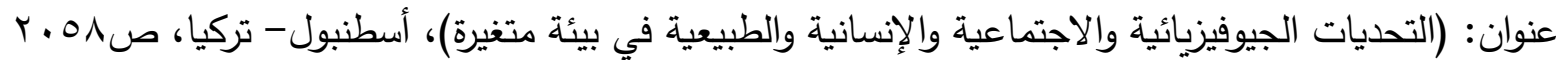

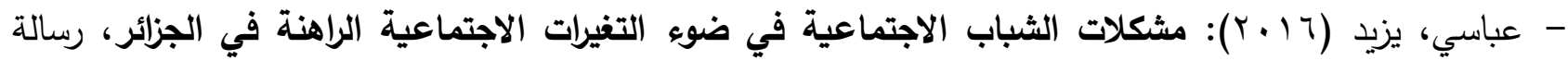

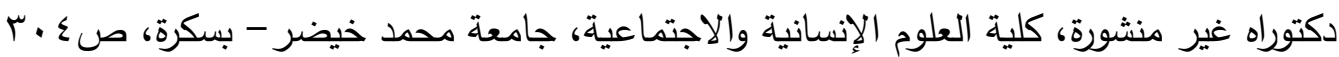

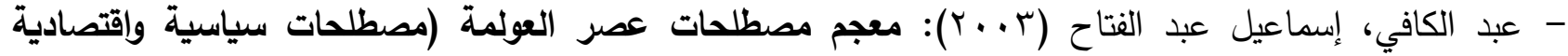
واجتماعية ونفسية وإعلامية)، ص

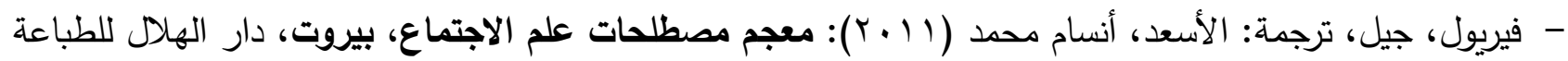

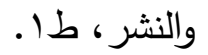

- هادناجي، كريستوفر : ترجمة مؤسسة بن راشد آل مكتوم (Y V V V): الهندسة الاجتماعية.. فن اختراق العقل البشري، كتاب في دقائق، مؤسسة بن راشد آل مكتوم.

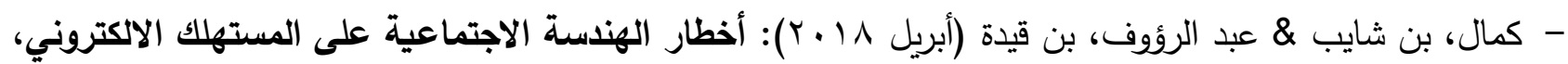

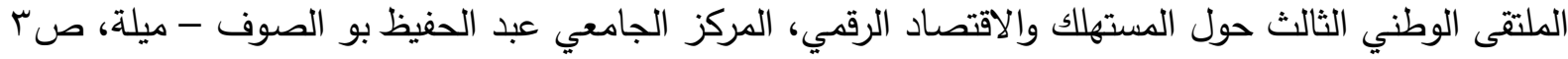

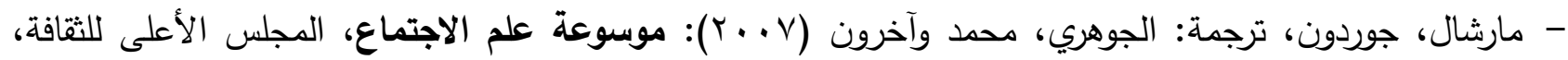
ط

- محمد، مها أحمد إبراهيم، (ديسمبر 9 (1) ب): الهندسة الاجتماعية وشبكات التواصل وتأثيرها على المجتمع العربي،

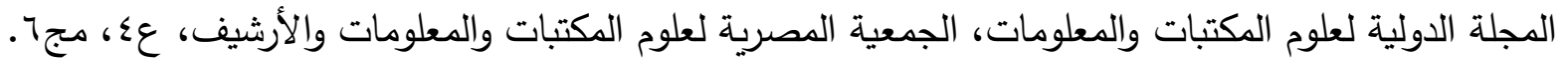

\section{• المراجع الإنجليزية:}

- Alireza PANAHI, (2015): Cultural invasion and moral insecurity in thoughts of imam Khamenei, Science Journal (CSJ), Cumhuriyet University Faculty of Science, Vol. 36, No:3.

- Bengt, Larson et, al (2012): transformation of the swidsh with Ferris State from social engineering to governance, US, PALGRAVE MACMILLAN.

- Christopher Hadnagy (2011): Social Engineering:The Art of Human Hacking, Canada, WileyPublishing.

- Frank L. Greitzer (2014): Analysis of Unintentional Insider Threats Deriving from Social Engineering Exploits, Richland, WA USA, IEEE COMPUTER SOCIETY, p239. 
- Holz, Thorsten. et, al, (7-8 July, 2011): Reverse Social Engineering Attacks in Online Social Networks, Detection of Intrusions and Malware, and Vulnerability Assessment, 8th International Conference, DIMVA 2011, Amsterdam, The Netherlands.

- Snr.Col \& Ha Duc Long, (September 2017): Countering "cultural invasion" in the current situation, National Defence journal, Political Academy.

- Sven, Uebelacker \& Susanne, Quiel (2013): The Social Engineering Personality Framework, Hamburg University of Technology, Hamburg, Germany.

- Yuanyuan, Zhang (2018): Views on the Cultural Invasion, International Conference on Sports, Arts, Education and Management Engineering, vol. 199. 